PADRÕES ESPAÇO-TEMPORAIS DA CAPTURA ACIDENTAL DE

TARTARUGAS MARINHAS DERMOCHELYS CORIACEA E CARETTA

CARETTA PELA PESCA COM ESPINHEL PELÁGICO NA REGIÃO

SUDESTE/SUL DO BRASIL

Dissertação apresentada ao Instituto Oceanográfico da Universidade de São Paulo, como parte dos requisitos para a obtenção do título de Mestre em Ciências, área de Oceanografia Biológica.

Orientador: Dra. Maria de los Angeles Gasalla

São Paulo 
Universidade de São Paulo

Instituto Oceanográfico

\title{
PADRÕES ESPAÇO-TEMPORAIS DA CAPTURA ACIDENTAL DE TARTARUGAS MARINHAS DERMOCHELYS CORIACEA E CARETTA CARETTA PELA PESCA COM ESPINHEL PELÁGICO NA REGIÃO SUDESTE/SUL DO BRASIL
}

\author{
MELISSA CUNHA CAJUEIRO MARCON
}

Dissertação apresentada ao Instituto Oceanográfico da Universidade de São Paulo, como parte dos requisitos para a obtenção do título de Mestre em Ciências, área de Oceanografia Biológica.

Versão corrigida

Julgada em $/ 2013$

$\operatorname{Prof}(\mathrm{a}) . \operatorname{Dr}(\mathrm{a})$.

Conceito

Prof (a). Dr(a).

Conceito

Prof (a). Dr(a).

Conceito 


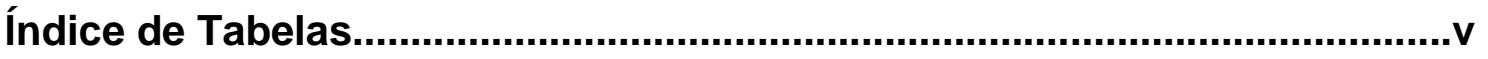

Índice de Figuras.................................................................................ii

Agradecimento..........................................................................................ii

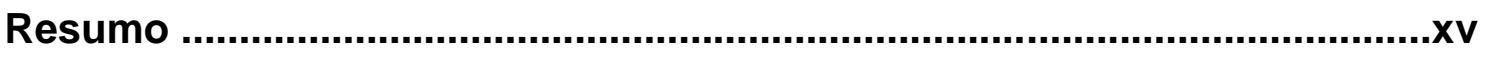

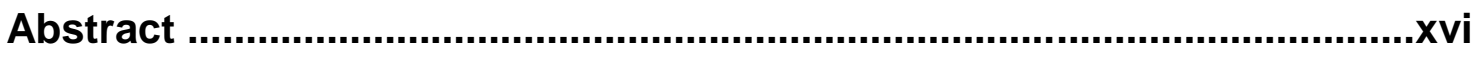

1. INTRODUÇÃO

2. OBJETIVO GERAL

3. ÁREA DE ESTUDO

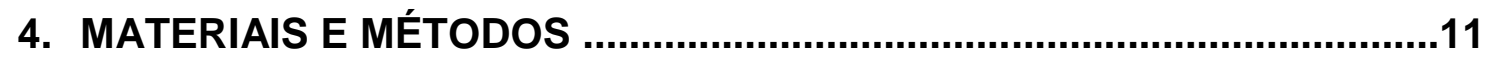

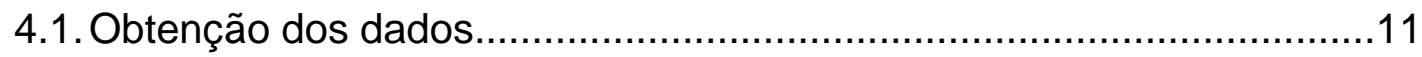

4.2. Determinação da distribuição espacial interanual e sazonal da atuação da frota pesqueira espinheleira e das capturas acidentais. 12

4.3. Determinação das áreas com maior taxa de captura durante 0 período

4.4. Determinação da variação temporal da captura por unidade de esforço (CPUE) 13

4.5. Análise dos dados abióticos das áreas de pesca. 14 
4.6. Representatividade da amostra dos dados em relação à frota total atuante .14

4.7. Determinação das embarcações com maior taxa de captura de tartarugas durante todo o período 15

4.8. Distribuição do comprimento curvilíneo da carapaça (CCC) das tartarugas capturadas 16

4.9. Modelos Aditivos Generalizados para Posição, Escala e Forma (GAMLSS) 16

5. RESULTADOS 20

5.1. Distribuição espacial interanual do esforço pesqueiro da frota espinheleira. 23

5.2. Distribuição espacial interanual das capturas acidentais de tartarugas .25

5.3. Distribuição espacial sazonal do esforço pesqueiro da frota espinheleira 28

5.4. Distribuição espacial sazonal das capturas acidentais de tartarugas 29

5.5. Variação interanual da captura por unidade de esforço (CPUE) das tartarugas .31 
5.6. Variação sazonal da captura por unidade de esforço (CPUE) das tartarugas. 34

5.7. Áreas de maior CPUE durante o período. 37

5.8. Dados abióticos e operacionais da frota espinheleira nas áreas de ocorrência de captura acidental de tartarugas marinhas. 38

5.9. Embarcações que apresentaram alta taxa de captura (tartaruga por lance) 41

5.9.1. Áreas de atuação das embarcações com maior taxa de captura de tartarugas marinhas .42

5.9.2. Características abióticas e operacionais das áreas de atuação da frota com maior taxa de captura de tartarugas marinhas .43

5.9.3. Variação temporal do esforço pesqueiro na área de atuação da frota analisada. .47

5.10. Distribuição das frequências do comprimento curvilíneo da carapaça $(\mathrm{CCC})$ das tartarugas capturadas. .48

5.11. Efeito de variáveis ambientais e operacionais na variável resposta (CPUE) das tartarugas marinhas. .52 


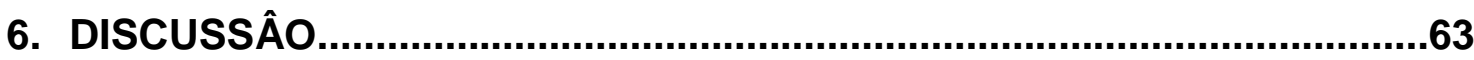

8.1. Infliencia das variáveis abióticas e operacionais na captura acidental

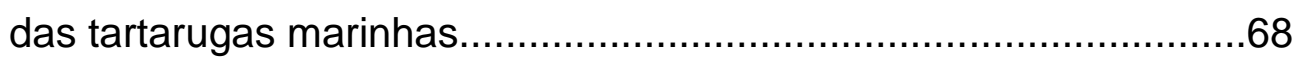

8.2. Distribuição espacial das tartarugas marinhas $C$. caretta e $D$. coriacea no grade ecossistema marinho do Sul do Brasil.................72

8.3. Conseideraçoes finais..............................................................

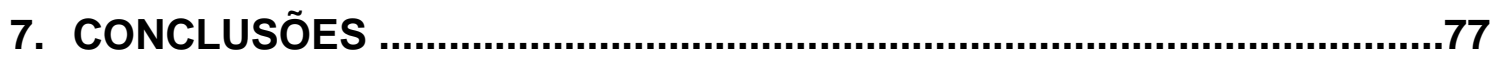

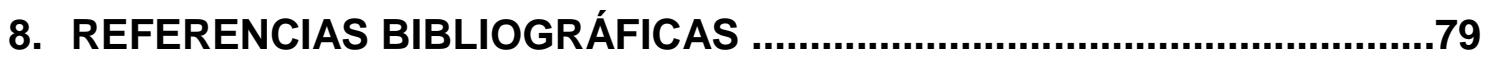




\section{ÍNDICE DE TABELAS}

Tabela 1. Síntese do número de anzóis lançados pelas embarcações, lances realizados e indivíduos acidentalmente capturados pela frota analisada entre os anos de 2003 a 2010

Tabela 2. Número de desembarques amostrados, desembarques totais e porcentagem amostrada dos portos de Itajaí (SC), Santos (SP) e Rio Grande (RG) entre os anos de 2003 a 2010 .21

Tabela 3. Síntese das capturas acidentais realizadas pela frota analisada......41

Tabela 4. Descrição das variáveis abióticas e operacionais (profundidade de atuação) das embarcações na área estudada .36

Tabela 5. Valores do AIC para as distribuições testadas da variável resposta (CPUE) para a espécie Caretta caretta. .54

Tabela 6. Comparação entre os valores de Akaike's Information Criterion (AIC) modelos gerados para a distribuição log normal gerados para a espécie Caretta caretta. 55

Tabela 7. Estimativa do parâmetro, erro padrão, valor do teste t e valor de $p$ para o modelo selecionado com distribuição log normal para a espécie Caretta caretta. 56

Tabela 8. Comparação entre os valores de Akaike's Information Criterion (AIC) dos modelos gerados para a distribuição log normal gerados para a espécie Dermochelys coriacea 
Tabela 9. Estimativa do parâmetro, erro padrão, valor do teste t e valor de $p$ para o modelo selecionado com distribuição log normal para a espécie Dermochelys coriacea... 61 


\section{ÍNDICE DE FIGURAS}

Figura 1. Distribuição espacial dos lances realizados pela frota analisada entre o ano de 2003 a 2008. Cada ponto no mapa representa um lance realizado. A isóbata assinalada representa 200 metros de profundidade

Figura 2. Distribuição de frequência do número lances com captura de indivíduos de Caretta caretta (Superior) e Dermochelys coriacea (Inferior) capturados entre os anos de 2003 e 2010 pela frota espinheleira amostrada

Figura 3. Distribuição espacial dos lances realizados pela frota analisada entre o ano de 2003 a 2008. Cada ponto no mapa representa um lance realizado. A isóbata assinalada representa 200 metros de profundidade .24

Figura 4. Distribuição espacial das capturas acidentais das tartarugas cabeçuda (ponto roxo) e tartaruga de couro (triangulo laranja) durante os anos de 2003 a 2006. .26

Figura 5. Distribuição espacial das capturas acidentais das tartarugas cabeçuda (ponto roxo) e tartaruga de couro (triangulo laranja) durante os anos de 2007 a 2010 
Figura 6. Distribuição espacial dos lances realizados pela frota analisada sazonalmente. Cada ponto no mapa representa um lance realizado. A isóbata assinalada representa 200 metros de profundidade. .28

Figura 7. Distribuição espacial das capturas acidentais das tartarugas cabeçuda (ponto roxo) e de couro (triangulo laranja) durante o outono e inverno 29

Figura 8. Distribuição espacial das capturas acidentais das tartarugas cabeçuda (ponto roxo) e de couro (triangulo laranja) durante a primavera e verão.

Figura 9. Variação interanual da CPUE para a tartaruga cabeçuda entre os anos de 2003 a 2010.

Figura 10. Variação interanual da CPUE para a tartaruga de couro entre os anos de 2003 a 2010.

Figura 11 - Variação interanual da CPUE para a espécie Caretta caretta durante os anos de 2003 a 2010 33

Figura 12. Variação interanual da CPUE para a espécie Dermochelys coriacea durante o ano de 2003 a 2010 .34

Figura 13. Variação sazonal da CPUE para a tartaruga cabeçuda e de couro. $1=$ verão, $2=$ outono, $3=$ inverno, $4=$ primavera .35

Figura 14. Variação da CPUE sazonalmente para a espécie Caretta caretta..36

Figura 15. Variação da CPUE sazonalmente para a espécie Dermochelys coriacea. 
Figura 16. Captura por unidade de esforço (CPUE) com base no número de animais capturados por 1000 anzóis para a espécie Caretta caretta por quadrante. 37

Figura 17. Captura por unidade de esforço (CPUE) com base no número de animais capturados por 1000 anzóis para a espécie Dermochelys coriacea por quadrante .38

Figura 18. Padrão das capturas acidentais das variáveis abióticas e profundidade de operação das embarcações para as espécies Caretta caretta (CC) e Dermochelys coriacea (DC) para as capturas acidentais ocorridas nos anos de 2003 a 2010. Box plot com mediana, quartil inferior e superior e outliers .40

Figura 19. Padrão da inserção do anzol durante as capturas acidentais das tartarugas marinhas. .40

Figura 20. Distribuição dos lances realizados pelas embarcações com maior taxa de captura (triângulo laranja) e as demais embarcações (ponto roxo) durante o período de 2003 a 2010

Figura 21. Padrão das variáveis abióticas e operacionais (profundidade de operação) das embarcações com maior taxa de captura (MAIOR) e demais embarcações (MENOR) durante o período estudado. Box plot com mediana, quartil inferior e superior e outliers

Figura 22. Histogramas de frequência doo número de lances com captura das embarcações que apresentaram maior taxa de captura $(a-c)$ e as demais 
embarcações $(d-f)$ para as variáveis operacionais: tipo de isca, espécie alvo e tipo de anzol.

Figura 23. Histogramas de frequência das embarcações que apresentaram maior taxa de captura (Maior taxa de captura) e as demais embarcações (Menor taxa de captura) para ano e estação da realização do lance. .48

Figura 24. Distribuição do CCC para a espécie Caretta caretta nas três regiões Elevação do Rio Grande (ERG), sudeste (SUD) e sul (SUL) durante o período de 2003 a 2010 .49

Figura 25. Distribuição do comprimento curvilíneo da carapaça (CCC) da espécie Caretta caretta durante o período de 2003 a 2010 nas regiões sudeste (superior), sul (meio) e Elevação do Rio Grande (inferior) .50

Figura 26. Distribuição do CCC para a espécie Dermochelys coriacea nas regiões sudeste (SUD) e sul (SUL) durante o período de 2003 a $2010 \ldots . .51$

Figura 27. Distribuição do comprimento curvilíneo da carapaça (CCC) da espécie Dermochelys coriacea durante o período de 2003 a 2010 nas regiões sudeste (esquerda) e sul (direita). 52

Figura 28. Análise de componentes principais PCA para as variáveis ambientais do modelo proposto para a espécie C. caretta (Superior) e D coriacea (inferior). Sendo: MTSM= média da temperatura superficial do mar, $\mathrm{MTA}=$ média da temperatura do ar, $\mathrm{MP}=$ media da profundidade $\mathrm{e}$ $\mathrm{MEM}=$ média do estado do mar 
Figura 29. Diagnóstico do modelo com distribuição log normal (resíduos contra valores ajustados, resíduos contra variável explanatória; função densidade dos resíduos; qq-plot dos resíduos) para a espécie Caretta caretta. .55

Figura 30. Relação entre a variável resposta CPUE e a variável categórica Tipo de isca (TI) para a espécie Caretta caretta. .57

Figura 31. Relação entre a variável resposta CPUE e a variável longitude (LONG) para a espécie Caretta caretta. .58

Figura 32. Relação entre a variável resposta CPUE e a variável média da temperatura superficial do mar (MTSM) 58

Figura 33. Relação entre a variável resposta CPUE e a variável ano para a espécie Caretta caretta. O ano de 2010 não está presente no plot, pois, devido a redução de dados para o modelo não houve registro deste ano nos dados do modelo .59

Figura 34. Diagnóstico do modelo com distribuição log - normal (resíduos contra valores ajustados, resíduos contra variável explanatória; função densidade dos resíduos; qq-plot dos resíduos) para a espécie Dermochelys coriacea. 60

Figura 35. Relação entre a variável resposta CPUE e a variável latitude (LAT) para a espécie Dermochelys coriacea. 62

Figura 36. Relação entre a variável resposta CPUE e a variável média da profundidade (MP) para a espécie Dermochelys coriacea. 62 
Figura 37. Movimento migratório da tartaruga cabeçuda na área de estudo durante seu desenvolvimento. Seta vermelha representa movimento dos animais em desenvolvimento e junenis e seta laranja dos animais afultos e subadultos. 


\section{AGRADECIMENTOS}

À Profa. Mary, orientadora desta dissertação, por todo empenho, sabedoria, suporte, e acima de tudo, por me proporcionar um grande crescimento e enriquecimento profissional e pessoal.

À Fundação Pró-TAMAR pela excelente parceria que me proporcionou a realização deste sonho. Aos companheiros Bruno Giffoni e Gilberto Sales pelo suporte, paciência e colaborações enriquecedoras.

À Universidade de São Paulo, especialmente ao Instituto Oceanográfico, pelo apoio institucional.

Ao CNPq, pelo auxílio financeiro durante dois anos, concedido pelo Programa de Pós Graduação em Oceanografia na área de concentração Biológica.

Agradeço ao Institut de La Recherche Pour Le Développement (IRD) por financiar minha participação no Simpósio "EBFM Tuna - 2012: Towards ecosystem-based management of tuna fisheries: Mitigating impacts of fishing on pelagic ecosystems", em Montpellier, na França.

Muito obrigada à todos os funcionários da secretaria de Pós Graduação em especial à Ana Paula, Silvana e Letícia. Obrigada também, aos funcionários da biblioteca "Prof. Dr. Gelso Vazzoler", pelos esclarecimentos e paciência.

Ao Laboratório de Ecossistemas Pesqueiros (LabPesq), especialmente à Mary, Amanda, Camila, Diogo, Felippe, Karen, Camila, Marta, Priscila, Renata, Rodrigo, Ruth, Tito, pelo apoio e incentivo.

Meu eterno agradecimento aos meus pais, que sempre me apoiaram e me ajudaram a alcançar meus sonhos. Agradeço também à minha irmã 
Patrícia, meu cunhado Vanderlei e meu sobrinho Felipe, pela segunda casa, pelas conversas, filmes a noite, festas de aniversário e pelos brigadeiros de panela.

Às minhas grandes parceiras Ruth, Carol, Marta, Amanda, Juliana, Michele e Jana. Obrigada pelas conversas, explicações e noites maravilhosas de muitas risadas!

Agradeço muito também ao Felippe Postuma e Rodrigo Martins pela ajuda com as modelos estatísticos no R e no Software Statistica.

À equipe da clínica veterinária Bicos \& Focinhos, em especial ao Alexandre por todo apoio e compreensão durante a minha "jornada" do mestrado.

Muito obrigada ao parceiro Venâncio pela colaboração e paciência.

A todos os amigos que fiz no Instituto Oceanográfico que sempre estiveram presentes me aconselhando e incentivando com carinho e dedicação.

A todas as pessoas que, direta ou indiretamente, contribuíram para a execução dessa dissertação de Mestrado.

Deus, muito obrigada! 


\section{RESUMO}

A interação das tartarugas marinhas da espécie Caretta caretta e Dermochelys coriacea com o espinhel pelágico é um dos fatores que mais causa a mortalidade destes animais no oceano. Estudos com o intuito de quantificar essa interação, bem como os fatores que influenciam a mesma, são crescentes, para os quais é necessário conhecer a distribuição dos animais, e correlacioná-la com variáveis ambientais e operacionais da pesca. O presente estudo visa avaliar e quantificar os padrões espaço-temporais das capturas acidentais das tartarugas marinhas $C$. caretta e $D$. coriacea na região Sudeste/Sul do Brasil, com base em dados coletados pelo Projeto TAMAR - ICMBio, entre 2003 e 2010, a partir de um programa de observadores à bordo da frota comercial com espinhel pelágico, assim como correlacioná-los com variáveis ambientais, biológicas e operacionais. Para tal, foram utilizados métodos estatísticos, como os Modelos Aditivos Generalizados para Posição, Escala e Forma (GAMLSS). Foram verificadas variações interanuais e sazonais, com destaque para maiores capturas por unidade de esforço (CPUE) no outono. A temperatura superficial do mar foi a variável abiótica de maior correlação com a CPUE de C. caretta, sendo tipo de isca, a variável operacional mais significativa. Para $D$. coriacea, profundidade e longitude foram os fatores que melhor explicam a CPUE. Padrões de distribuição ontogenética e áreas prioritárias de conservação para essas populações são discutidas, assim como os efeitos potenciais do aquecimento do oceano. O presente estudo deve contribuir para a definição de políticas de conservação marinha e no contexto da abordagem ecossistêmica para a pesca.

Palavras chave: Tartarugas marinhas, Caretta caretta, Dermochelys coriacea, pesca espinhel pelágico, sudeste-sul do Brasil, impacto da pesca, conservação marinha. 


\begin{abstract}
The interaction between the sea turtles Caretta caretta and Dermochelys coriacea with pelagic longline is one of the factors that cause mortality of these animals in the ocean. Studies in order to quantify this interaction, as well as the factors that influence it, are increasing, focusing mostly on the turtles distribution, and how it correlates with environmental and fishing operational variables. Present study aims to evaluate and quantify the spatio-temporal patterns of the sea turtles $C$. caretta and $D$. coriacea bycatch off Southeast/South Brazil, based on data collected by Project TAMAR ICMBio between 2003 and 2010, from an observer program on-board the commercial pelagic longline fleet, as well as to correlate them with environmental, biological and operational variables,. Statistical methods such as Generalized Additive Models for Location, Scale and Shape (GAMLSS) were applied. Interannual and seasonal variations were observed, with a higher catch per unit effort (CPUE) during fall. The sea surface temperature was the abiotic variable that most correlated with CPUE of $C$. caretta, being the type of bait the most significant operational variable. For $D$. coriacea, depth and longitude were the factors that better explained the CPUE. Ontogenetic distribution patterns and priority areas for the species conservation are discussed, as well as the potential effects of ocean warming. This study should contribute to the definition of conservation policies as well as to the ecosystem approach to fisheries context.
\end{abstract}

Keywords: sea turtles, Caretta caretta, Dermochelys coriacea, pelagic longline, south Brazil, fishing impacts, priority conservation areas, marine conservation. 


\section{INTRODUÇÃO}

As tartarugas marinhas apresentam-se distribuídas globalmente e podem ser encontradas em mares tropicais e subtropicais de todos os oceanos (MÁRQUEZ, 1990). Das sete espécies de tartarugas marinhas existentes no planeta cinco utilizam a costa brasileira para alimentação e reprodução (MARCOVALDI \& MARCOVALDI 1999), entre estas, a tartaruga-cabeçuda, Caretta caretta e a tartaruga de couro, Dermochelys coriacea.

A espécie Caretta caretta (LINNAEUS, 1758) é amplamente distribuída em águas tropicais, subtropicais, temperadas e quentes do mundo, ocupando diversos tipos de habitats (DODD, 1988). No Brasil, as áreas prioritárias de desova estão localizadas no norte da Bahia, Espírito Santo, norte do Rio de Janeiro e Sergipe e áreas secundárias ocorrem em alguns pontos dos litorais do Espírito Santo e sul da Bahia (MARCOVALDI \& MARCOVALDI 1999; MARCOVALDI \& CHALOUPKA 2007). Esta espécie está listada pela IUCN como ameaçada ao longo de sua área de distribuição mundial (IUCN 2013).

Já a espécie Dermochelys coriacea (VANDELLI, 1761) está classificada como criticamente ameaçada e apresenta distribuição mundial. É encontrada desde oceanos tropicais aos sub-polares; nidificando em praias tropicais e subtropicais (IUCN, 2013). Vive usualmente na zona oceânica durante a maior parte da vida. A única área regular de desova conhecida no Brasil situa-se no litoral norte do Espírito Santo (ALMEIDA et al.,2011). O conhecimento sobre a distribuição de recém nascidos e juvenis desta espécie é escasso. No entanto, tartarugas de couro menores do que 100 centímetros de comprimento curvilíneo da carapaça (CCC) parecem limitadas a regiões mais 
quentes do que $26^{\circ} \mathrm{C}$. Avistamentos de tartarugas de tamanho inferior a $145 \mathrm{~cm}$ de CCC mostram que alguns juvenis permanecem perto da costa, em St. Lucia, Bonaire, Porto Rico, Venezuela, costa leste dos EUA (Geórgia, Carolina do Sul, Texas, Pacífico leste tropical, Samoa americana, Espanha, Escócia e Inglaterra (IUNC, 2013). A espécie apresenta ciclo de vida longo com maturação sexual entre 24,5 e 29 anos, valor estimado para a população que desova no Atlântico norte. É uma espécie altamente migratória. As fêmeas migram das áreas de alimentação e descanso para as áreas de reprodução, em deslocamentos que podem chegar até mais de $4.000 \mathrm{~km}$. São carnívoros, alimentando-se de zooplâncton gelatinoso, como celenterados, pyrossomos e salpas durante todo o ciclo de vida (ALMEIDA et al., 2011).

As causas da redução na população das tartarugas marinhas estão ligadas direta ou indiretamente à destruição do ambiente pela ação antrópica nas praias de desova, predação dos ninhos, interação com a pesca, e poluição (SPOTILA et al., 2000; BUGONI et. al., 2001; TOMÁS et al., 2001; BARROS et al., 2010). A interação das tartarugas marinhas com as artes de pesca é um dos fatores de mortalidade e injúria de indivíduos jovens e adultos desse grupo biológico em todo o mundo (LUTICAVAGE et al., 1997; PINEDO \& POLACHECK, 2004; KOTAS et al., 2004; DOMINGO et al., 2006; GARDNER et al., 2008).

Estudos recentes vêm examinando a captura acidental das tartarugas marinhas pela pesca nos Oceanos Atlântico Norte e Pacífico, principalmente em relação à pesca de atuns com espinhel de superfície (ou pelágico) (SPOTILA et al., 2000; POLOVINA et al., 2003; HAYS et al., 2003; KOCH et al., 2006; BARTRAM et al., 2010), apontando esta arte de pesca como uma das 
principais causas para o declínio e/ou dificuldade de recuperação das populações das tartarugas marinhas cabeçudas e de couro (GARDNER et al., 2008).

Estudos caracterizam o comportamento de tartarugas marinhas e identificam áreas de uso intenso, variações no temporais e espaciais são importantes para o planejamento de sua conservação, particularmente quando as tartarugas interagem com a pesca, o que pode involuntariamente prejudicálas (BARCELÓ et al., 2013). Por outro lado, o conhecimento sobre os aspectos oceanográficos relacionados ao ciclo de vida e rotas de migração das tartarugas marinhas é ainda bastante limitado. Sabe-se que após emergirem de seu ninho, os recém nascidos nadam ativamente para o oceano aberto, não reaparecendo no ambiente nerítico por anos, até a idade juvenil. Evidências sugerem que os recém nascidos dependem das correntes oceânicas para serem transportados das praias natais para seus habitas pelágicos onde permanecerão por aproximadamente 10 anos alimentando-se de plâncton. Estas áreas de alimentação são encontradas especialmente em zonas de frontes e convergência (CARR, 1986; POLOVINA et al., 2000; LUSCHI et al., 2003).

Estimativas da captura incidental dessas tartarugas pelo espinhel pelágico têm gerado preocupação em relação às taxas de mortalidade por pesca, e ao baixo potencial de recuperação dessas populações no Oceano Atlântico (WATSON et al., 2005; KOCH et al., 2006). Segundo Marcovaldi et al. (2002), o esforço de pesca pelas frotas brasileiras e estrangeiras, está aumentando no Atlântico Sul, sendo que a diminuição das quotas de pesca no Atlântico Norte incentivaria um direcionamento ao Sul, com potencial 
aumentando a mortalidade por pesca dessas espécies de tartaruga marinha nesta área (KOTAS et al., 2004).

Estima-se que, entre 1992 e 1999, a frota de espinhel pelágico (modelo americano) no Oceano Atlântico Norte capturou acidentalmente cerca de 7891 tartarugas cabeçudas e 6363 tartarugas de couro (WATSON et al., 2005). Kotas et al. (2004), em um estudo realizado no sul do Brasil durante o ano de 1998, relatou uma captura acidental de 145 tartarugas cabeçudas e de 20 tartarugas de couro. Por outro lado, Pinedo \& Polacheck (2004), relataram a captura acidental de 19 tartarugas marinhas por essa frota, entre novembro de 1996 e agosto de 1999. Domingo et al. (2006), descreveram para as frotas de espinhel pelágico do Brasil e do Uruguai, que operaram no Oceano Atlântico entre os anos de 1998 a 2004, uma captura de 1128 tartarugas cabeçudas e 259 tartarugas de couro. Archaval et al. (2000) contabilizaram um total de 106 tartarugas marinhas capturadas acidentalmente, das quais $68,9 \%$ representado por tartarugas cabeçudas, 30,2\% por tartarugas de couro e 0,9\% sendo animais que não foram identificados pela pesca de espinhel modelo espanhol e americano, entre os anos de 1994 a 1996. Coluchi (2006) destaca uma elevada CPUE (captura-por-unidade-de-esforço) pelas frotas do sul e sudeste do Brasil com 4,31 tartarugas/1000 anzóis da espécie Caretta caretta.

Assim sendo, estudos demonstram a urgência em se conhecer mais sobre o ciclo de vida dessas espécies no Atlântico Sul, e em se buscarem soluções para minimizar a sua interação com a pesca espinheleira (KOTAS et al., 2004; PINEDO \& POLACHECK, 2004; COLUCHI, 2006; DOMINGO et al., 2006). Para isso, é necessária uma ênfase particular no conhecimento sobre as populações na região (CARR, 1987), sua relação entre distribuição e feições 
oceanográficas biologia populacional, e análises quantitativas da interação das mesmas com as artes de pesca (BJORNDAL, 1999; KOTAS et al. 2004). Esse conhecimento será fundamental para se estabelecerem bases sólidas para a conservação das espécies e sua importância no ecossistema marinho regional.

Neste contexto foi estabelecido como objetivo avaliar e quantificar os padrões espaço-temporais de distribuição das capturas acidentais das tartarugas marinhas da espécie Caretta caretta e Dermochelys coriacea no ecossistema marinho da região Sudeste/Sul do Brasil, e correlacioná-los com variáveis ambientais (oceanográficas), biológicas, e operacionais esperando contribuir com a formulação de estratégias de conservação e manejo de pesca que beneficiem a manutenção do ecossistema pesqueiro. 


\section{OBJETIVOS}

2.1 Objetivo geral

O objetivo deste estudo é avaliar a distribuição espacial e temporal da captura incidental de tartarugas marinhas da espécie Dermochelys coriacea e Caretta caretta pela frota de espinhel pelágico (modelo americano) na região sudeste/sul do Brasil, e assim identificar eventuais fatores biológicos, ambientais e/ou operacionais que determinam essas interações.

\subsection{Objetivos específicos}

1. Verificar a distribuição espacial da distribuição dos lances realizados pela frota e das capturas acidentais e das tartarugas marinhas.

2. Avaliar a variação temporal das capturas acidentais das tartarugas marinhas.

3. Determinar a captura por unidade de esforço (CPUE) conforme as coordenadas geográficas, espécie-alvo da embarcação, e tipo de isca utilizada no espinhel.

4. Avaliar a correlação entre a captura acidental das duas espécies de tartarugas marinhas com as variáveis abióticas. 


\section{3. ÁREA DE ESTUDO}

A região Sudeste/Sul do Brasil, tambem determinada de Grande Ecossitema marinho do Sul do Brasil (HELINEMAN \& GASALLA, 2008) compreende a área entre o Cabo Frio $\left(23^{\circ} \mathrm{S}, \mathrm{RJ}\right)$ e o Chuí ( $\left.33^{\circ} \mathrm{S}, \mathrm{RS}\right)$, e apresenta variações sazonais na composição das massas de água, passagem de frentes, áreas de ressurgência costeira e formação de vórtices. Estes fenômenos ocasionam, por conseguinte, mudanças na composição da flora e fauna presentes ao longo da região (GONÇALVES, 2000).

De modo geral, ao longo da região Sudeste-Sul a Corrente do Brasil flui (CB) em direção sul, onde chega a encontrar águas costeiras da Corrente das Malvinas (BORZONE et al., 1999; SILVEIRA et al., 2000). A CB é formada pelo empilhamento de massas de água características do Atlântico Sul, e se separa da costa ao sul da área de estudo, entre $33^{\circ} \mathrm{S}$ e $38^{\circ} \mathrm{S}$, onde pode ser observada a formação de uma intensa frente devido ao encontro com as águas frias da Corrente das Malvinas (GONÇALVES, 2000).

$\mathrm{Na}$ região encontram-se a Água tropical (AT), Água Central do Atlântico Sul (ACAS), Água intermediária Antártica (AIA), Água Circumpolar Superior (ACS) e Água Profunda do Atlântico Norte (APAN) (SILVEIRA et al., 2000). A AT ocupa a superfície do Atlântico Sul Tropical e se caracteriza por possuir temperaturas superiores a $20^{\circ} \mathrm{C}$ e salinidade superior a 36 (GOLÇALVES, 2000). A ACAS é encontrada fluindo na região da picnoclina, e com temperaturas maiores que $6^{\circ} \mathrm{C}$ e menores que $20^{\circ} \mathrm{C}$, e salinidades entre 34,6 e 36 ups (SILVEIRA et al., 2000) 
A Plataforma Continental Sudeste possui características dinâmicas típicas de plataformas continentais de latitudes médias. A parte mais larga está localizada em frente a Santos, com $230 \mathrm{~km}$, e as partes mais estreitas, nas proximidades de Cabo Frio, com $50 \mathrm{~km}$. Seu comprimento é de aproximadamente $1100 \mathrm{~km}$ e sua topografia é suave, com as isóbatas dispondo-se paralelamente à linha da costa. Já a Plataforma Continental Sul caracteriza-se por um limite costeiro e topografia de fundo submarino relativamente uniforme. É delimitada pela isóbata de $180 \mathrm{~m}$, é estreita ao norte (110 km) e alarga-se para o sul (170 km) (CASTRO et al., 2006).

A plataforma continental interna é ocupada pela Água Costeira (AC) e há a formação de uma frente térmica de fundo que separa a plataforma interna da plataforma intermediária. Durante o verão, uma termoclina pouco profunda ocorre e se identifica a Água Central do Atlântico Sul (ACAS) na camada inferior. Uma frente salina pouco profunda separa as águas da plataforma intermediaria da plataforma externa. Águas mais salinas são características da Água Tropical (AT) e estão presentes na camada superior do domínio externo da plataforma (BRAGA \& NIENCHESKI, 2006). Durante o período de verão existe um aumento progressivo da temperatura em toda a região com médias de $25^{\circ} \mathrm{C}$, apresentando em fevereiro médias de $28^{\circ} \mathrm{C}$. Durante o período de inverno a porção norte apresenta queda das temperaturas médias mensais de $26^{\circ} \mathrm{C}$ para $24^{\circ} \mathrm{C}$, sendo as mínimas temperaturas médias mensais da área nesse período de $9^{\circ} \mathrm{C}$ (CASTRO et al., 2006).

Dentre os principais processos oceanográficos que ocorrem na região estão a ressurgência, que se caracteriza pelo afloramento de nutrientes regenerados das camadas mais profundas para a zona fótica, promovendo 0 
aumento do potencial trófico local; os vórtices que identificam a combinação da frente formada pela água de ressurgida próximo à costa e a água superficial oceânica podendo estar associados a núcleos com concentração elevada de nutrientes; e os aportes de águas continentais, que representam a entrada de água proveniente da drenagem continental e de estuários nos sistemas costeiros, promovendo por sua vez, a diminuição da salinidade e alterações na composição química da água e consequentemente um enriquecimento de nutrientes (BRAGA \& NIENCHESKI, 2006).

A frente de quebra da plataforma continental sudeste é formada pela diferença existente entre as águas da plataforma e do talude continental, na região do Atlântico Sul Ocidental. A localização desta frente esta intimamente ligada a isóbata de $200 \mathrm{~m}$, que corresponde à interface entre as águas mais frias e de menor salinidade da plataforma, e as águas mais quentes e mais salinas da Corrente do Brasil (BRAGA \& NIENCHESKI, 2006; PEREIRA et al., 2009).

A presença de estruturas vorticais, tanto ciclônicas como anticiclônicas, na região ao largo de Cabo Frio, foi verificada a partir de mapas de topografia dinâmica (SILVEIRA et al., 2000). Em algumas das distribuições apresentadas pode ser notado um padrão tal como o de uma onda de vorticidade, com a presença de anticiclones sucedendo ciclones. A parte deste meandramento atinge regiões interiores à plataforma continental. Também é especulado que feições topográficas da região favoreçam o meandramento, geram de vórtices pela corrente do Brasil nesta região. É atribuída a ocorrência de meandros e vórtices à mudança de orientação da costa e ao gradiente da topografia de 
fundo (plataforma estreita e abrupta ao norte de Cabo Frio, mais extensa e suave na Bacia de Santos) (SILVEIRA et al., 2000).

Mais ao sul da Bacia de Santos ocorre a formação de pares vorticais tanto de ciclones como de anticiclones, em lados opostos ao eixo da corrente. Essas estruturas são menores em comparação com as encontradas na região do Cabo Frio e aparentemente não se desprendem do eixo principal da Corrente do Brasil (BRAGA \& NIENCHESKI, 2006).

A região sul do Brasil é uma região de alta produtividade primária, o que faz dessa região um local de reprodução, desenvolvimento e alimentação de inúmeras espécies de animais (MONTEIRO, 2008), e a principal área de atuação da frota de espinhel pelágico sediada nos portos do sudeste-sul do Brasil no outono e no inverno (CASTELLO et al., 1998). 


\section{MATERIAL E MÉTODO}

\subsection{Obtenção dos dados}

Os dados empregados neste estudo foram obtidos a partir de uma parceria previamente estabelecia com o Projeto TAMAR, os quais foram coletados por instituições parceiras (Giffoni, comunicação pessoal) ${ }^{1}$.

Os dados coletados entre 2003 e 2010, na região que compreende as coordenadas $23^{\circ} \mathrm{S}$ a $39^{\circ} \mathrm{S}$ e $24^{\circ} \mathrm{W}$ a $50^{\circ} \mathrm{W}$. Os dados foram disponibilizados em planilhas eletrônicas e em um banco de dados em MS ACCESS.

Ao todo as observações foram realizadas junto a frota espinheleira nacional (19 barcos pesqueiros) e arrendada (6 barcos pesqueiros), totalizando registros de 1408 tartarugas marinhas em 106 cruzeiros/viagens de pesca dos barcos sediados nos portos pesqueiros de Santos (SP), Itajaí (SC), Navegantes (SC) e Rio Grande (RG) que atuaram na região.

Os dados abióticos foram coletados a bordo no início do lançamento do espinhel e no seu recolhimento. Data de embarque, horário e posição geográfica foram coletados com auxílio de aparelho GPS. A pressão atmosférica foi aferida a partir de um barômetro. Dados sobre o estado do mar foram coletados conforme a escala Beaufort. A profundidade foi aferida com auxílio da ecossonda do barco ou com a carta náutica.

Para cada viagem de pesca, foi registrado o número de tartarugas marinhas e a espécie acidentalmente capturada. Quando possível, o indivíduo

\footnotetext{
${ }^{1}$ Biólogo Bruno Giffoni, Coordenador Técnico do Programa Interação Tartarugas Marinhas e Pesca Projeto TAMAR - ICMBio / Fundação Pró-TAMAR
} 
era embarcado e feita a medição do comprimento curvilíneo da carapaça (CCC) e largura curvilínea da carapaça (LCC).

Dados como condição física do animal (viva, morta ou desmaiada), presença de tumores, local de inserção do anzol (interno, externo ou enredada), tipo de anzol (“J", circular ou "tuna hook") e tipo de isca (lula, cavalinha, sardinha ou outras espécies de peixes) foram coletados pelos observadores.

Para este estudo, foram utilizados, para cada viagem de pesca os valores médios das variáveis abióticas e operacionais que foram aferidas no lançamento e recolhimento do espinhel.

\subsection{Determinação da distribuição espacial interanual e sazonal da atuação da frota pesqueira espinheleira e das capturas acidentais}

Para a determinação da distribuição espacial da atuação da frota e das capturas acidentais analisada foram mapeados todos os lances ocorridos entre o período de 2003 a 2010, anualmente e sazonalmente para as duas espécies de tartarugas marinhas. O programa computacional utilizado para a confecção do mapa base foi o GEBCO e para a confecção dos mapas de distribuição foi o SURFER.

\subsection{Determinação das áreas de maior taxa de captura durante o período}


Para determinar as áreas que ocorreu maior taxa de captura foram confeccionados gráficos de dispersão e plotados os índices de CPUE (captura por unidade de esforço) em relação à latitude e longitude para as duas espécie de tartarugas identificadas.

A área de estudo foi dividida em quadrantes latitudinais $\left(5^{\circ}\right)$ e gráficos foram confeccionados, estabelecendo a distribuição dos índices de captura em cada quadrante.

Os índices de CPUE foram calculados com base no número de animais capturados a cada mil anzóis em cada quadrante, sendo utilizada a seguinte equação:

CPUEq $=$ (Número de animais capturados no quadrante / Número de anzóis lançados no quadrante) ${ }^{\star} 1000$

\subsection{Determinação da variação temporal da captura por unidade de esforço (CPUE)}

Para se determinar a variação temporal da CPUE durante o período estudado, a CPUE foi calculada interanualmente e sazonalmente com base na equação:

CPUE $=$ (Número de animais capturados por lance de pesca $/$ Número de anzóis utilizados por lance) * 1000

O teste de qui-quadrado foi aplicado para se estabelecer se houve diferença estatisticamente significativa entre o número de indivíduos 
capturados entre os anos e entre as estações do ano (verão, outono, inverno e primavera).

\subsection{Análise dos dados abióticos das áreas de pesca}

Os dados abióticos dos locais onde ocorreram as capturas acidentais, tais como temperatura superficial do mar (TSM), estado do mar (EM), temperatura do ar (TA), velocidade do vento (VV) e profundidade de operação da embarcação $(P)$ foram relacionados com o volume das capturas por meio do programa $R$, além da plotagem dos dados e verificação da correlação entre as variáveis.

\subsection{Representatividade da amostra de dados em relação à frota total} atuante

A representatividade da frota analisada foi calculada a partir dos dados disponíveis sobre a frota operante com base em consulta dos boletins estatísticos e bancos de dados estatísticos de pesca. Para os portos de Navegantes e Itajaí, foram consultados os Boletins Estatísticos da Pesca Industrial de Santa Catarina (GEP - Grupo de Estudos de Pesca), para o porto de Santos, foi consultado o site do Instituto de Pesca, e para o porto de Rio Grande, foi consultado o site do CEPERG (Centro de Pesquisas e Gestão dos Recursos Pesqueiros Lagunares e Estaurinos), sendo todos os registros referentes aos anos de 2003 a 2010. 


\subsection{Determinação das embarcações com maior taxa de captura de tartarugas durante todo o período.}

Para se verificar eventuais particularidades (abióticas e operacionais) das embarcações que apresentaram maiores taxas de captura (número de tartarugas por lance de pesca) foram, primeiramente, mapeadas as áreas de atuação e distribuição dos lances de pesca. Posteriormente, foram verificadas as características abióticas das áreas de atuação, características operacionais das embarcações.

Com o intuito de detectar as características (ambientais e operacionais) que podem ter levado certas embarcações a obterem uma maior taxa de captura, os dados gerais foram divididos em dois grupos, sendo um com as embarcações com maior taxa de captura e outro grupo com as demais embarcações. As variáveis abióticas para os dois grupos de embarcações foram testadas quanto à normalidade utilizando o teste de Shapiro-Wilk. Nenhuma variável apresentou normalidade na sua distribuição. O teste não paramétrico Mann-Whitney foi utilizado para se verificar a existência de diferença estatística significativa entre as variáveis abióticas (média do estado do mar (MEM), média da temperatura do ar (MTA), média da temperatura superficial do mar (MTSM)) e operacional (média da profundidade de atuação (MP)) dos dois grupos de embarcaçoes. O tipo de isca utilizado pelas embarcações foi classificado nas seguintes categorias: peixe; peixe e lula; e lula. A espécie alvo das embarcações foi classificada em três categorias, como sendo: meca, atuns e tubarões; atuns; e tubarões. O tipo de anzol também foi 
classificado e foram geradas 5 classes, sendo: Jota; Jota e Tuna Hook; Tuna Hook; Jota e circular; e Circular.

\subsection{Distribuição do comprimento curvilíneo da carapaça (CCC) das tartarugas capturadas}

Para a análise espacial, a área de estudo foi dividida em sub-áreas (Sudeste, Sul e Elevação do Rio Grande), isso permitiu a comparação da distribuição do comprimento curvilíneo da carapaça (CCC) das duas espécies de tartarugas marinhas, por área.

O $n$ amostral da espécie Caretta caretta foi de 993 animais na região Sul, 152 na Elevação do Rio Grande e 6 na região Sudeste. Já para a espécie Dermochelys coriacea o $n$ amostral foi de 12 indivíduos na região Sul e 4 indivíduos na Sudeste. O número limitado de dados desta espécie se explica pela dificuldade de se embarcar animais que possuem um grande tamanho.

\subsection{Modelos aditivos generalizados para Posição, Escala e Forma (GAMLSS)}

Para testar a hipótese de que a CPUE é afetada por mudanças nas variáveis ambientais, biológicas e operacionais foram utilizadas duas análises multivariadas, a Análise de Componentes Principais (PCA) e Modelos Aditivos Generalizados para posição, escala e forma (GAMLSS).

A PCA foi conduzida para verificar a correlação entre as variáveis abióticas e evitar colinearidade (ZAR, 2009) nos GAMLSSs. A partir dos 
resultados da PCA, foi verificado que todas as variáveis definidas puderam ser utilizadas nos modelos GAMLSS.

Foi confeccionada uma tabela para a utilização no modelo, para o qual o critério de entrada dos dados foram os lances realizados. Dos 1.290 lances de pesca observados, apenas 115 (para Caretta caretta) e 56 (para Dermochelys coriacea) foram possíveis de se utilizar no modelo GAMLSS. Isto ocorreu devido à falta de informação sobre certas variáveis, em determinados lances.

A CPUE (captura por unidade de esforço) foi calculada por lance, conforme equação a seguir:

\section{CPUE = (Número de tartarugas capturadas por lance / Número de} anzóis lançados por lance) ${ }^{*} 1000$

GAMLSSs foram utilizados para verificar a relação entre CPUE para as duas espécies de tartarugas marinhas e as variáveis abióticas e categóricas (ano, estação, tipo de isca, tipo de anzol e espécie alvo).

Foram ajustados dois modelos, um para cada espécie de tartaruga marinha. Para selecionar empiricamente o melhor modelo foi utilizado como critério de escolha os menores valores de Akaike's Information Criterion (AIC) (BURNHAM \& ANDERSON, 2002).

Para os modelos utilizados, para cada espécie, a captura por unidade de esforço (CPUE) ( $Y$ foi testada como uma função de dez variáveis explanatórias (ano, estação do ano, latitude, longitude, temperatura superficial 
do mar, temperatura do ar, profundidade, tipo de isca e tipo de anzol, código da embarcação).

As variáveis, latitude, longitude, média da temperatura superficial do mar (MTSM), média da temperatura do ar (MTA), média do estado do mar (MEM) e média da profundidade (MP) são variáveis contínuas e seus valores foram inseridos nos modelos. As demais variáveis são categóricas e foram inseridas com seus respectivos níveis nos modelos. Estação do ano (Estação) com quarto níveis (outono, inverno, primavera e verão), ano, tipo de isca (TI) com três níveis (lula, peixe ou lula e peixe, quando no mesmo lance foram utilizadas lulas e peixes) e tipo de anzol (TA) com cinco níveis (Jota; Jota e Tuna Hook; Tuna Hook; Jota e Circular; e Circular.).

Sendo assim, a equação do modelo GAMLSS foi:

\section{CPUE Longitude + Latitude + MEM + MTSM + MTA + MP + Estação + $\mathrm{TI}+\mathrm{TA}+$ ano}

Para algumas das variáveis abióticas coletadas tanto no início como no fim do lançamento de pesca, utilizou-se o valor médio.

As distribuições da variável resposta CPUE, para ambas as espécies, foram testadas utilizando a função GAIC presente no pacote GAMLSS do software R. A função realiza a seleção da melhor distribuição da variáveis resposta usando o Critério de Informação de Akaike generalizada GAIC. As distribuições testadas foram: Lognormal, Gamma, Weibull, Weibull 3, Normal e Fam Normal. 
As análises estatísticas foram realizadas utilizando o software $R$ versão 2.6.0 (R. Development Core Team, 2007) e o programa Statistica for Windows versão 10. 


\section{RESULTADOS}

Na frota espinheleira da região Sudeste/Sul do Brasil, foi registrado, pelos observadores de bordo, um total de 1290 lances entre 2003 a 2010. Um total de 1153 tartarugas cabeçudas e 255 tartarugas de couro foram capturadas acidentalmente no período analisado (Tabela 1). Foram amostrados um total de 110 cruzeiros entre os anos de 2003 a 2010. Os cruzeiros amostrados representam $5,47 \%$ dos cruzeiros totais realizados nos portos de Itajaí (SC), Santos (SP) e Rio Grande (RG) (Tabela 2).

Tabela 1. Síntese do número de anzóis lançados pelas embarcações, lances realizados e indivíduos acidentalmente capturados pela frota analisada entre os anos de 2003 a 2010.

\begin{tabular}{ccccc}
\hline Ano & $\begin{array}{c}\text { Número de } \\
\text { anzóis }\end{array}$ & $\begin{array}{c}\text { Número de } \\
\text { lances }\end{array}$ & $\begin{array}{c}\text { Tartaruga } \\
\text { cabeçuda }\end{array}$ & $\begin{array}{c}\text { Tartaruga de } \\
\text { couro }\end{array}$ \\
\hline 2003 & 69700 & 80 & 16 & 42 \\
2004 & 324625 & 238 & 85 & 13 \\
2005 & 453797 & 411 & 222 & 71 \\
2006 & 208422 & 176 & 183 & 4 \\
2007 & 226275 & 196 & 456 & 74 \\
2008 & 68761 & 65 & 63 & 27 \\
2009 & 69005 & 56 & 80 & 15 \\
2010 & 67200 & 68 & 48 & 9 \\
\hline Total & $\mathbf{1 4 8 7 7 8 5}$ & $\mathbf{1 2 9 0}$ & $\mathbf{1 1 5 3}$ & $\mathbf{2 5 5}$ \\
\hline
\end{tabular}

Houve registro de captura entre as coordenadas $23^{\circ} \mathrm{S}$ a $33^{\circ} \mathrm{S}$ a $24^{\circ} \mathrm{W}$ a $50^{\circ} \mathrm{W}$. A figura 1 mostra a área de distribuição dos lances realizados pela frota analisada durante o período de 2003 a 2010 para as espécies Caretta caretta e Dermochelys coriacea. 
Tabela 2. Número de desembarques amostrados, desembarques totais e porcentagem amostrada dos portos de Itajaí (SC), Santos (SP) e Rio Grande (RG) entre os anos de 2003 a 2010.

\begin{tabular}{cccc}
\hline Ano & $\begin{array}{c}\text { Desembarques } \\
\text { amostrados }\end{array}$ & $\begin{array}{c}\text { Desembarques } \\
\text { totais }\end{array}$ & $\begin{array}{c}\text { Porcentagem } \\
\text { amostrada } \\
(\%)\end{array}$ \\
\hline \hline 2003 & 8 & 335 & 2.39 \\
2004 & 14 & 191 & 7.33 \\
2005 & 29 & 252 & 11.51 \\
2006 & 20 & 344 & 5.81 \\
2007 & 18 & 289 & 6.23 \\
2008 & 9 & 234 & 3.85 \\
2009 & 4 & 205 & 1.95 \\
2010 & 8 & 162 & 4.94 \\
\hline Total & 110 & 2012 & $\mathbf{5 . 4 7}$ \\
\hline \hline
\end{tabular}

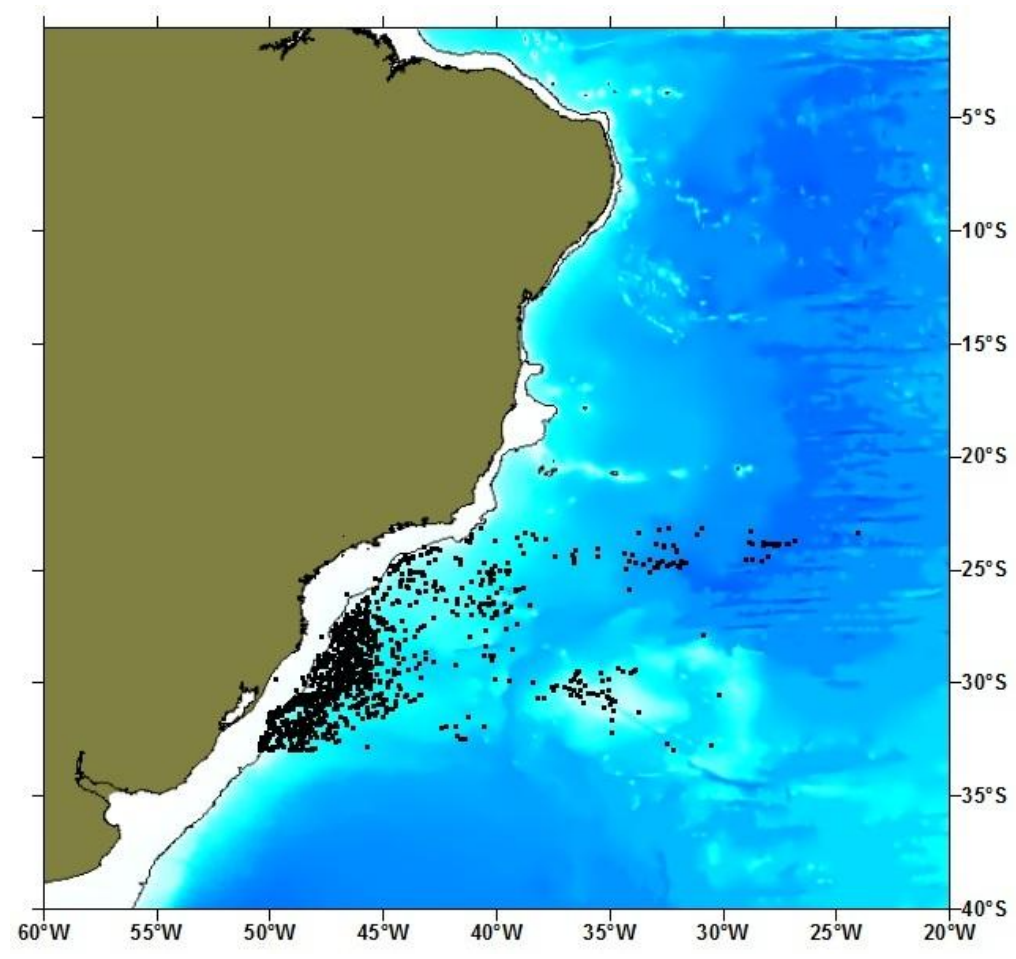

Figura 1. Distribuição dos lances realizados pela frota de espinhel pelágico analisada entre 2003 e 2010. Cada ponto no mapa representa um lance realizado. A isóbata assinalada representa $200 \mathrm{~m}$ de profundidade. 
Em aproximadamente $50 \%$ dos lances de pesca houve captura acidental de tartarugas marinhas das duas espécies. A captura da espécie Caretta caretta ocorreu em $36,56 \%$ dos lances. Já a espécie Dermochelys coriacea foi registrada em $12,39 \%$ dos lances.

A maior parte dos lances com captura de tartaruga teve um indivíduo capturado por lance. Para a espécie Caretta caretta a porcentagem de lances com captura acidental de apenas um unico indivíduo foi de 17,67\% ( $n=228)$ e para a espécie Dermochelys coriacea foi de $8,13 \%$ ( $n=105)$ (Figura 2).
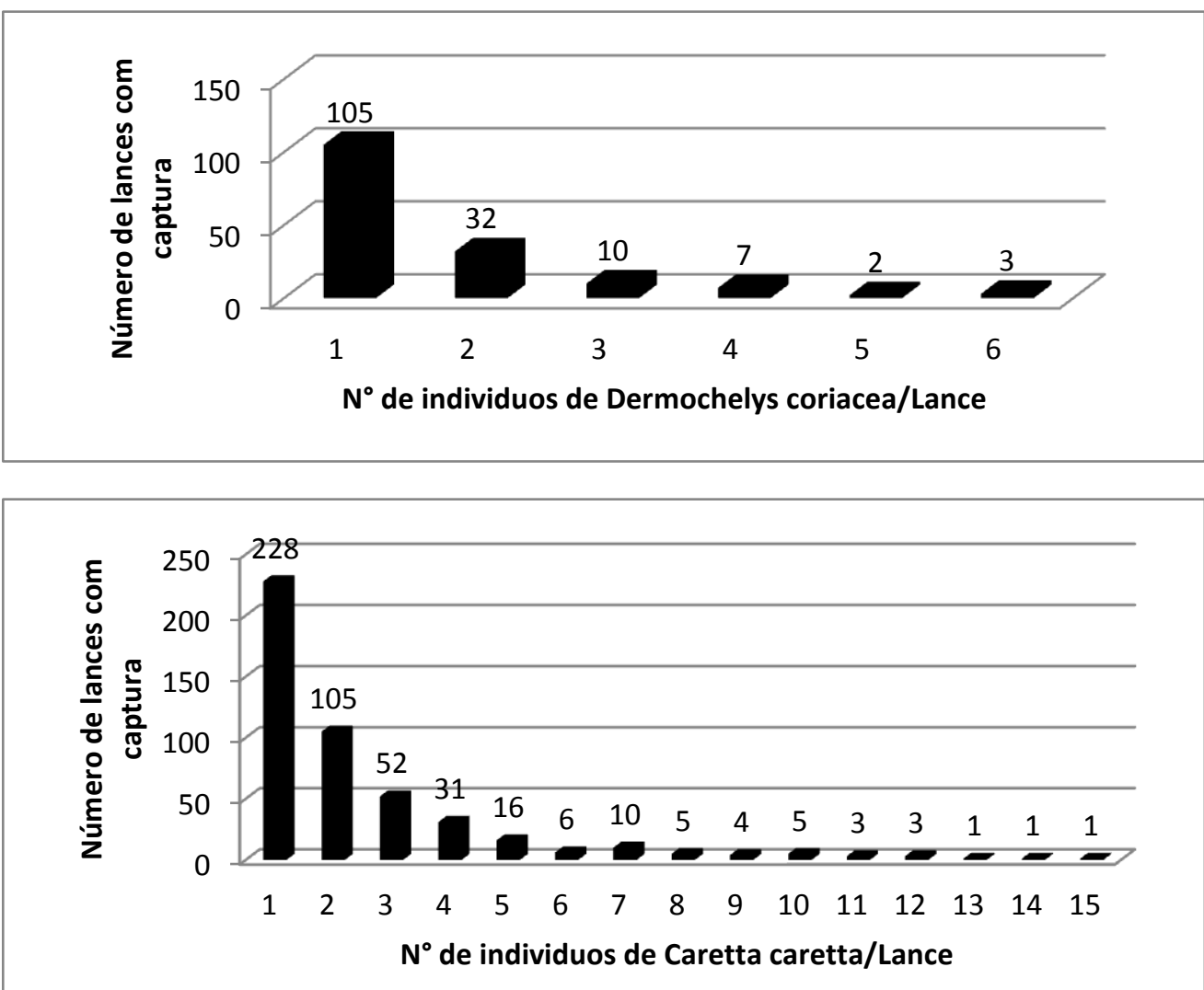

Figura 2. Distribuição de frequência do número lances com captura de indivíduos de Caretta caretta (Superior) e Dermochelys coriacea (Inferior) capturados entre os anos de 2003 e 2010 pela frota espinheleira amostrada. 
5.1. Distribuição espacial interanual do esforço pesqueiro da frota espinheleira

A análise da distribuição espacial dos lances de pesca demonstrou que houve variação interanual entre os locais. Durante os anos de 2003, 2008 e 2010 a distribuição dos lances se concentrou próxima à isóbata de 200 metros. Já durante os demais anos $(2004,2005,2006,2007,2009)$ os lances se distribuíram a maior distância da plataforma, continental próximos a elevação do Rio Grande (Figura 3). 

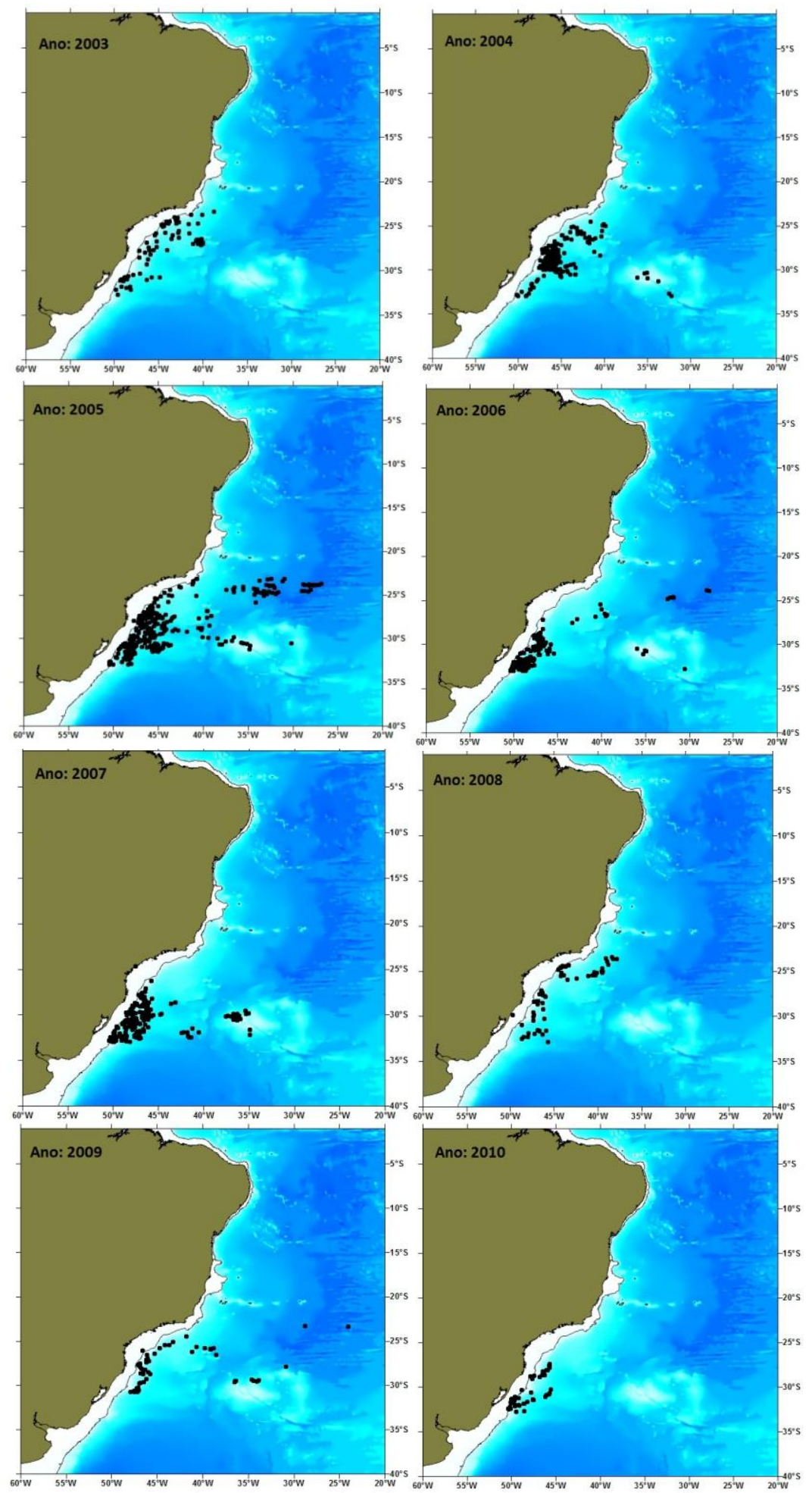

Figura 3. Distribuição espacial dos lances realizados pela frota analisada entre o ano de 2003 a 2010. Cada ponto no mapa representa um lance realizado. A isóbata assinalada representa 200 metros de profundidade. 


\subsection{Distribuição espacial interanual das capturas acidentais de tartarugas}

A análise da distribuição das capturas acidentais das tartarugas (cabeçudas e de couro) demonstrou que houve variação interanual na distribuição espacial das mesmas, para as duas espécies.

Para tartaruga cabeçuda durante os anos 2003, 2004, 2008 e 2010 as capturas se concentraram na região mais ao Sul da área de estudo e próximas a plataforma continental (Figura 4 e 5). Durante os anos de 2005 e 2007 as capturas se concentraram também na região Sul da área de estudo, próximas a plataforma e também na área oceânica e próximas a Elevação do Rio Grande. O ano de 2009 apresentou a particularidade de as capturas se concentrarem na região Sudeste e região oceânica próxima a Elevação do Rio Grande (Figura 4 e 5).

Já a tartaruga de couro, teve suas capturas concentradas na região mais ao norte da área de estudo, e próximas à plataforma continental. Os anos de 2006 e 2010 apresentaram capturas mais ao Sul da área de estudo. Os anos de 2003 e 2009 apresentaram capturas exclusivamente na região Sudeste da área de estudo. Os demais anos concentram as capturas próximas à plataforma continental (Figura 4 e 5). 


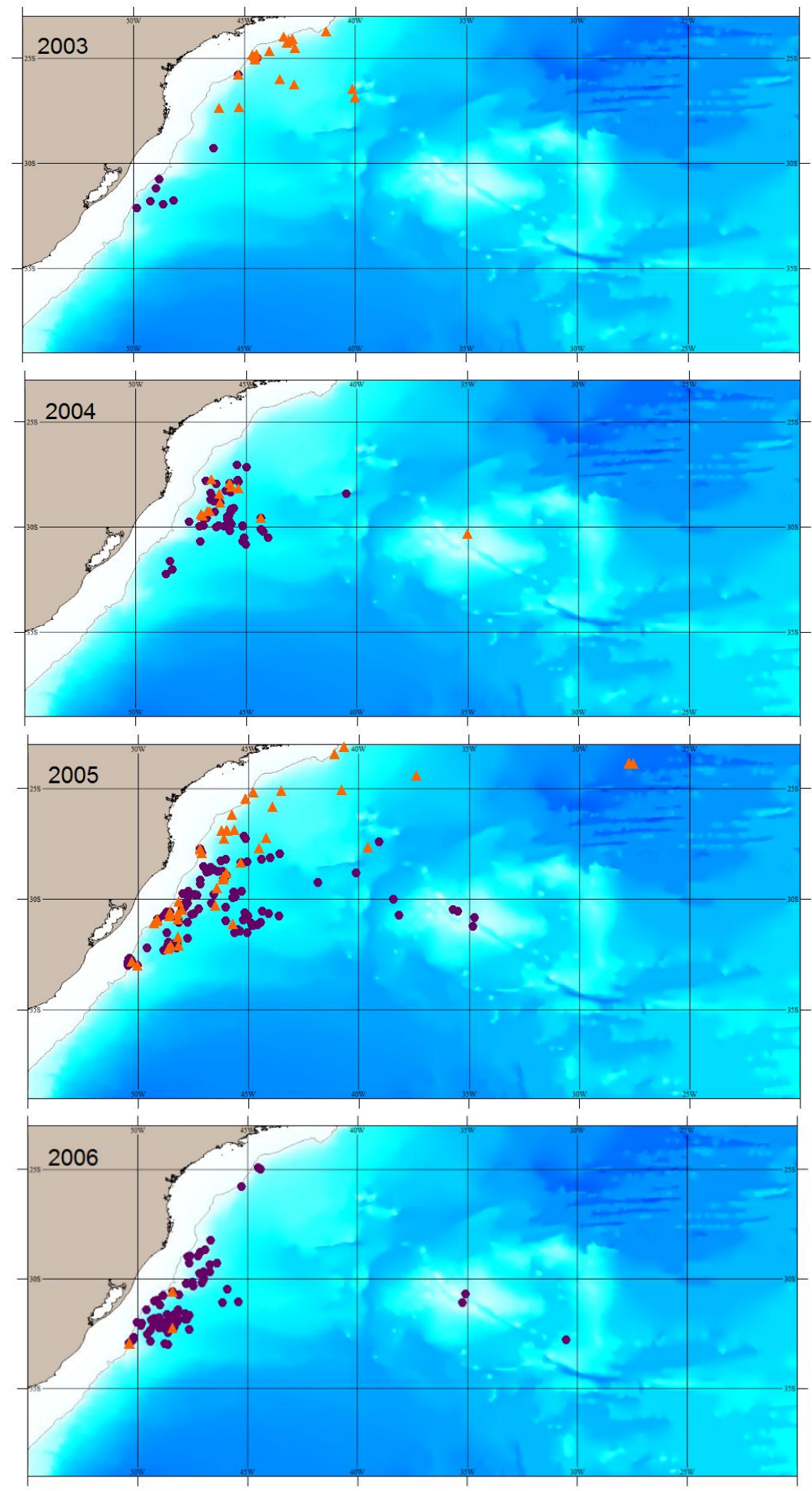

Figura 4. Distribuição espacial das capturas acidentais das tartarugas cabeçuda (ponto roxo) e tartaruga de couro (triangulo laranja) durante os anos de 2003 a 2006. 

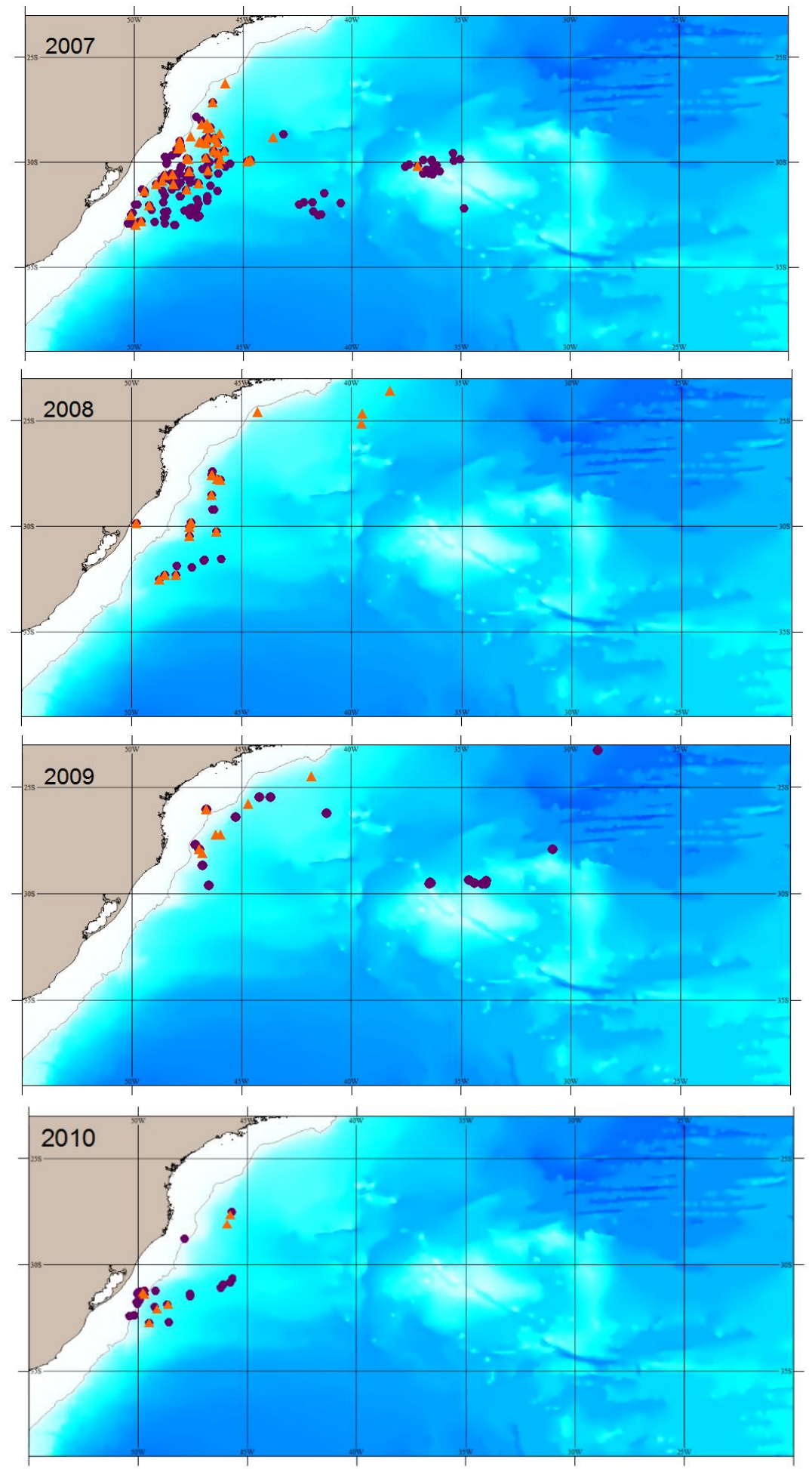

Figura 5. Distribuição espacial das capturas acidentais das tartarugas cabeçuda (ponto roxo) e tartaruga de couro (triangulo laranja) durante os anos de 2003 a 2006. 


\subsection{Distribuição espacial sazonal do esforço pesqueiro da frota} espinheleira

Foi detectado um padrão sazonal na área de atuação da frota espinheleira. Durante os meses de outono e inverno a distribuição dos lances da frota analisada se concentrou próxima à plataforma continental. Já nos meses de verão e primavera a distribuição chegou a maiores profundidades e próximas à elevação do Rio Grande (Figura 6).
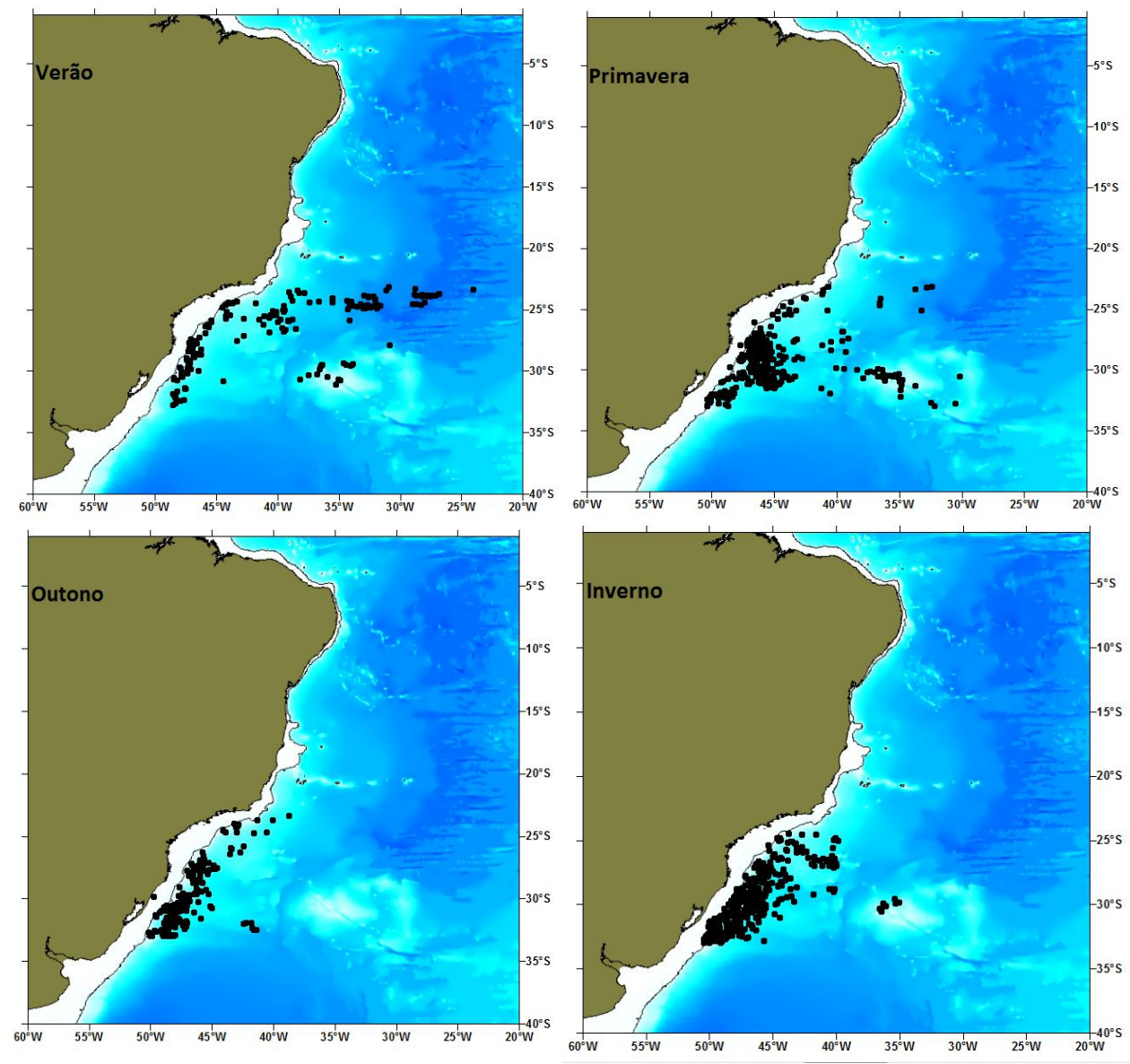

Figura 6. Distribuição espacial dos lances realizados pela frota analisada sazonalmente. Cada ponto no mapa representa um lance realizado. A isóbata assinalada representa 200 metros de profundidade. 


\subsection{Distribuição espacial sazonal das capturas acidentais de tartarugas}

A distribuição das capturas acidentais também variou sazonalmente para as duas espécies de tartarugas marinhas.

Para a tartaruga cabeçuda, durante o outono e inverno as capturas se concentraram na região sul da área de estudo, próximas a plataforma continental, região oceânica e próximo a Elevação do Rio Grande. Durante a primavera e o verão as capturas se distribuíram na região Sudeste, Sul e oceânica da área de estudo (Figura 7).

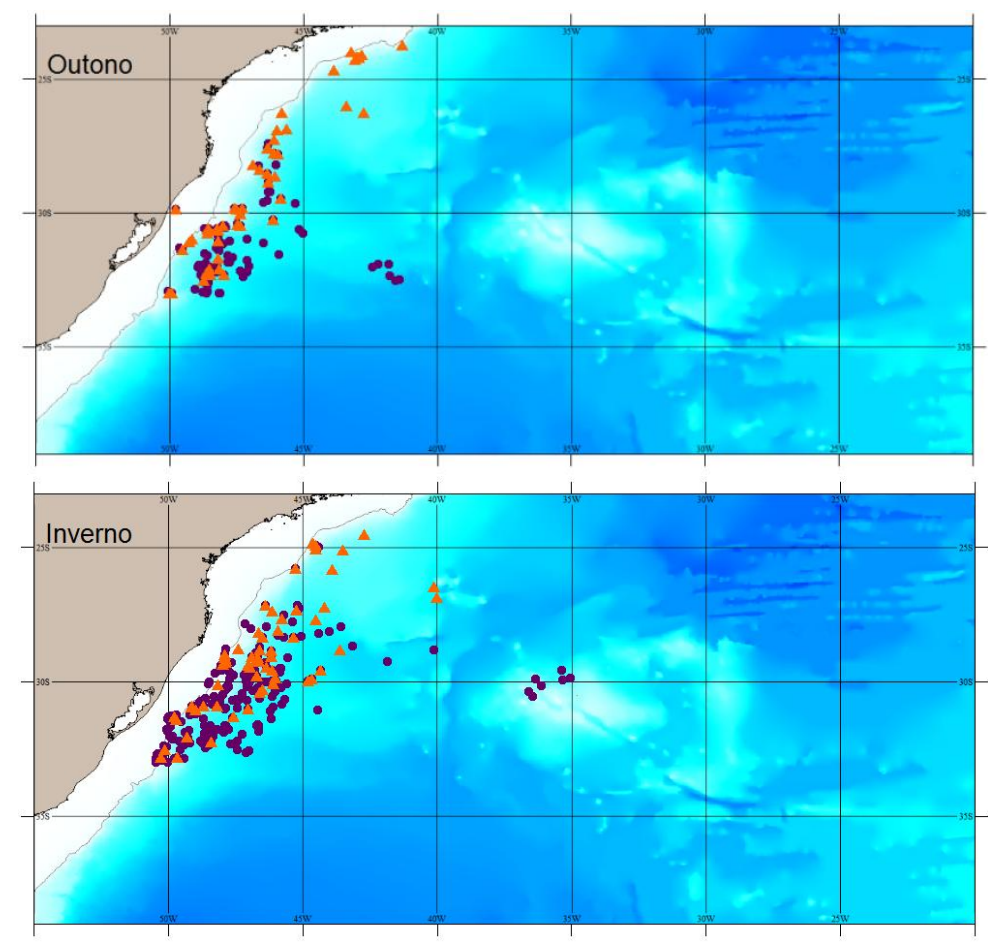

Figura 7. Distribuição espacial das capturas acidentais das tartarugas cabeçuda (ponto roxo) e de couro (triangulo laranja) durante o outono e inverno. 
Durante o verão, a tartaruga de couro apresentou capturas acidentais nas áreas oceânicas e plataforma continental mais ao norte da área de estudo. Já na primavera as capturas se apresentaram distribuídas na plataforma continental Sudeste e Sul e região oceânica da área de estudo (Figura 8).

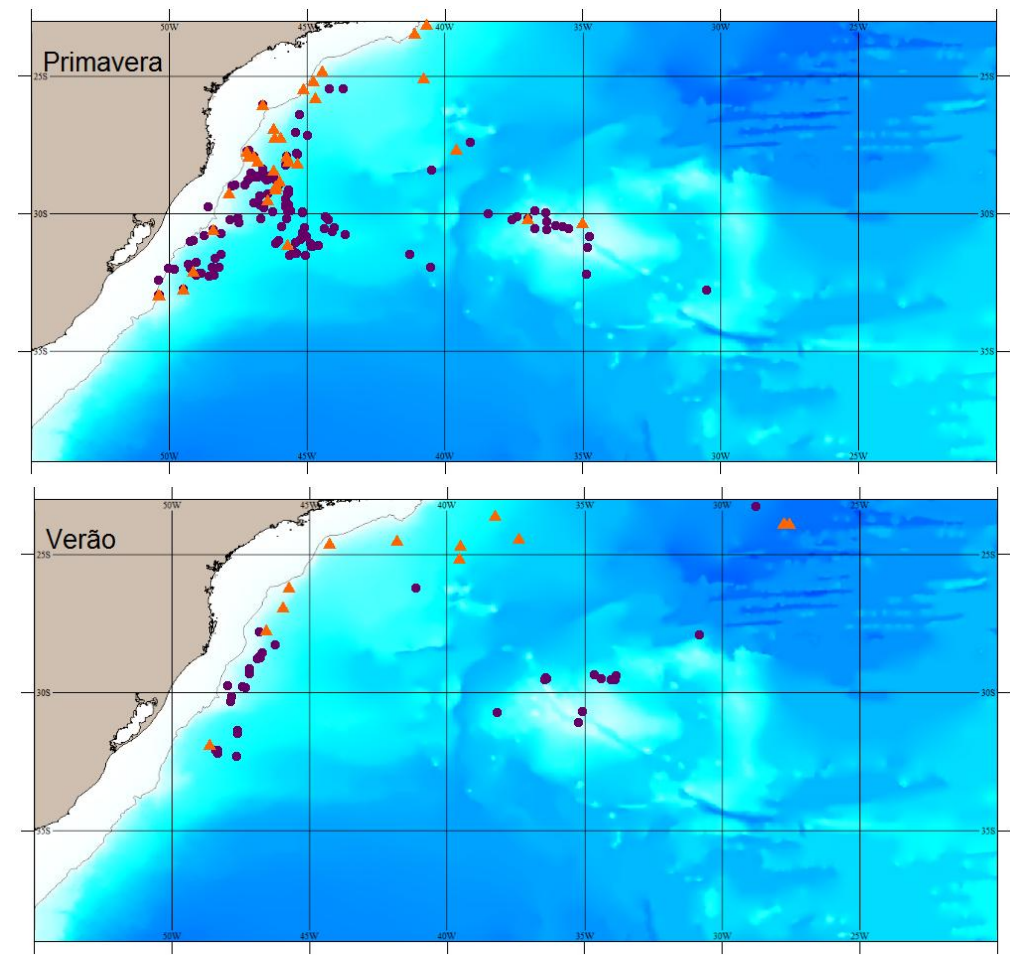

Figura 8. Distribuição espacial das capturas acidentais das tartarugas cabeçuda (ponto roxo) e de couro (triangulo laranja) durante a primavera e verão. 


\subsection{Variação interanual da captura por unidade de esforço (CPUE) das tartarugas}

A CPUE da espécie Caretta caretta variou entre 0,41 e 17,50 com média de 2,14 animais por 1000 anzóis. Já para a espécie Dermochelys coriacea a CPUE variou entre 0,41 e 6,66 com média de 1,46 animais por 1000 anzóis.

As figuras 9 e 10 mostram a distribuição interanual da CPUE para as duas espécies de tartarugas marinhas entre 2003 a 2010.

\section{Caretta caretta}

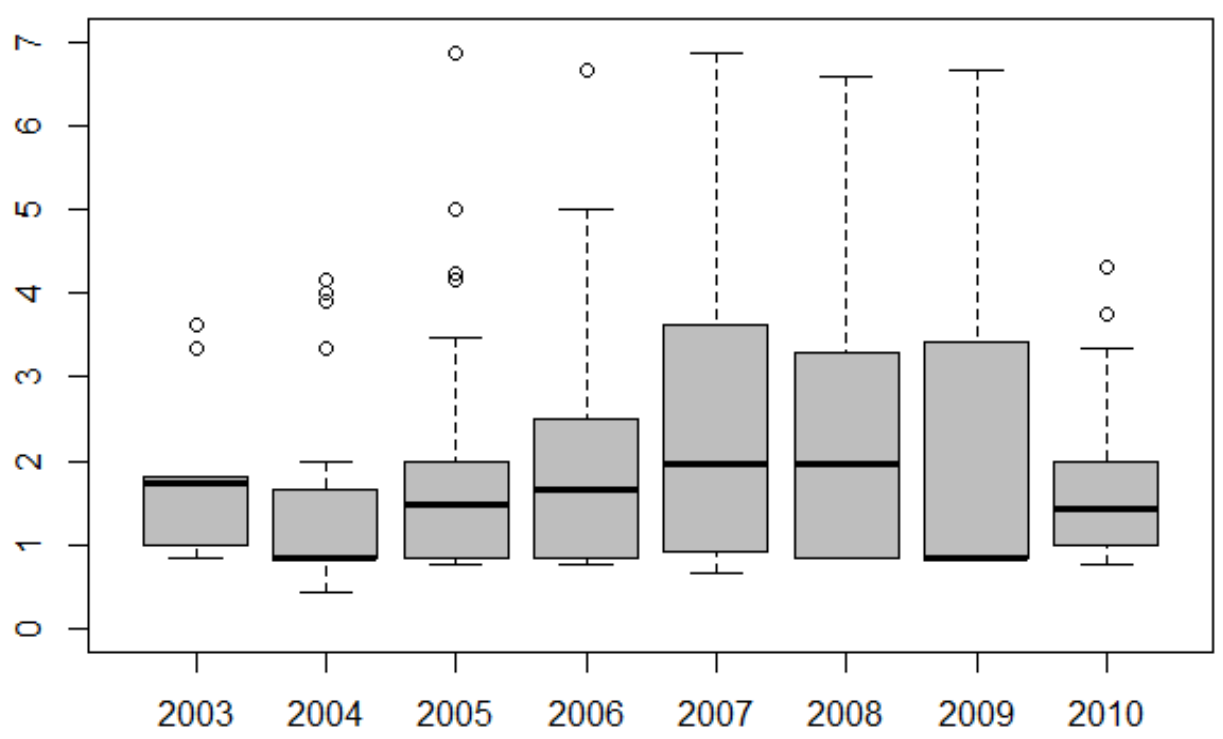

Figura 9. Box - plot do comportamento interanual da CPUE para a tartaruga cabeçuda entre os anos de 2003 a 2010. 


\section{Dermochelys coriacea}

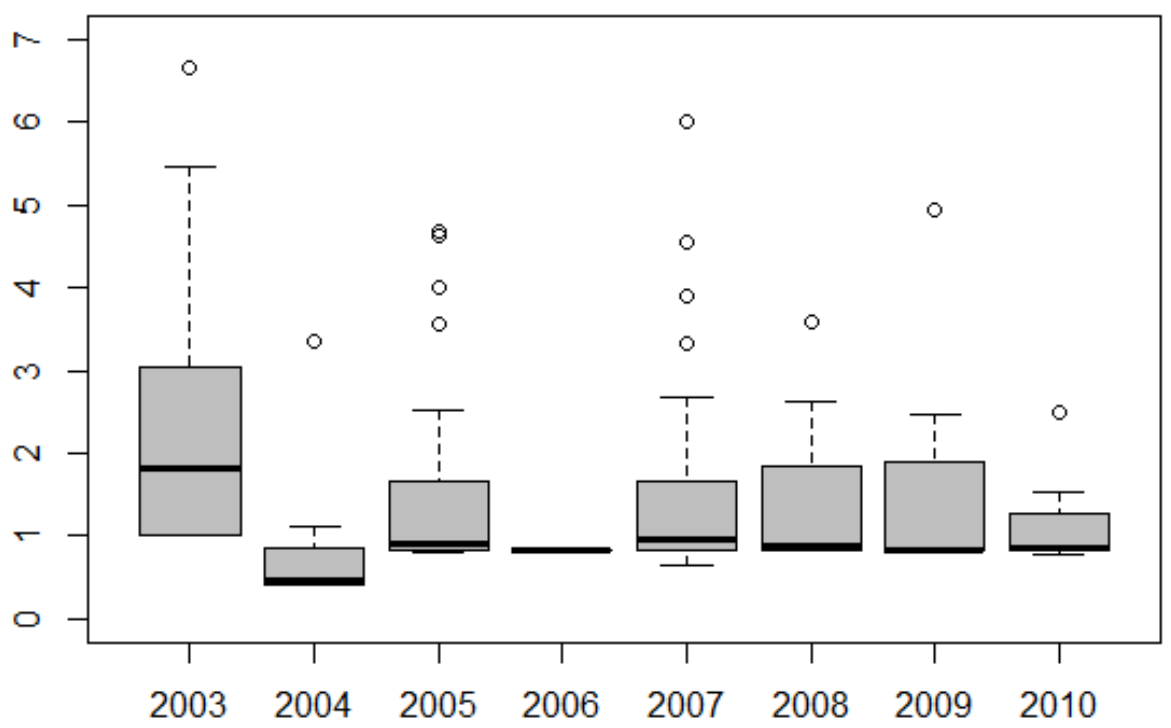

Figura 10. Box - plot do comportamento interanual da CPUE para a tartaruga de couro entre os anos de 2003 a 2010.

Para a espécie Caretta caretta foi observada diferença interanual significativa no número de indivíduos capturados $\left(x^{2}=867.9685\right.$; gl=7; com nível de significância de $2.2^{\mathrm{e}-16}$ ). O ano de 2007, foi o que apresentou maior CPUE para a espécie Caretta caretta, com 2,015 tartarugas/1000 anzóis, seguido pelo ano de 2009, com 1,159 tartarugas/1000 anzóis (Figura 11).

Para a espécie Dermochelys coriacea também foi observada diferença significativa no número de indivíduos capturados entre os anos $\left(x^{2}=164.7483\right.$; gl=7; com nível de significância de $2.2^{\text {e-16 }}$ ). O ano 2003, foi o que ocorreu maior CPUE com 0,603 tartarugas desta espécie capturadas/1000 anzóis (Figura 12). 
As duas espécies de tartarugas marinhas apresentaram diferentes picos de CPUE entre o período estudado. Para a espécie Caretta caretta estes ocorreram nos anos de 2007 e 2009 e para a espécie Dermochelys coriácea os picos ocorreram nos anos de 2003 e 2008.

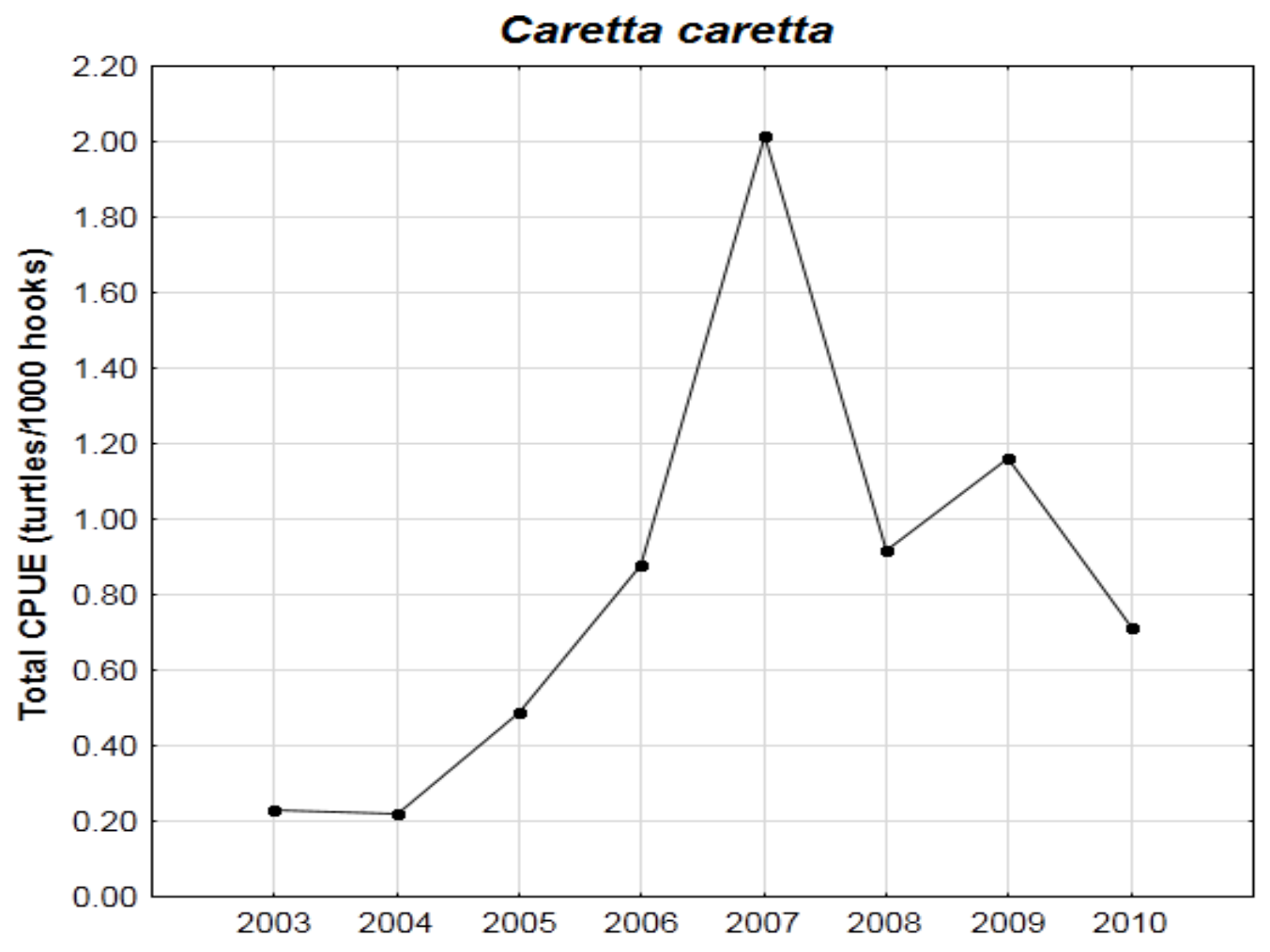

Figura 11. Variação interanual da CPUE para a espécie Caretta caretta durante os anos de 2003 a 2010. 


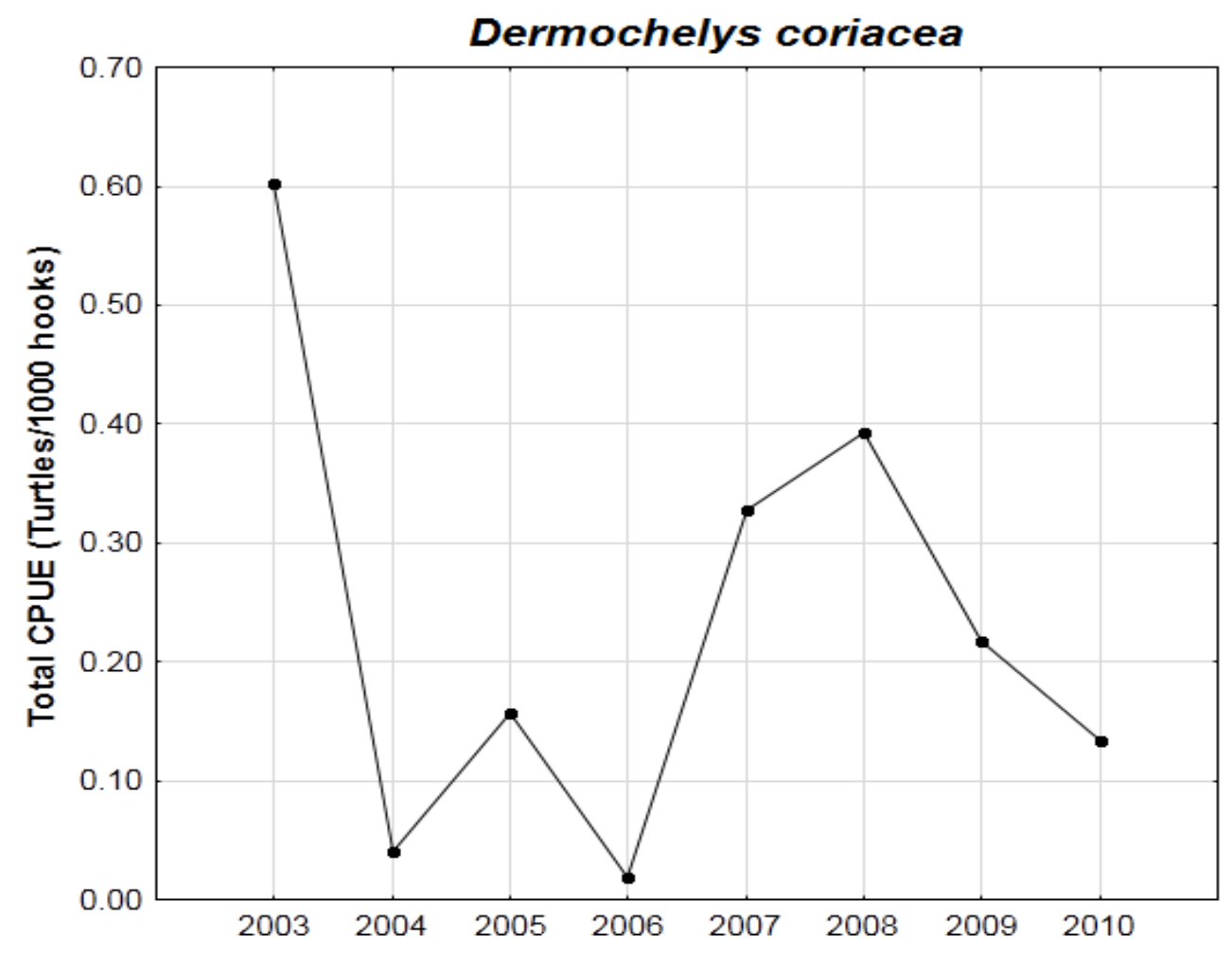

Figura 12. Variação interanual da CPUE para a espécie Dermochelys coriacea durante o ano de 2003 a 2010.

\subsection{Variação sazonal da captura por unidade de esforço (CPUE) das tartarugas}

As duas espécies de tartarugas marinhas apresentaram variação sazonal na CPUE. A maior CPUE para a tartaruga cabeçuda e de couro foi registrada no outono, 1.1 e 0.32 respectivamente. Já a menor CPUE foi registrada durante a primavera, para a tartaruga cabeçuda e durante o verão para a de couro (Figura 13). 
Caretta caretta

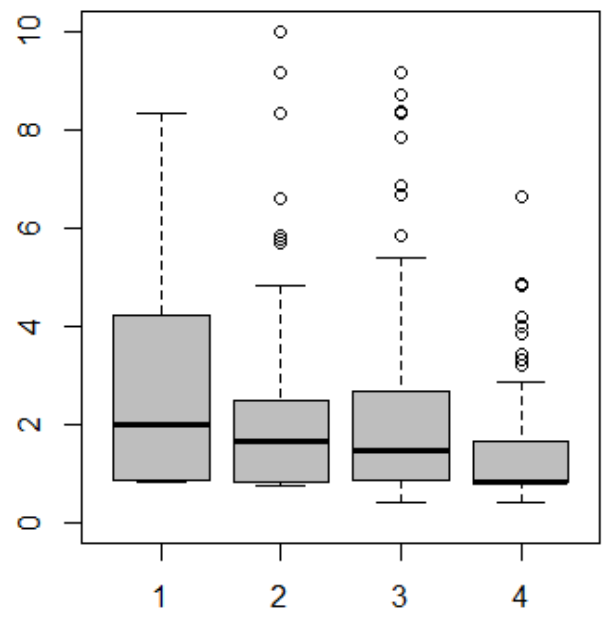

Dermochelys coriacea

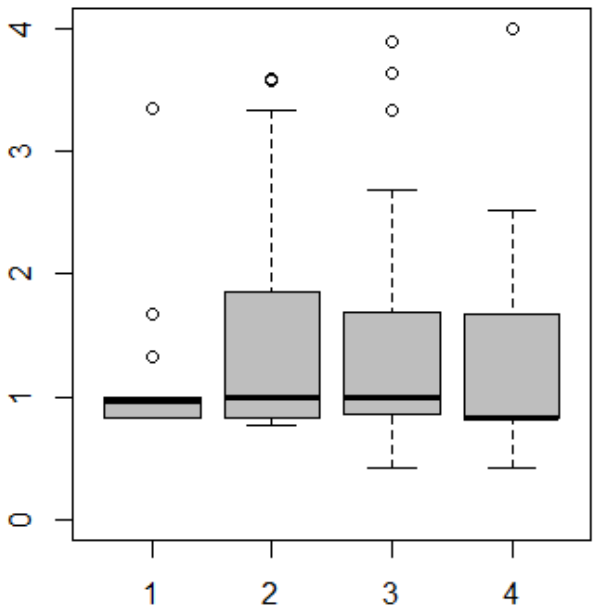

Figura 13. Variação sazonal da CPUE para a tartaruga cabeçuda e de couro. $1=$ verão, $2=$ outono, $3=$ inverno, $4=$ primavera .

Para a espécie Caretta caretta foi observada diferença significativa no número de indivíduos capturados sazonalmente $\left(x^{2}=184,5614\right.$; gl=3; com nível de significância de $2.2^{\mathrm{e}-16}$ ). Para a espécie Dermochelys coriacea, também foi observada diferença estatisticamente significativa $\left(x^{2}=65,0471\right.$; gl=3; com nível de significância de $\left.4.901^{\mathrm{e}-14}\right)$. Tanto a tartaruga de couro como a tartaruga cabeçuda apresentaram um pico da CPUE no outono (Figura 14 e 15). 


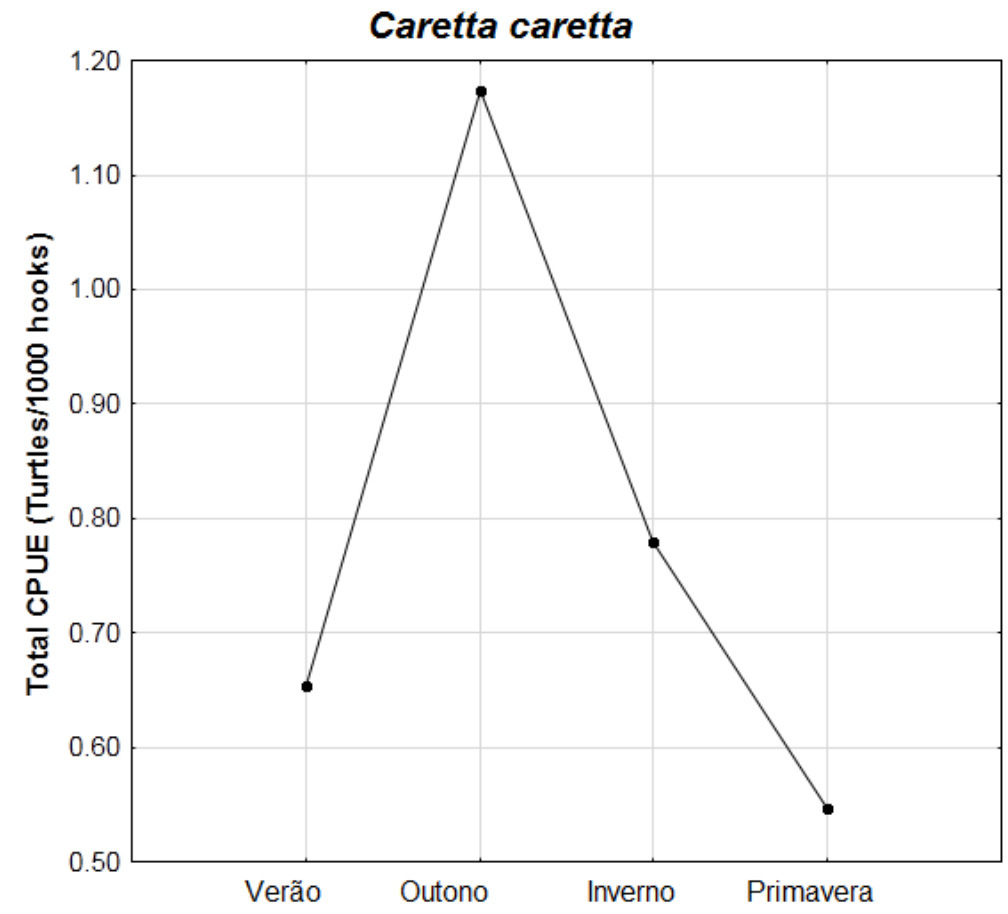

Figura 14. Variação da CPUE sazonalmente para a espécie Caretta caretta.

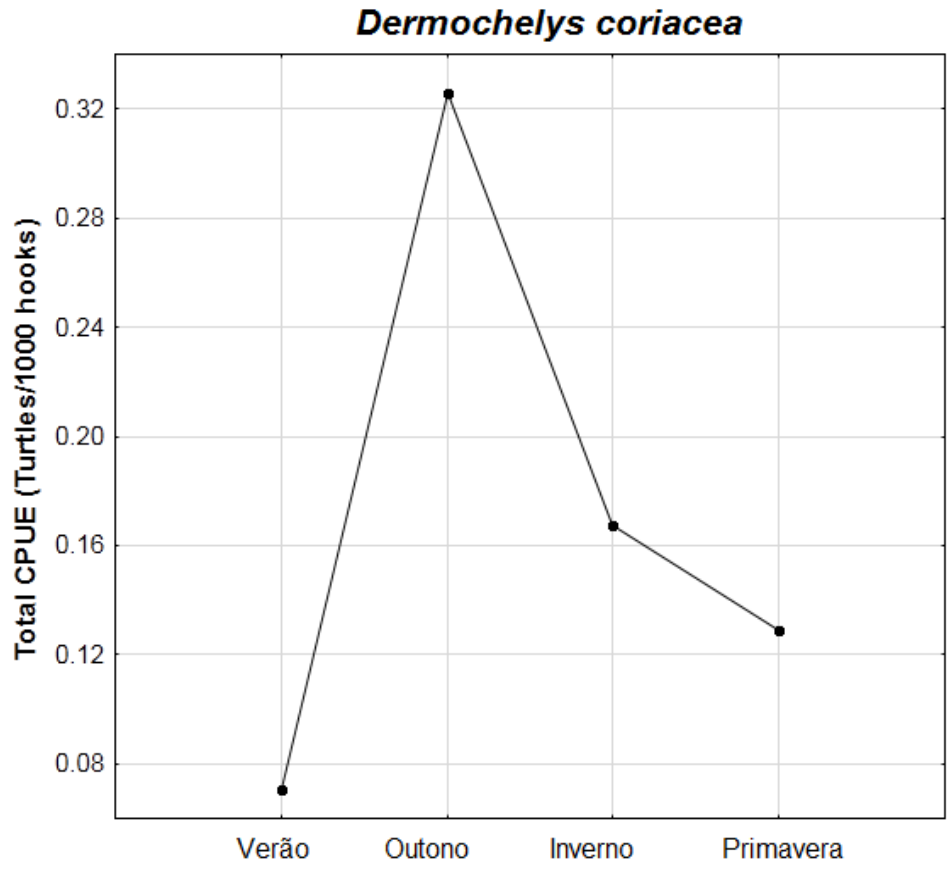

Figura 15. Variação da CPUE sazonalmente para a espécie Dermochelys coriacea. 


\section{7. Áreas de maior CPUE durante o período}

A área de concentração das CPUE da espécie Caretta caretta se localizou entre $27^{\circ} \mathrm{S}$ a $33^{\circ} \mathrm{S}$ e $34^{\circ} \mathrm{W}$ a $50^{\circ} \mathrm{W}$ (Figura 16).

Os maiores índices de CPUE encontrados para a espécie C. caretta foram na área oceânica compreendida pela Elevação do Rio Grande. A CPUE nesta área variou de 1 a 3 tartarugas capturadas a cada 1000 anzóis.

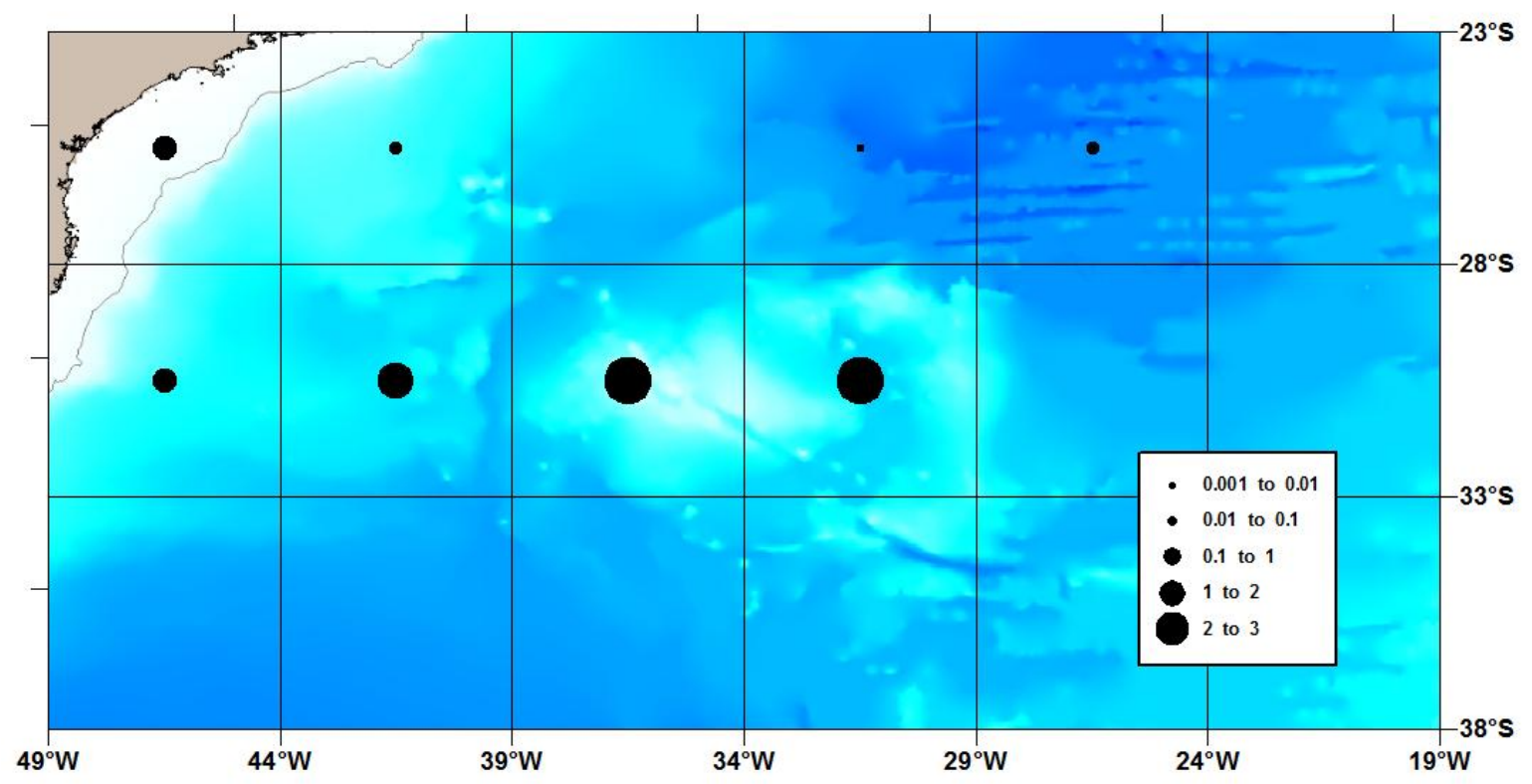

Figura 16. Captura por unidade de esforço (CPUE) com base no número de animais capturados por 1000 anzóis para a espécie Caretta caretta por quadrante.

Já para a espécie Dermochelys coriacea, os maiores índices da CPUE estiveram entre $23^{\circ} \mathrm{S}$ a $33^{\circ} \mathrm{S}$ e $40^{\circ} \mathrm{W}$ a $50^{\circ} \mathrm{W}$, sobre a plataforma continental Sudeste (Figura 17) e variaram entre 0,3 a 04 animais capturados a cada 1000 anzóis. 


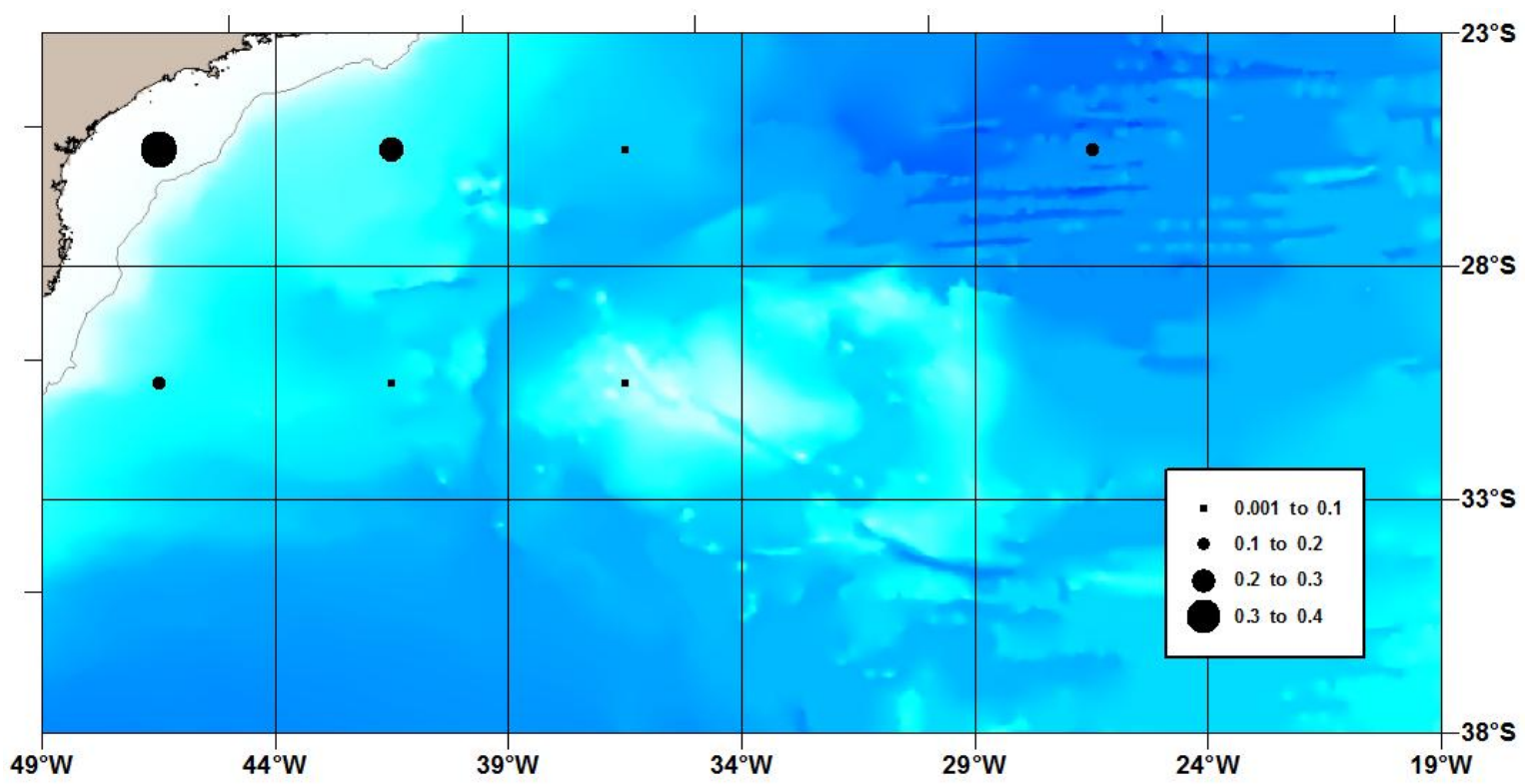

Figura 17. Captura por unidade de esforço (CPUE) com base no número de animais capturados por 1000 anzóis para a espécie Dermochelys coriacea por quadrante.

\subsection{Dados abióticos e operacionais da frota espinheleira nas áreas de ocorrência de captura acidental de tartarugas marinhas}

Com relação ao estado do mar médio a captura acidental se concentrou entre 1 e 3,5 para ambas as espécies.

Quanto a temperatura do ar média as capturas ocorreram entre $12^{\circ} \mathrm{C}$ a $34^{\circ} \mathrm{C}$, com concentração das capturas entre $18-24^{\circ} \mathrm{C}$, para a espécie Caretta caretta, e entre $12-36^{\circ} \mathrm{C}$, com maior concentração entre $20-26^{\circ} \mathrm{C}$ para a espécie Dermochelys coriacea. Tartarugas cabeçudas foram capturadas em áreas com temperatura do ar relativamente mais baixas do que a tartaruga de couro.

Em relação à $T S M$, as capturas se encontraram entre $15-27^{\circ} \mathrm{C}$, com maior número de animais capturados entre $19-22{ }^{\circ} \mathrm{C}$ para Caretta caretta e 
entre $16-29^{\circ} \mathrm{C}$, com maior número de animais capturados entre $21-23^{\circ} \mathrm{C}$ para Dermochelys coriacea. Assim como para a temperatura do ar, as tartarugas cabeçudas também foram capturadas em áreas com TSM mais baixa do que a tartaruga de couro.

Com relação a media da velocidade do vento as concentrações estiveram entre 1-14 para Caretta caretta e Dermochelys coriacea, com concentração das capturas entre 1-2.

Para as duas espécies a concentração de animais acidentalmente capturados com relação a média da pressão atmosférica esteve entre 1010 e $1040 \mathrm{~atm}$.

As capturas acidentais ocorreram entre as profundidades de operação de 100 a 5500 metros. Para Caretta caretta as capturas se concentraram entre 2500-3000 metros e para Dermochelys coriacea entre 500 a 1000 metros.

Com relação à forma que as tartarugas marinhas foram acidentalmente capturadas a espécie C. caretta foi encontrada em sua maioria com o anzol fisgado a boca $(n=766)$, já a espécie D. coriacea foi encontrada em sua maioria enrolada a linha, com o anzol externo ao corpo $(n=113)$ (Figura 19).

A Figura 18 ilustra as diferenças observadas entre os padrões encontrados nas capturas das duas espécies de tartarugas marinhas para as variáveis abióticas e a profundidade de operação das embarcações. Esta análise permitiu a observação de diferentes padrões para cada espécie 

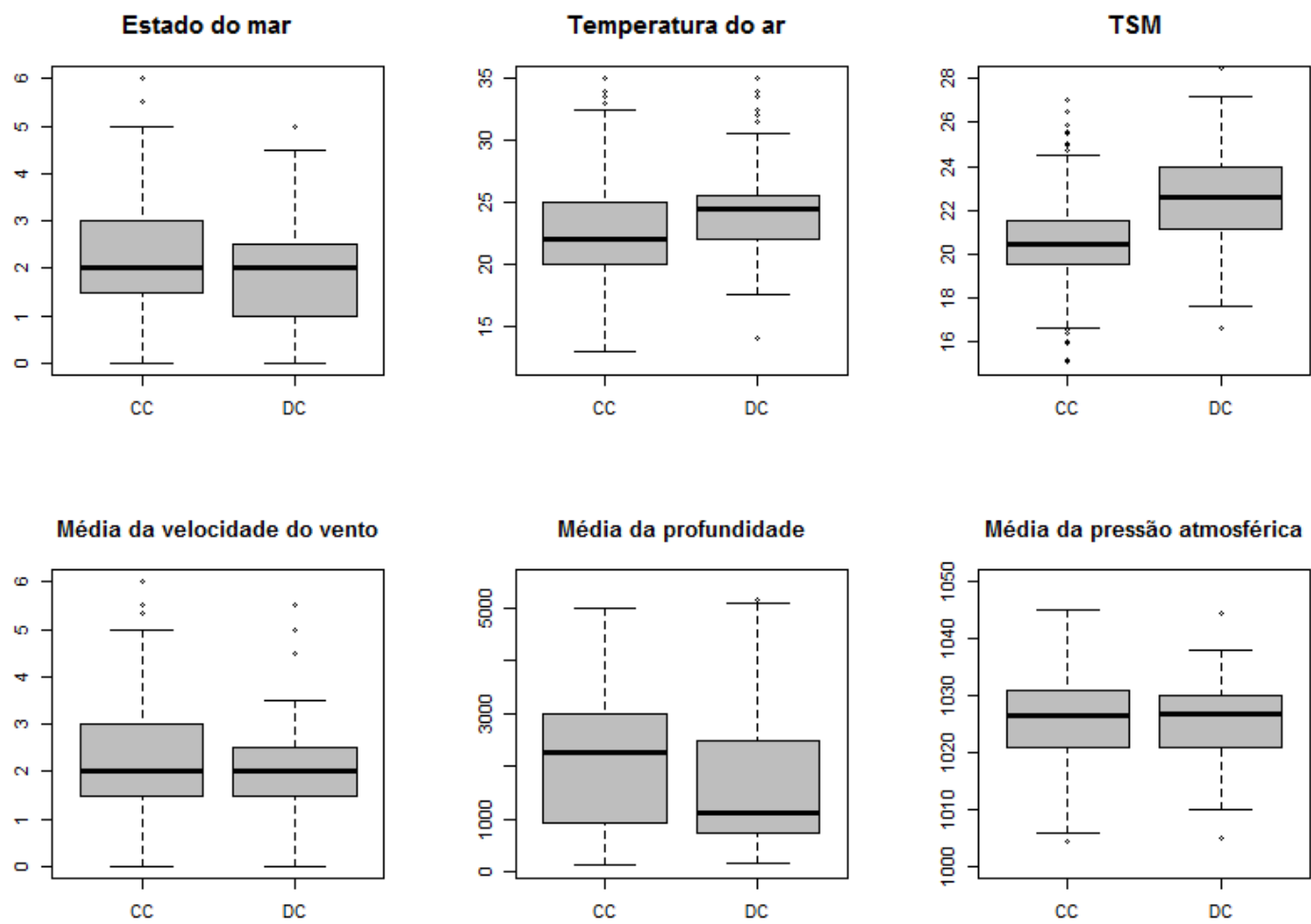

Figura 18. Padrão das capturas acidentais das variáveis abióticas e profundidade de operação das embarcações para as espécies Caretta caretta (CC) e Dermochelys coriacea (DC) para as capturas acidentais ocorridas nos anos de 2003 a 2010. Box plot com mediana, quartil inferior e superior e outliers.
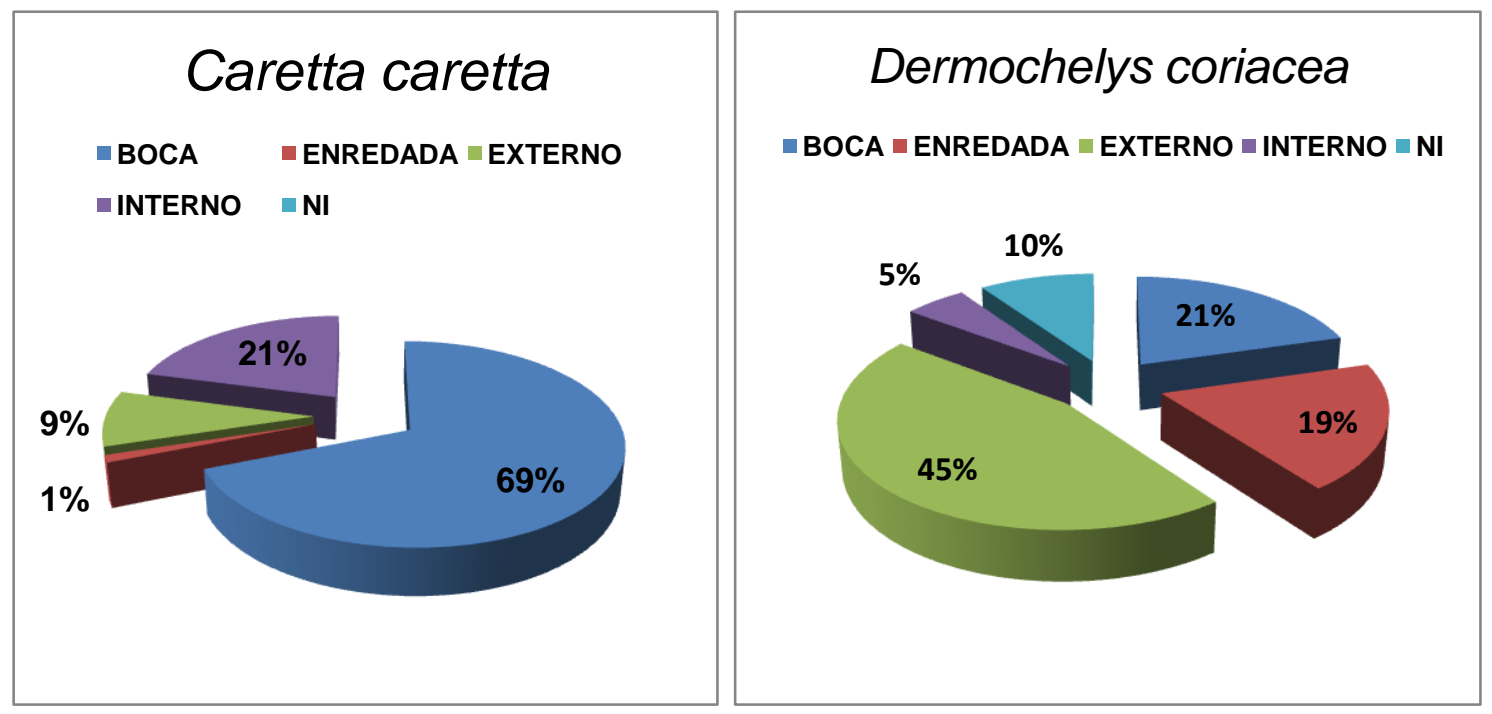

Figura 19. Padrão da inserção do anzol durante as capturas acidentais das tartarugas marinhas 


\subsection{Embarcações que apresentaram alta taxa de captura (tartarugas por lance)}

Das 25 embarcações analisadas, um total de 8 embarcações apresentaram alta taxa de captura (mais de 2 animais por lance), sendo que estas realizaram 117 lances e capturaram um total de 402 tartarugas, 335 Caretta caretta e 67 Dermochelys coriacea (Tabela 3)

Tabela 3. Síntese das capturas acidentais realizadas pela frota analisada.

\begin{tabular}{ccccc}
$\begin{array}{c}\text { Código da } \\
\text { embarcação }\end{array}$ & $\begin{array}{c}\text { Tartarugas } \\
\text { capturadas }\end{array}$ & $\begin{array}{c}\text { Número de lances } \\
\text { com capturas }\end{array}$ & $\begin{array}{c}\text { Tartarugas } \\
\text { por cruzeiro }\end{array}$ & $\begin{array}{c}\text { Tartarugas } \\
\text { por lance }\end{array}$ \\
\hline \hline 115 & 49 & 8 & 49 & 5.444 \\
59 & 14 & 2 & 14 & 4.667 \\
99 & 58 & 12 & 58 & 4.143 \\
39 & 61 & 14 & 20.33 & 3.813 \\
40 & 101 & 27 & 20.2 & 3.156 \\
78 & 72 & 21 & 24 & 3.13 \\
98 & 17 & 6 & 17 & 2.833 \\
2 & 30 & 13 & 30 & 2.143 \\
89 & 55 & 23 & 13.75 & 1.833 \\
8 & 119 & 43 & 13.22 & 1.63 \\
9 & 259 & 82 & 19.92 & 1.619 \\
90 & 15 & 10 & 15 & 1.071 \\
1 & 79 & 30 & 15.8 & 1.068 \\
79 & 45 & 18 & 15 & 1 \\
144 & 6 & 3 & 6 & 1 \\
140 & 33 & 20 & 6.6 & 0.917 \\
26 & 147 & 71 & 8.17 & 0.865 \\
6 & 16 & 10 & 8 & 0.64 \\
91 & 4 & 4 & 4 & 0.571 \\
51 & 139 & 87 & 9.93 & 0.511 \\
74 & 28 & 14 & 14 & 0.467 \\
70 & 25 & 18 & 25 & 0.272 \\
4 & 15 & 11 & 1.15 & 0.25 \\
96 & 1 & 1 & 1 & 0.1 \\
\hline
\end{tabular}




\subsection{1. Área de atuação das embarcações com maior taxa de captura de tartarugas marinhas}

Com relação a área de atuação das embarcações com maior taxa de captura pode ser observado que houve diferença na distribuição dos lances latitudinalmente. As embarcações com maior taxa de captura distribuíram seus lances na região sul e Elevação do Rio Grande da área de estudo. Já as demais embarcações realizaram lances nestas regiões e também na região sudeste mais ao norte da área de estudo (Figura 20). O quadrante compreendido pelas coordenadas $45-40^{\circ} \mathrm{S}$ e $35-30^{\circ} \mathrm{W}$ representou uma área exclusiva de lançamento para as embarcações com alta taxa de captura.

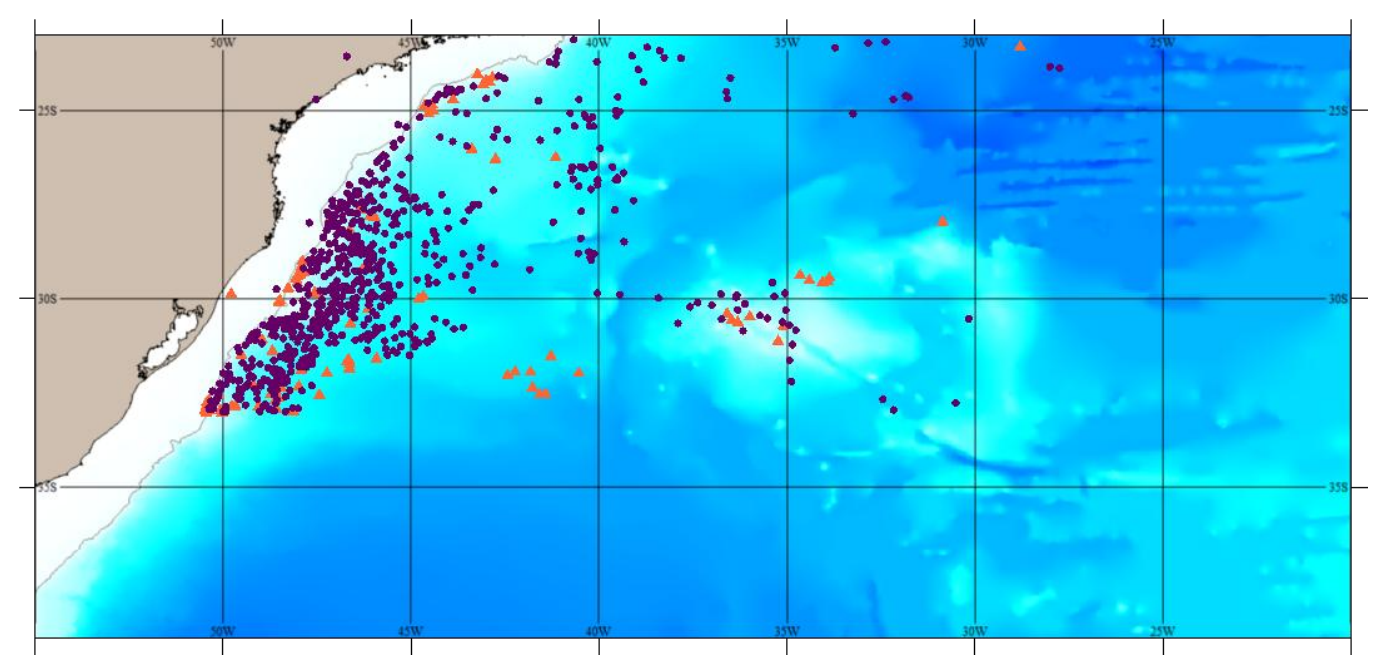

Figura 20. Distribuição dos lances realizados pelas embarcações com maior taxa de captura (triângulo laranja) e as demais embarcações (ponto roxo) durante o período de 2003 a 2010. 


\subsubsection{Características abióticas e operacionais das áreas de atuação das embarcações com maior taxa de captura de tartarugas}

As embarcações com maior taxa de captura atuaram em áreas com média de temperatura do ar e temperatura superficial do mar mais baixas que as demais embarcações $\left(1,13^{\circ} \mathrm{C}\right.$ e $1,25^{\circ} \mathrm{C}$ a menos respectivamente). Com relação a velocidade do vento, as embarcações com maior taxa atuaram em áreas com velocidade do vento praticamente duas vezes menor do que as embarcações com menor taxa (Figura 21). Com relação à profundidade (Pmédia) de atuação das embarcações, as com maior taxa de captura atuaram em locais com 221 metros de profundidade a menos aproximadamente (Tabela 3). 


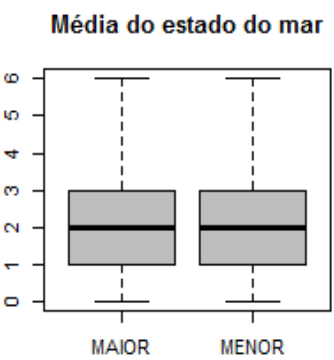

Média da TSM
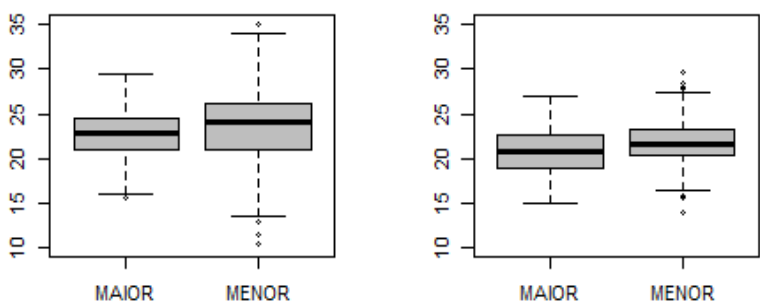

Média da velocidade do vento

Média da profundidade

Média da pressão atmosférica
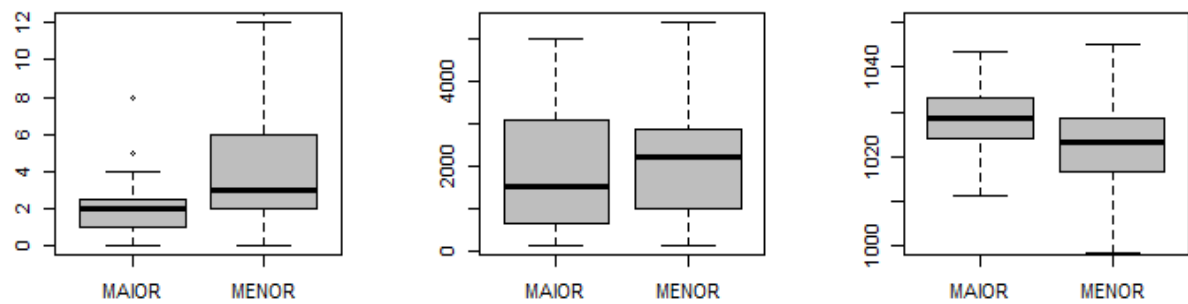

Figura 21. Padrão das variáveis abióticas e operacionais (profundidade de operação) das embarcações com maior taxa de captura (MAIOR) e demais embarcações (MENOR) durante o período estudado. Box plot com mediana, quartil inferior e superior e outliers.

Tabela 4. Descrição das variáveis abióticas e operacionais (profundidade de atuação) das embarcações na área estudada.

\begin{tabular}{cccccccccc}
\cline { 2 - 8 } & \multicolumn{3}{c|}{$\begin{array}{c}\text { Embarcações com maior taxa } \\
\text { de captura (n=8) }\end{array}$} & \multicolumn{4}{c}{ Demais embarcações (17) } \\
\cline { 2 - 9 } & Média & $\begin{array}{c}\text { Desvio } \\
\text { Padrão }\end{array}$ & Mínimo & Máximo & Média & $\begin{array}{c}\text { Desvio } \\
\text { Padrão }\end{array}$ & $\begin{array}{c}\text { Mínim } \\
\text { o }\end{array}$ & $\begin{array}{c}\text { Máxim } \\
\text { o }\end{array}$ \\
\hline \hline $\begin{array}{c}\text { Estado do } \\
\text { mar }\end{array}$ & 2,244 & 1,264 & 0,000 & 6,000 & 2,083 & 1,149 & 0,000 & 6,000 \\
$\begin{array}{c}\text { Temperatura } \\
\text { do ar }\end{array}$ & 22,75 & 2,755 & 15,500 & 29,500 & 23,894 & 4,212 & 10,500 & 35,000 \\
TSM & 20,75 & 2,666 & 15,050 & 27,000 & 22,008 & 2,289 & 13,900 & 29,700 \\
$\begin{array}{c}\text { Velocidade } \\
\text { do vento }\end{array}$ & 2,125 & 1,508 & 0,000 & 8,000 & 4,534 & 4,087 & 0,000 & 24,000 \\
$\begin{array}{c}\text { Profundidade } \\
\text { de operação }\end{array}$ & 1890 & 1367,4 & 159 & 5000 & 2111,77 & 1191,5 & 137,50 & 5400 \\
\hline
\end{tabular}


O teste não paramétrico Mann-Whitney demonstrou que existe diferença estatisticamente significativa entre os valores da média da temperatura do ar $(U=8)$ e média da velocidade do vento $(U=10.50)$ entre as embarcações que apresentaram maior taxa de captura e as demais embarcações.

A análise dos histogramas de frequência dos lances de pesca (Figura 22) demonstrou que em relação as variáveis operacionais o tipo de isca foi o que apresentou maior diferença entre as embarcações que foram classificadas com maior taxa de captura e as demais embarcações.

As embarcações que apresentaram maior taxa de captura utilizaram em $50 \%$ dos lances somente lula; e lula e peixe como isca e as demais embarcações utilizaram em $58 \%$ dos lances peixes. As embarcações com maior taxa de captura tiveram como espécie alvo em aproximadamente $70 \%$ dos lances Meca, atuns, tubarões, sendo a mesma espécie alvo predominante para as demais embarcações (90\%). Para as embarcações com maior taxa de captura na maioria dos lances realizados o tipo de anzol utilizado foi o Jota e Jota e Circular, assim como para as demais embarcações. 
Tipo de isca

a)

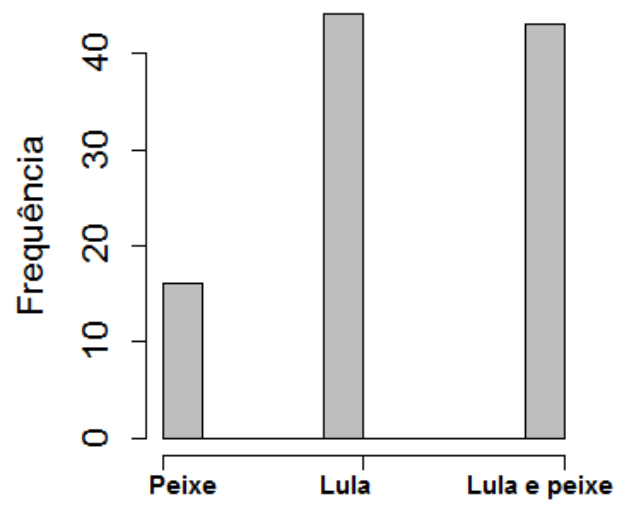

d)

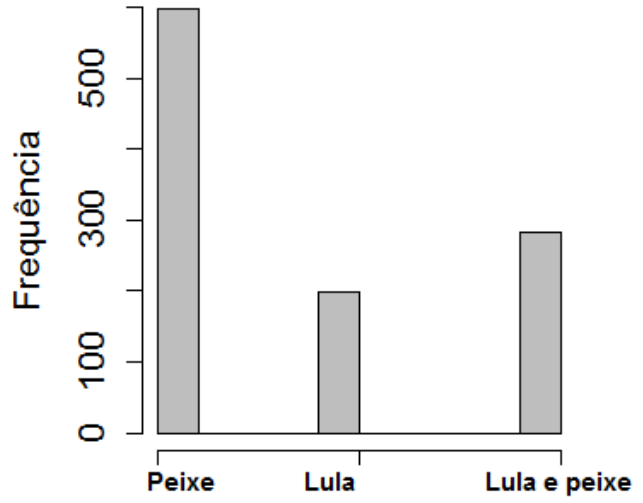

b)

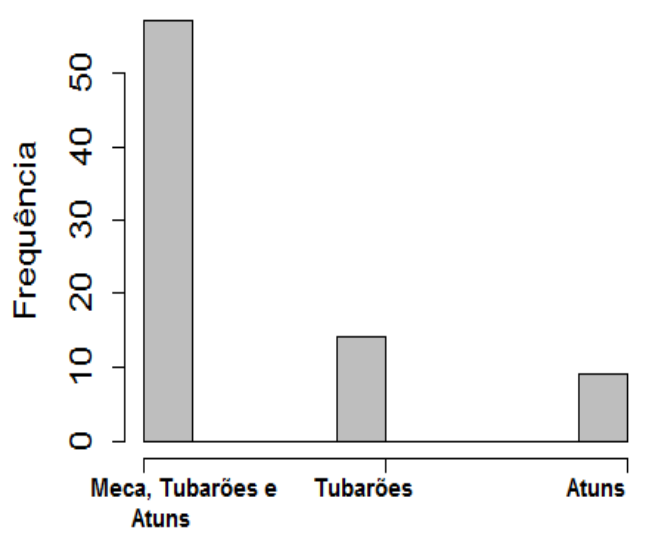

Espécie alvo

e)

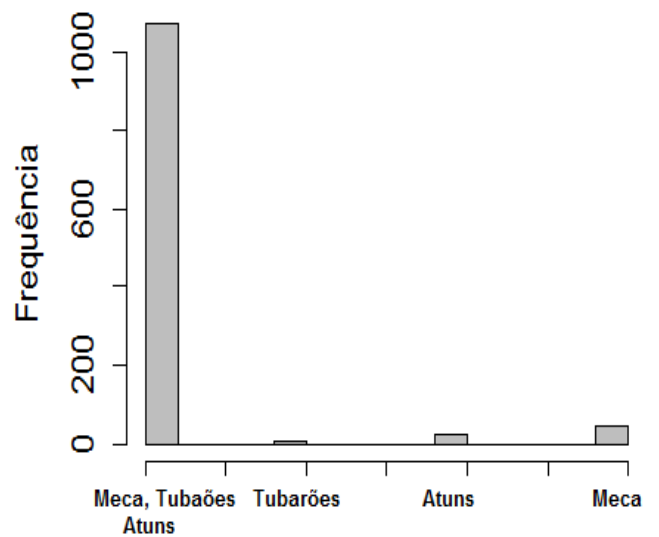

c)

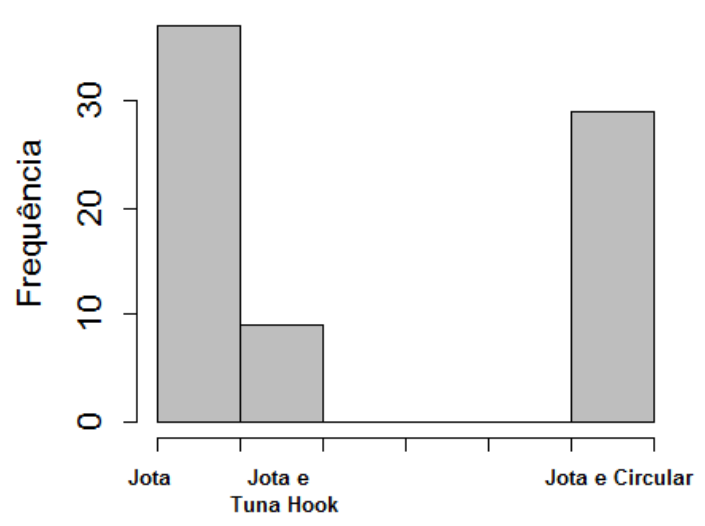

Tipo de anzol

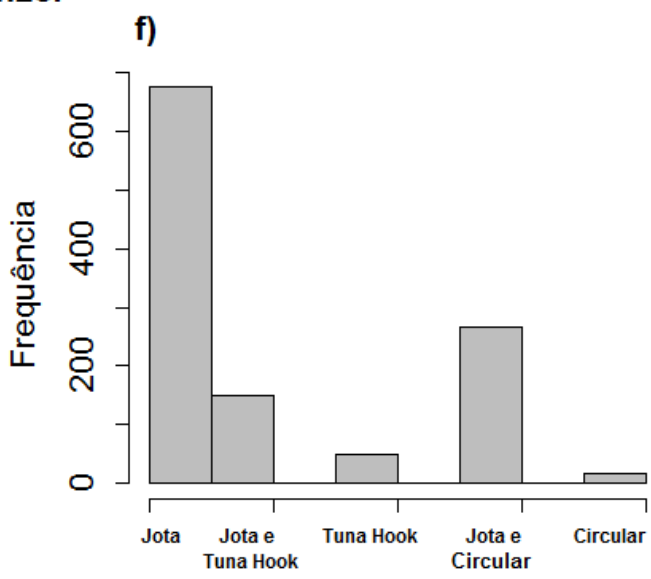

Figura 22. Histogramas de frequência dos número de lances com captura das embarcações que apresentaram maior taxa de captura $(a-c)$ e as demais embarcações $(d-f)$ para as variáveis operacionais: tipo de isca, espécie alvo e tipo de anzol. 


\subsubsection{Variação temporal do esforço pesqueiro das embarcações com maior taxa de captura de tartarugas}

A análise temporal dos lances realizados pelas embarcações que apresentaram maior taxa de captura demonstrou que houve diferença interanual em relação as demais embarcações.

As embarcações com maior taxa de captura realizaram aproximadamente $32 \%$ dos seus lançamentos durante o ano de 2007. Já as demais embarcações realizaram a maioria dos seus lances (34\%) durante o ano de 2005 (Figura 23).

Em relação a sazonalidade dos lançamentos realizados pelas embarcações foi observado que para ambas as categorias a maioria dos lançamentos foram realizadas durante o inverno, porem as embarcações com maior taxa de captura apresentaram maior porcentagem de lançamentos realizados durante o outono $(36,4 \%)$ se comparado com as demais embarcações (16,09\%) (Figura 23). 

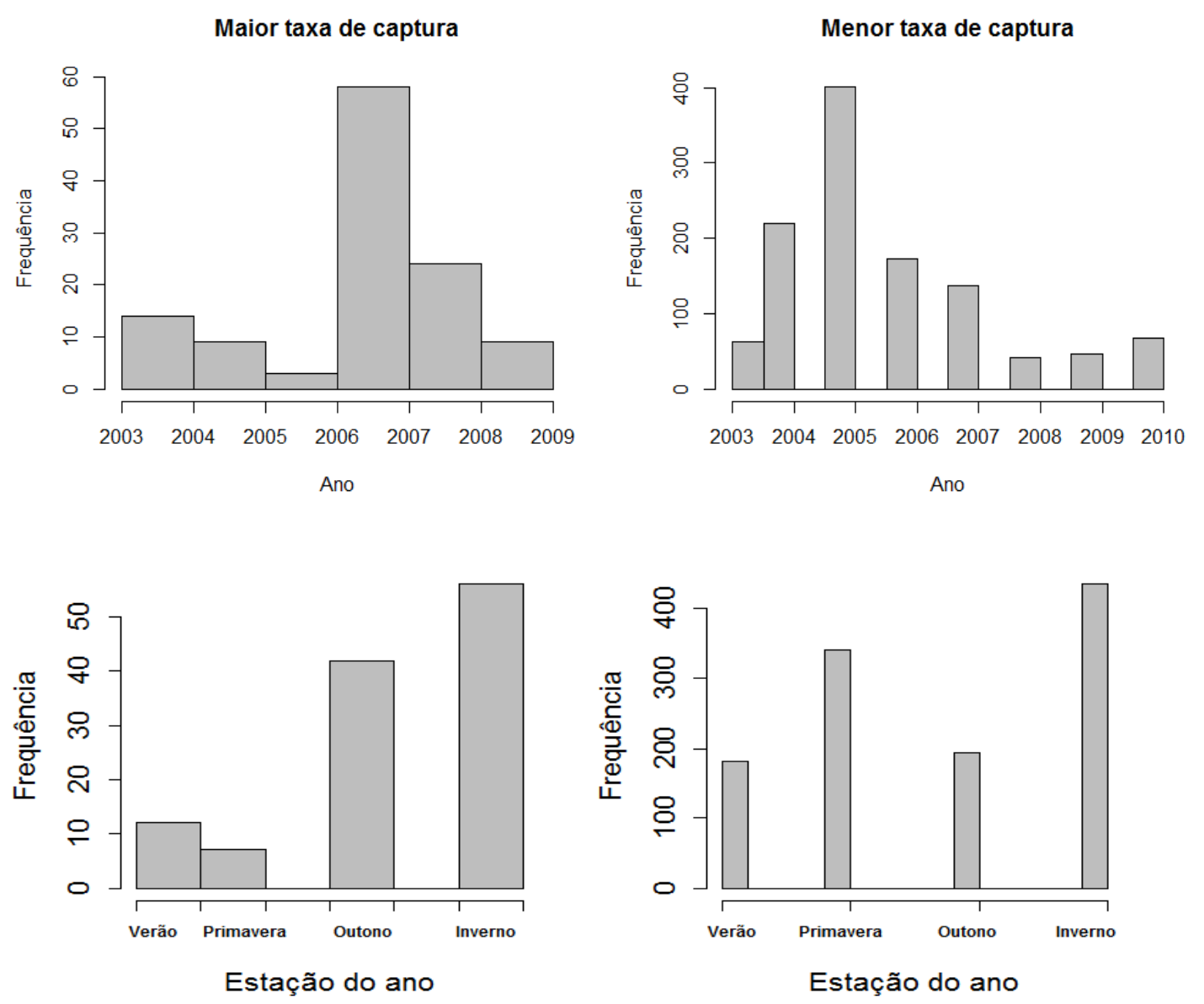

Figura 23. Histogramas de frequência das embarcações que apresentaram maior taxa de captura (Maior taxa de captura) e as demais embarcações (Menor taxa de captura) para ano e estação da realização do lance.

\subsection{Distribuição das frequências do comprimento curvilíneo da carapaça (CCC) das tartarugas capturadas}

Na região da Elevação do Rio Grande a espécie Caretta caretta foi capturada com CCC médio de 57,36 cm, na região sudeste a CCC médio de $77,16 \mathrm{~cm}$ e na região sul apresentou CCC médio de 59,13 cm. O tamanho máximo de CCC encontrado neste estudo para a região sudeste foi de $98 \mathrm{~cm}$, 
para a região sul $96 \mathrm{~cm}$ e para a região da elevação do Rio Grande foi de 73 cm (Figura 24).

Nas áreas oceânicas próximas à Elevação do Rio Grande as tartarugas da espécie $C$. caretta apresentaram tamanho menor do que os $73 \mathrm{~cm}$. Já as tartarugas capturadas próximas à plataforma continental sudeste e sul e área oceânica adjacente apresentaram maior variação do CCC (Figura 25).

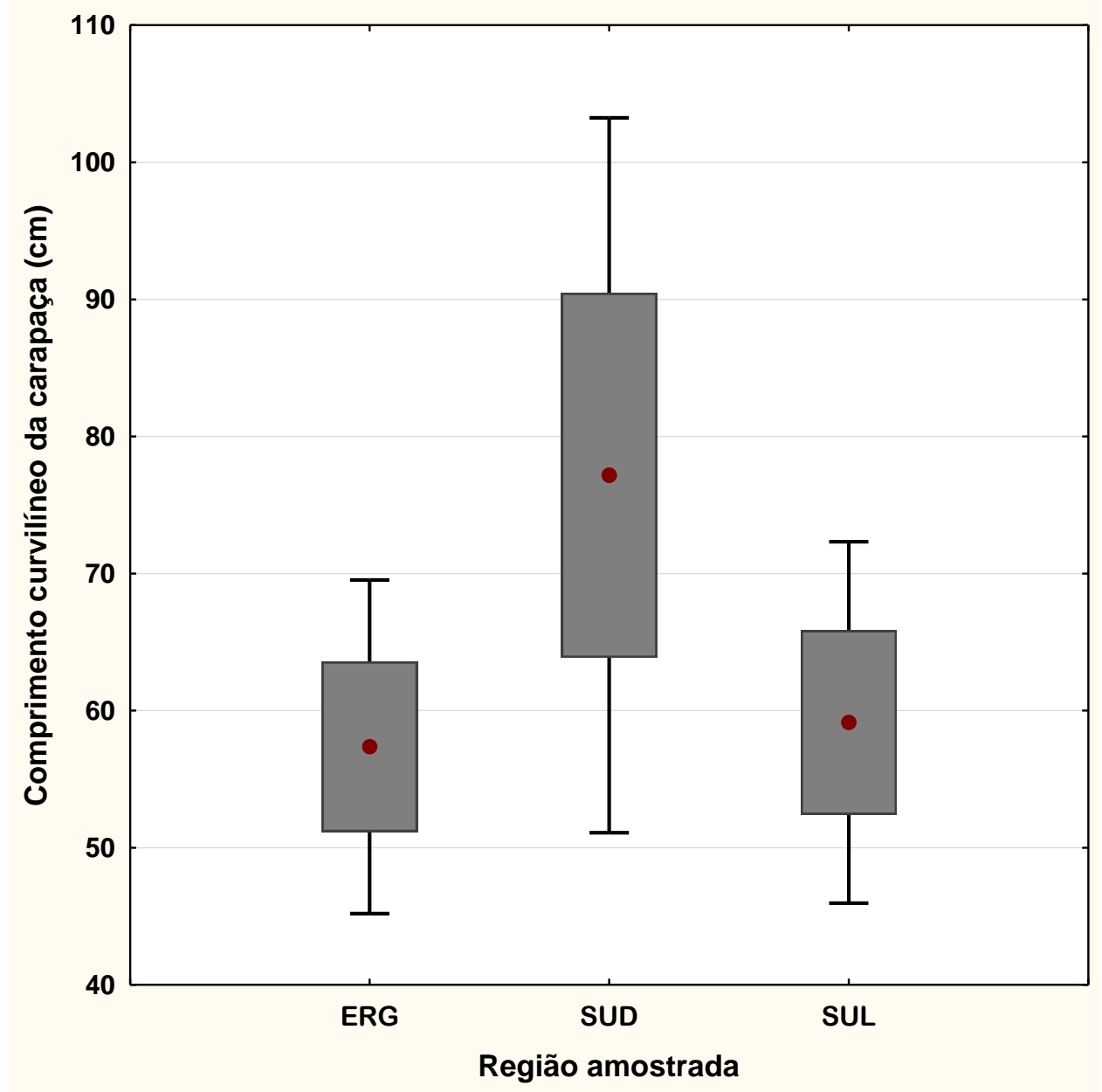

Figura 24. Distribuição do CCC para a espécie Caretta caretta nas três regiões Elevação do Rio Grande (ERG), sudeste (SUD) e sul (SUL) durante o período de 2003 a 2010. 

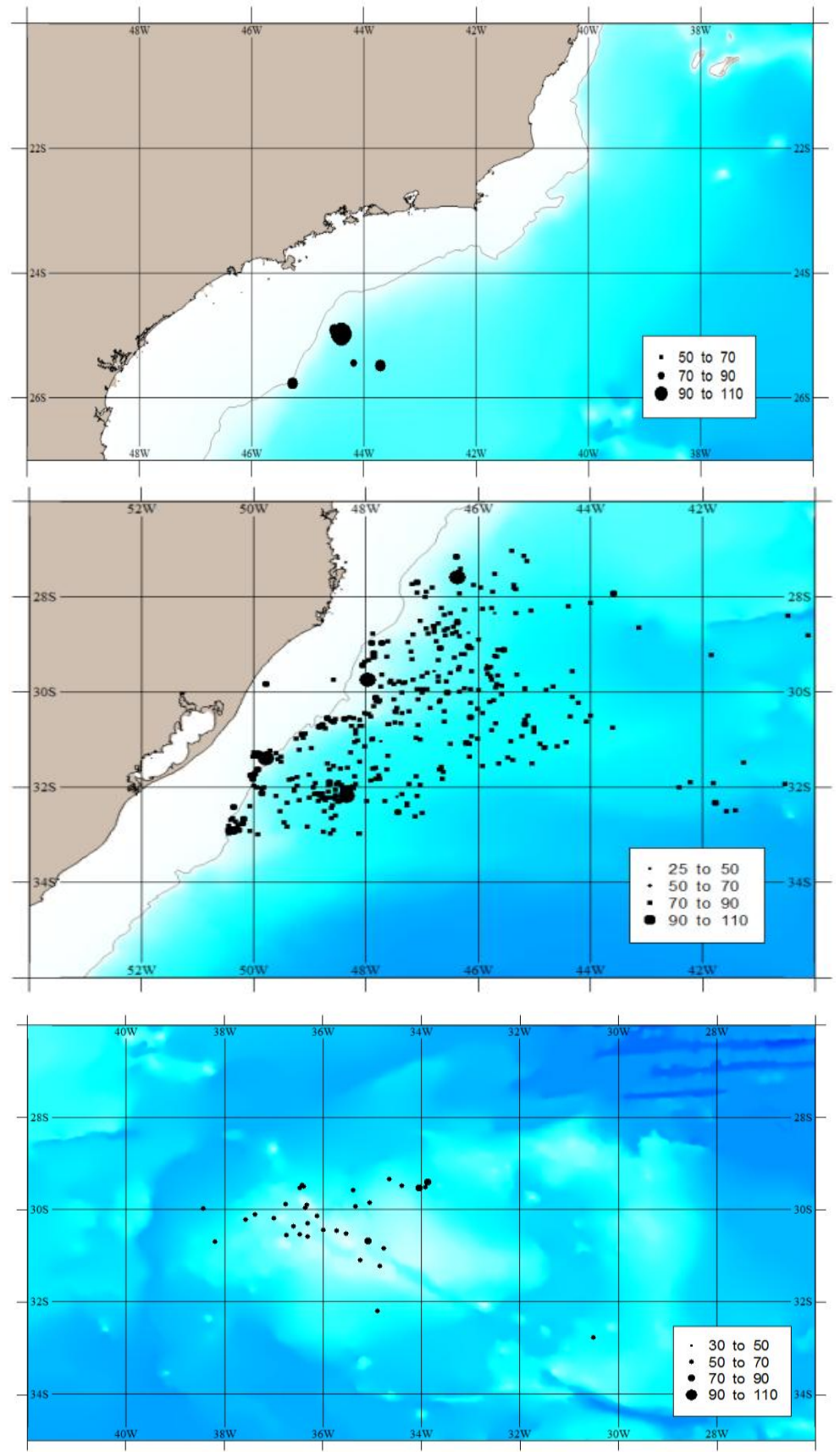

Figura 25. Distribuição do comprimento curvilíneo da carapaça (CCC) da espécie Caretta caretta durante o período de 2003 a 2010 nas regiões sudeste (superior), sul (meio) e Elevação do Rio Grande (inferior). 
A espécie Dermochelys coriacea foi capturada acidentalmente na região sudeste com CCC médio de 134,5 cm, mínimo de 127 cm e máximo de 142 cm. Já na região sul a média de CCC foi de 140,29, máximo de 157 cm e mínimo de $112 \mathrm{~cm}$ (Figura 26). Houve apenas dois registros com CCC desta espécie na região da Elevação do Rio Grande, 129 e 140 cm. A distribuição do CCC para esta espécie não apresentou diferença entre as três áreas (Figura 27)

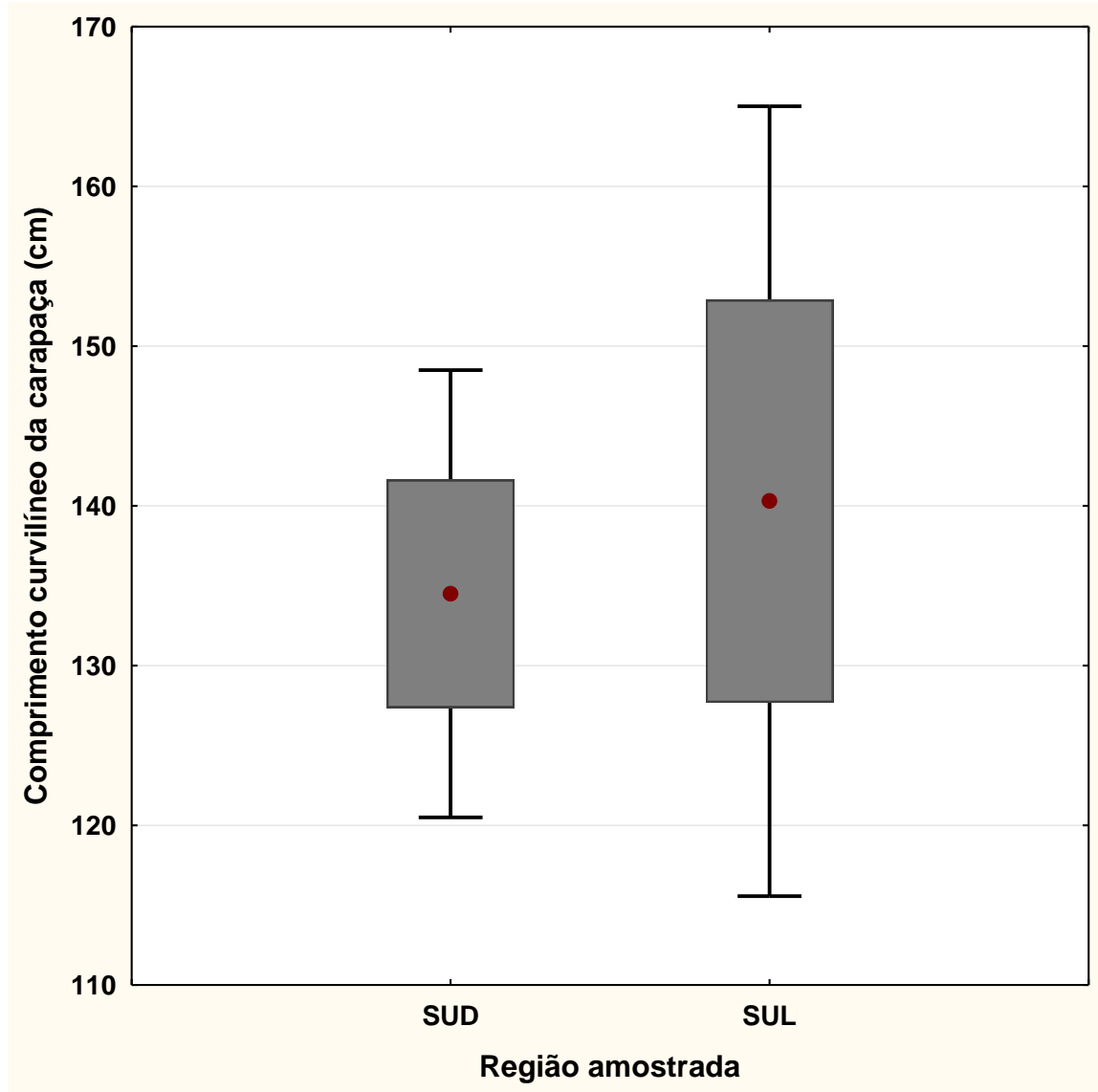

Figura 26. Distribuição do CCC para a espécie Dermochelys coriacea nas regiões sudeste (SUD) e sul (SUL) durante o período de 2003 a 2010. 

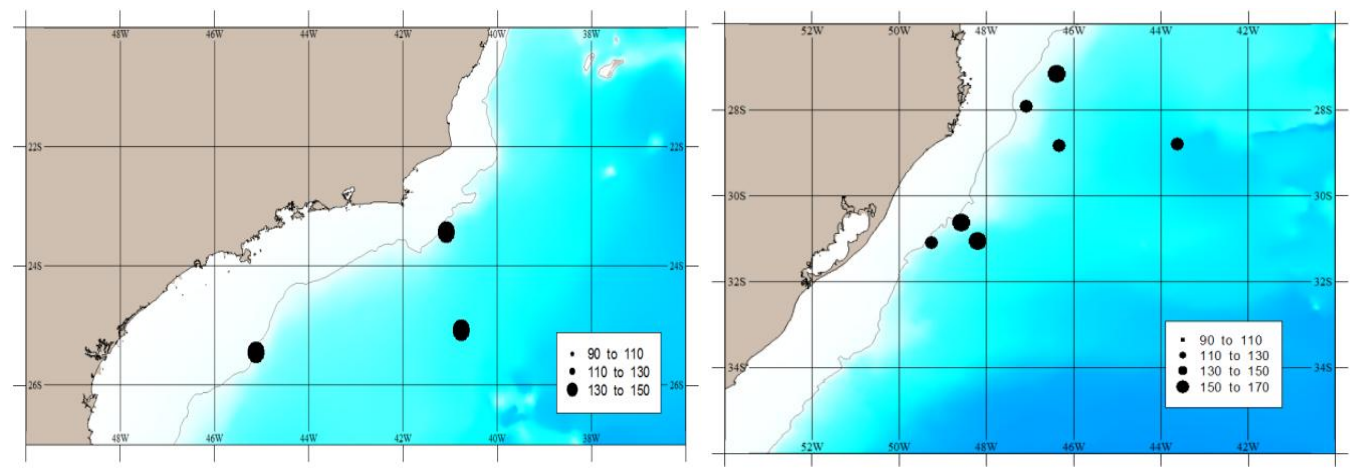

Figura 27. Distribuição do comprimento curvilíneo da carapaça (CCC) da espécie Dermochelys coriacea durante o período de 2003 a 2010 nas regiões sudeste (esquerda) e sul (direita).

\subsection{Efeito de variáveis ambientais e operacionais na variável resposta (CPUE) das tartarugas marinhas}

A PCA demonstrou que não existe colinearidade entre as variáveis utilizadas para a modelagem (Figura 28).

O teste de distribuição da variável resposta (CPUE) apresentou menor GAIC para a distribuição log - normal (Tabela 4). Sendo assim, os modelos foram rodados a partir desta família para as duas espécies de tartarugas marinhas. 
Projection of the variables on the factor-plane $\left(\begin{array}{ll}1 \times & 2\end{array}\right)$

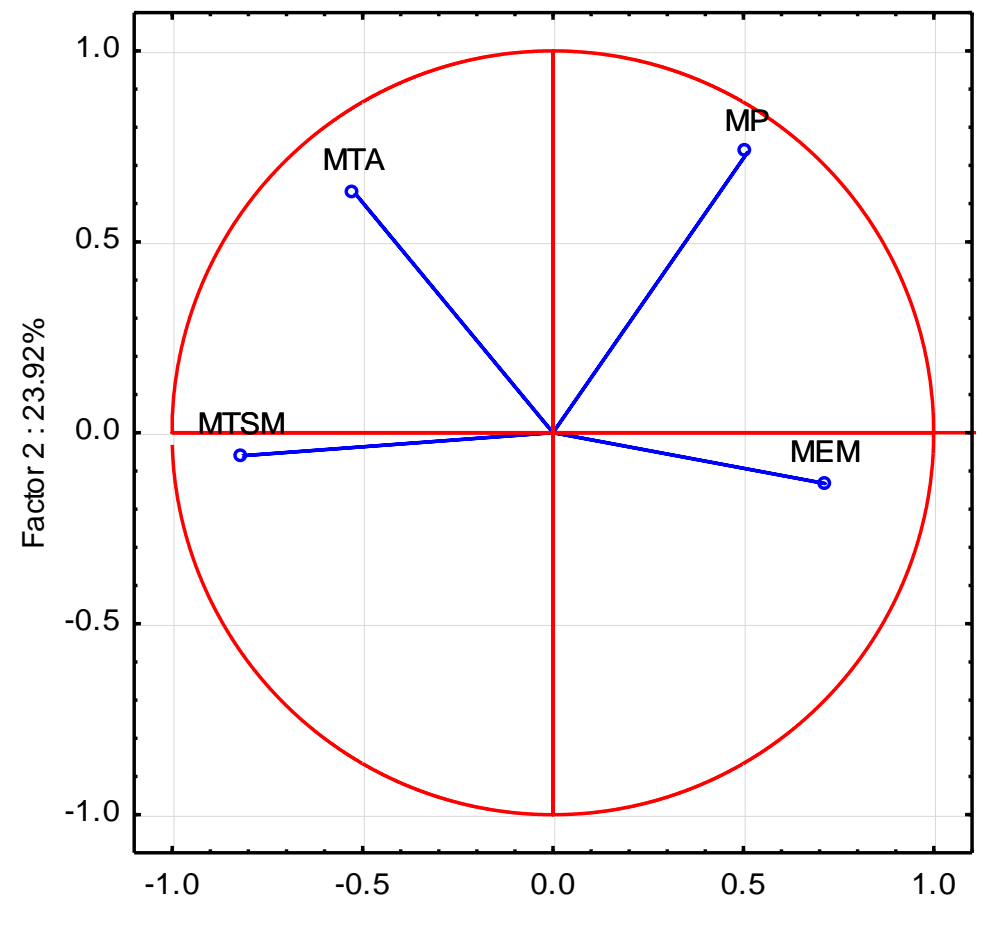

Factor $1: 42.85 \%$

- Active

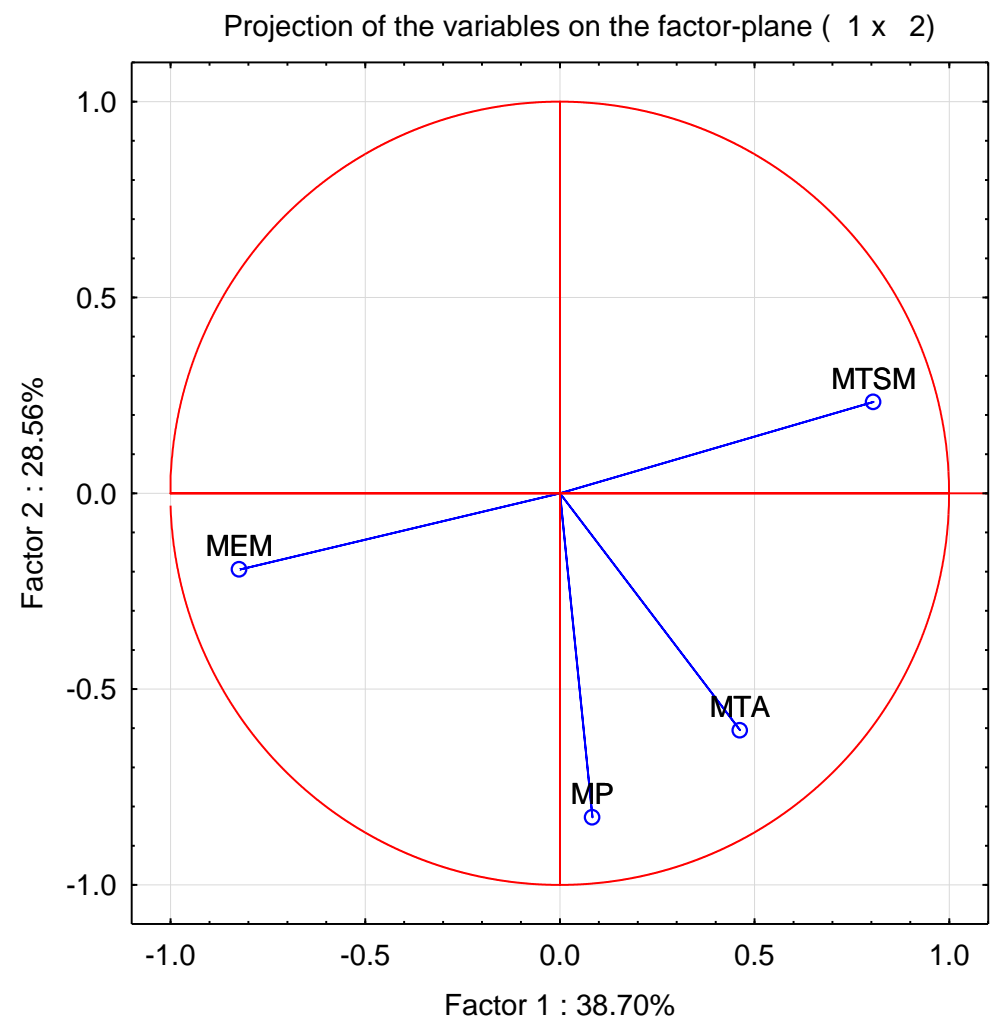

○ Active

Figura 28. Análise de componentes principais PCA para as variáveis ambientais do modelo proposto para a espécie C. caretta (Superior) e D coriacea (inferior). Sendo: MTSM= média da temperatura superficial do mar, $\mathrm{MTA}=$ média da temperatura do $\mathrm{ar}, \mathrm{MP}=$ media da profundidade e $\mathrm{MEM}=$ média do estado do mar 
Tabela 5. Valores do AIC para as distribuições testadas da variável resposta (CPUE) para a espécie Caretta caretta.

\begin{tabular}{lcc}
\hline Distribuição & Df & AIC \\
\hline Log normal & 2 & 138.8043 \\
Gamma & 2 & 147.3326 \\
Weibull1 & 2 & 153.9994 \\
Weibull3 & 2 & 153.9994 \\
Normal & 2 & 176.2578 \\
Fam Normal & 3 & 179.5943 \\
\hline
\end{tabular}

\section{Caretta caretta}

Foram realizadas combinações com as variáveis e foram gerados 200 modelos para esta espécie. Foi selecionado como melhor modelo o que apresentava menor valor de AIC (Tabela 6)

O modelo com longitude, ano, MTSM, MTA, tipo de isca e tipo de anzol foi o modelo que apresentou menor AIC.

As estimativas dos coeficientes dos parâmetros do modelo GAMLSS estão presentes na tabela 7 e a figura 29 apresenta 0 gráfico de resíduos quantílicos normalizados do modelo. 
Tabela 6. Comparação entre os valores de Akaike's Information Criterion (AIC) modelos gerados para explicar a distribuição log normal gerados para a espécie Caretta caretta.

\begin{tabular}{|c|c|c|c|c|c|c|c|c|c|}
\hline \multicolumn{9}{|c|}{ Modelos } & \multirow{2}{*}{$\begin{array}{c}\text { AIC } \\
489.127817\end{array}$} \\
\hline$\overline{L O N G}$ & ANO & MTA & MTSM & ESTACAO & $\mathrm{TI}$ & TA & & & \\
\hline LONG & ANO & MTA & MTSM & MP & ESTACAO & $\mathrm{TI}$ & TA & & 489.997762 \\
\hline LONG & ANO & MEM & MTA & MTSM & ESTACAO & $\mathrm{TI}$ & TA & & 490.501301 \\
\hline LONG & ANO & MTA & MTSM & ESTACAO & $\mathrm{TI}$ & & & & 490.658282 \\
\hline LAT & LONG & ANO & MTA & MTSM & ESTACAO & $\mathrm{TI}$ & TA & & 491.102123 \\
\hline LONG & ANO & MTSM & MP & ESTACAO & $\mathrm{TI}$ & TA & & & 491.162186 \\
\hline LONG & ANO & MTSM & ESTACAO & $\mathrm{TI}$ & TA & & & & 491.208764 \\
\hline LONG & ANO & MEM & MTA & MTSM & MP & ESTACAO & $\mathrm{TI}$ & TA & 491.752958 \\
\hline LAT & LONG & ANO & MTA & MTSM & MP & ESTACAO & $\mathrm{TI}$ & TA & 491.97737 \\
\hline LONG & MTA & MTSM & ESTACAO & $\mathrm{TI}$ & TA & & & & 492.085783 \\
\hline
\end{tabular}
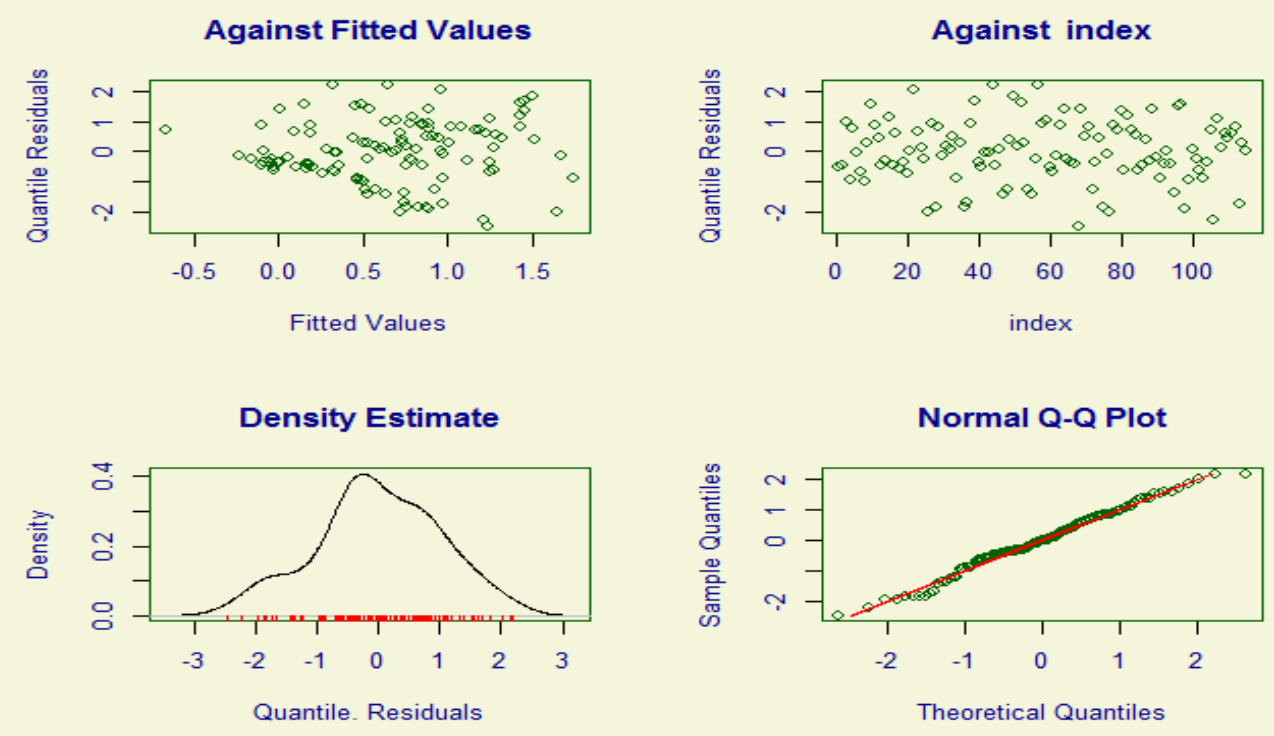

Figura 29. Diagnóstico do modelo com distribuição log normal (resíduos contra valores ajustados, resíduos contra variável explanatória; função densidade dos resíduos; qq-plot dos resíduos) para a espécie Caretta caretta. 
Tabela 7. Estimativa do coeficiente dos parâmetro, erro padrão, valor do teste t e valor de p para o modelo selecionado com distribuição log normal para a espécie Caretta caretta.

\begin{tabular}{lrrrc}
\hline \multicolumn{1}{c}{ Categoria } & Estimativa & Erro Padrão & Valor de $\mathbf{t}$ & $\operatorname{Pr}(>|\mathbf{z}|)$ \\
\hline (Intercept) & 567.95219 & 143.73287 & 3.95144 & $1.564 \mathrm{e}-04$ \\
CS $($ LONG, df $=4)$ & 0.06316 & 0.01360 & 4.64422 & $1.187 \mathrm{e}-05$ \\
CS $($ ANO, df $=5)$ & -0.27965 & 0.07139 & -3.91727 & $1.765 \mathrm{e}-04$ \\
CS $($ MTSM, df $=3)$ & -0.09184 & 0.03684 & -2.49326 & $1.453 \mathrm{e}-02$ \\
CS $($ MTA, $\mathrm{df}=3)$ & -0.03095 & 0.01595 & -1.94040 & $5.553 \mathrm{e}-02$ \\
TILULA E OUTROS & -0.42867 & 0.16748 & -2.55949 & $1.219 \mathrm{e}-02$ \\
TINI & -1.52873 & 0.43062 & -3.55005 & $6.209 \mathrm{e}-04$ \\
TIPEIXES & -1.33021 & 0.19363 & -6.86974 & $8.783 \mathrm{e}-10$ \\
TAJOTA & -0.30025 & 0.60344 & -0.49757 & $6.200 \mathrm{e}-01$ \\
TAJOTA E CIRCULAR $18 / 0$ & 0.03726 & 0.58829 & 0.06334 & $9.496 \mathrm{e}-01$ \\
TANI & 0.08762 & 0.60778 & 0.14417 & $8.857 \mathrm{e}-01$ \\
TATUNA HOOK & -0.10344 & 0.69813 & -0.14816 & $8.826 \mathrm{e}-01$ \\
\hline
\end{tabular}

O tipo de isca foi a variável operacional que apresentou maior significância dentro do modelo, seguido pela variável longitude.

O tipo de isca lula provou, segundo o modelo aumentar a CPUE para esta espécie (Figura 30). 


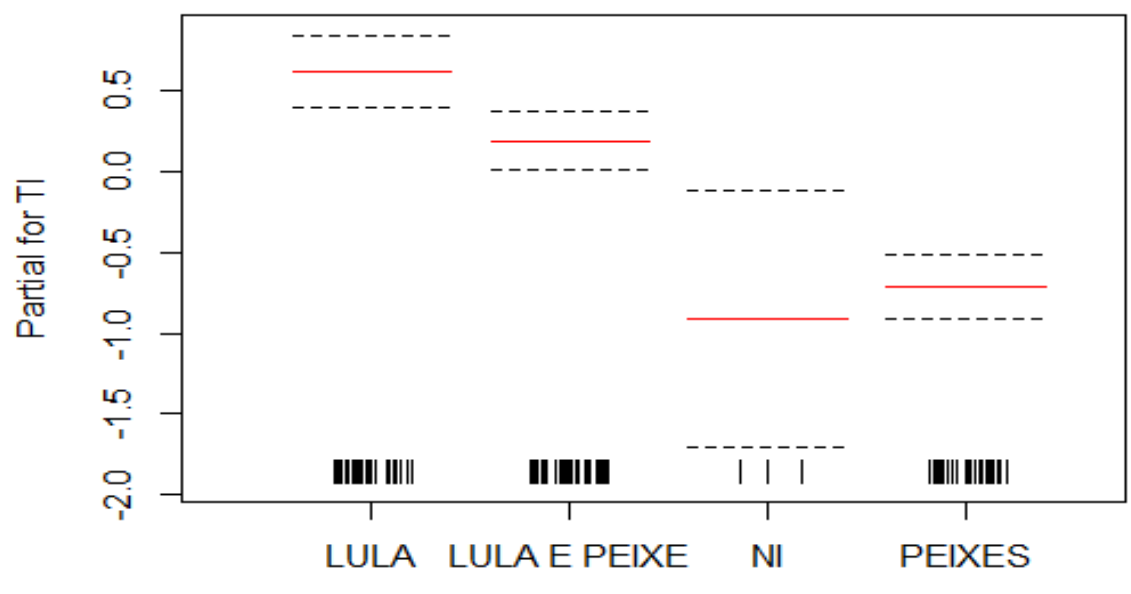

TI

Figura 30. Distribuição dos resíduos parciais para diferentes tipos de isca em relação a variável resposta CPUE para a espécie Caretta caretta.

O comportamento da CPUE em relação a variável longitude demonstrou que existe um aumento da mesma conforme a diminuição da longitude. Sendo assim o modelo demonstrou que a CPUE é maior em áreas oceânicas, para a tartaruga cabeçuda (Figura 31).

Com relação as variáveis ambientais a TSM foi a que apresentou maior significância dentro do modelo. A variável resposta CPUE apresentou diminuição conforme o aumento da TSM (Figura 32). 


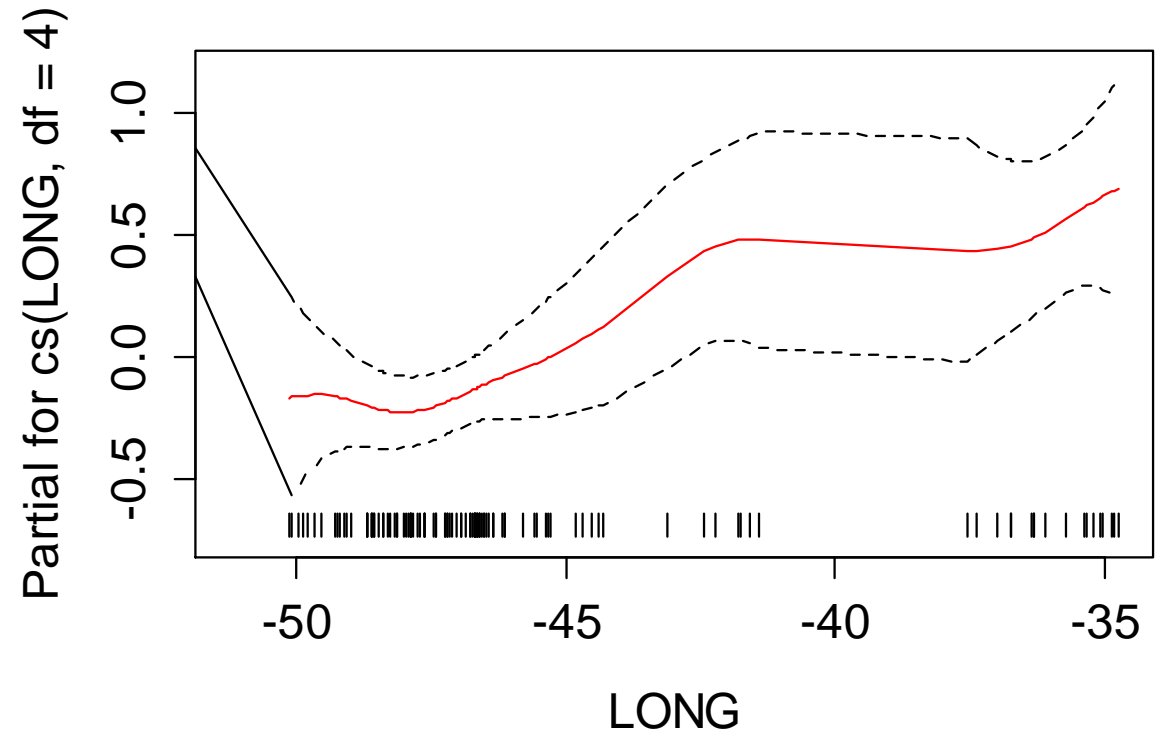

Figura 31. Relação entre a variável resposta CPUE e a variável longitude (LONG) para a espécie Caretta caretta.

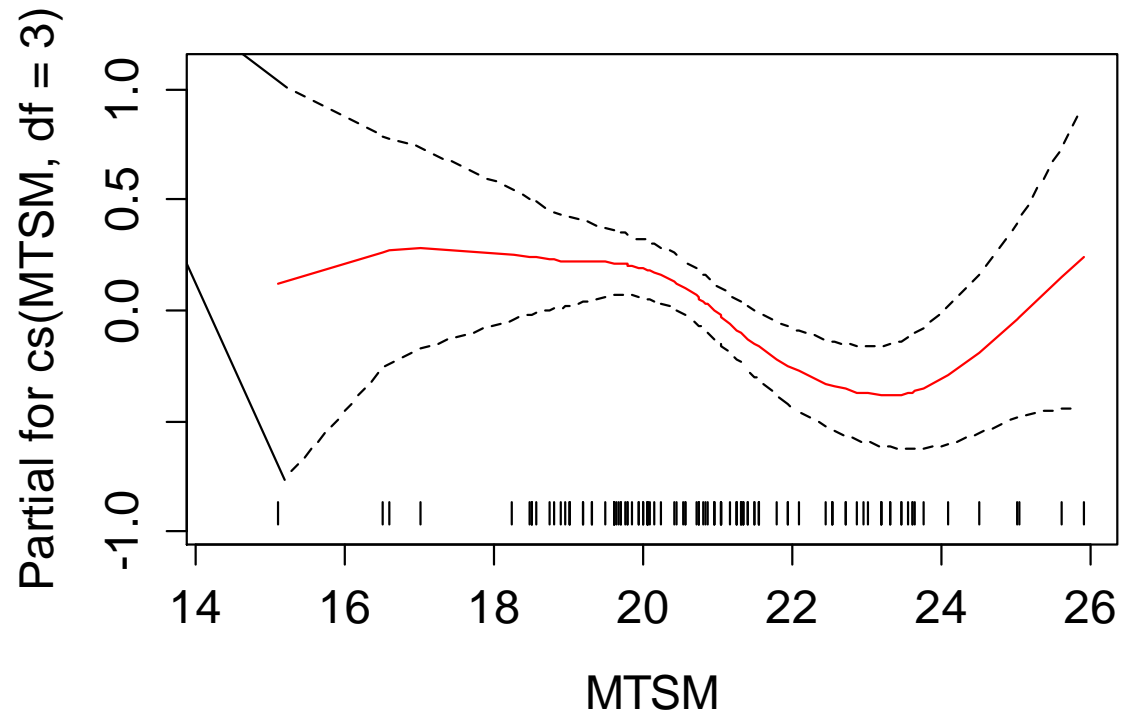

Figura 32. Relação entre a variável resposta CPUE e a variável média da temperatura superficial do mar (MTSM). 
A variável categórica ano apresentou significância dentro do modelo (Figura 33). Foi observada diferença no número de cruzeiros monitorados entre os anos, porem devido a redução de dados para a elaboração do modelo este resultado deve ser revisto.

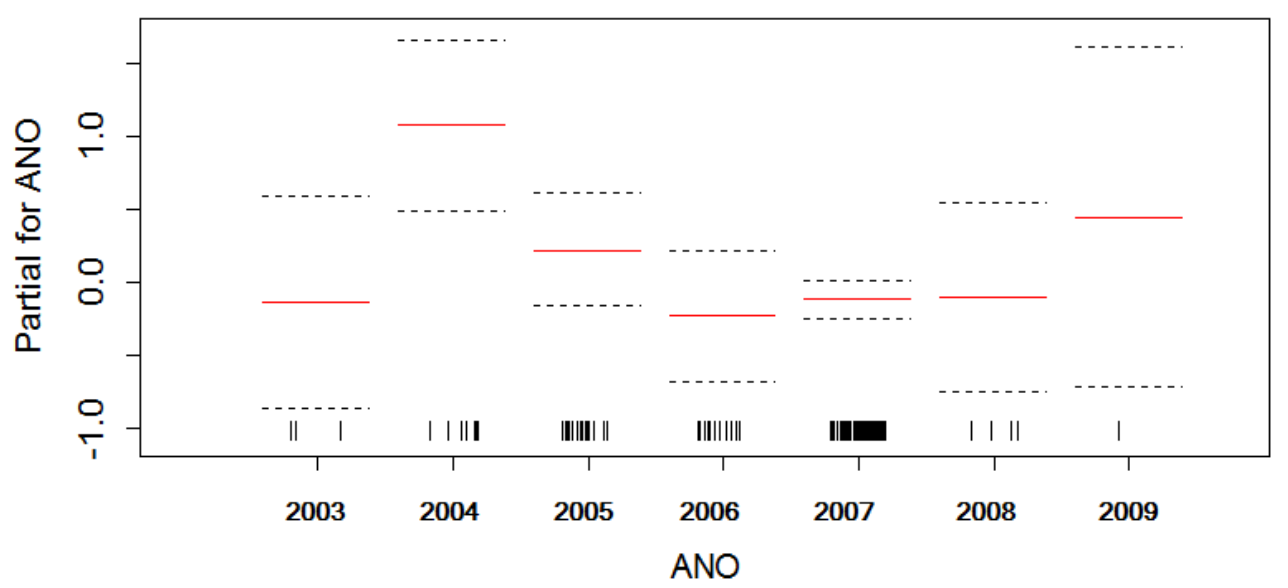

Figura 33. Relação entre a variável resposta CPUE e a variável ano para a espécie Caretta caretta. O ano de 2010 não está presente no plot, pois, devido a redução de dados para o modelo não houve registro deste ano nos dados do modelo.

\section{Dermochelys coriacea}

Para a tartaruga de couro também foram realizadas combinações com as variáveis e foram gerados 200 modelos. Foi selecionado como melhor modelo o que apresentava menor valor de AIC.

O modelo com latitude, profundidade e estação do ano foi o modelo que apresentou menor AIC. Os valores dos coeficientes do modelo gerado estão presentes na tabela 9 e a figura 34 apresenta o gráfico de resíduos quantílicos normalizados do modelo. 
Tabela 8. Comparação entre os valores de Akaike's Information Criterion (AIC) dos modelos gerados para a distribuição log normal gerados para a espécie Dermochelys coriacea.

\begin{tabular}{|c|c|c|c|c|c|}
\hline \multicolumn{5}{|c|}{ Modelos } & \multirow{2}{*}{$\begin{array}{c}\text { AIC } \\
158.3977\end{array}$} \\
\hline$\overline{M P}$ & $\overline{\text { LAT }}$ & ESTACAO & & & \\
\hline MTSM & MP & LAT & ESTACAO & & 159.9473 \\
\hline MP & LAT & LONG & ESTACAO & & 160.3183 \\
\hline MP & LAT & ANO & ESTACAO & & 160.3321 \\
\hline MEM & MP & LAT & ESTACAO & & 160.3434 \\
\hline MTA & MP & LAT & ESTACAO & & 160.3954 \\
\hline LAT & ESTACAO & & & & 160.6199 \\
\hline MTSM & MP & LAT & & & 161.4249 \\
\hline MTSM & LAT & ESTACAO & & & 161.6810 \\
\hline LAT & ANO & ESTACAO & & & 161.7919 \\
\hline MTSM & MP & LAT & LONG & ESTACAO & 161.9303 \\
\hline
\end{tabular}
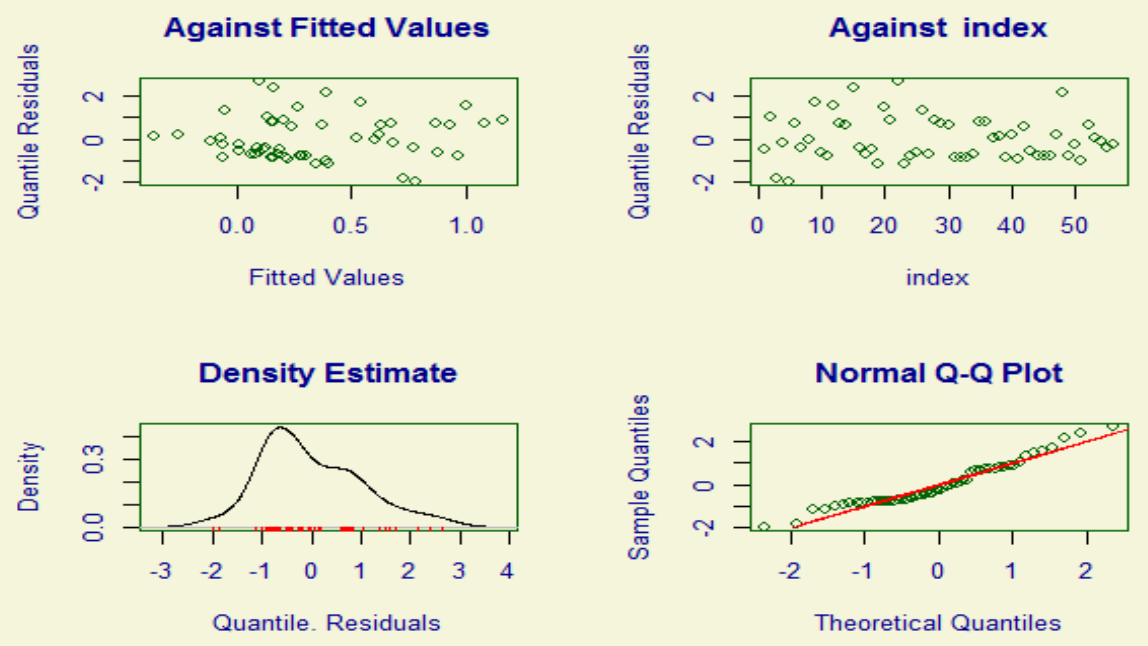

Figura 34. Diagnóstico do modelo com distribuição log - normal (resíduos contra valores ajustados, resíduos contra variável explanatória; função densidade dos resíduos; qq-plot dos resíduos) para a espécie Dermochelys coriacea. 
Tabela 9. Estimativa do parâmetro, erro padrão, valor do teste t e valor de $p$ para o modelo selecionado com distribuição log normal para a espécie Dermochelys coriacea.

\begin{tabular}{lrrrl}
\hline \multicolumn{1}{c}{ Categoria } & Estimativa & Erro Padrão & Valor de $\mathbf{~}$ & $\operatorname{Pr}(>|\mathbf{z}|)$ \\
\hline (Intercept) & 3.63970 & $6.994 \mathrm{e}-01$ & 5.204 & $5.482 \mathrm{e}-06$ \\
CS $(M P$, df $=4)$ & -0.00023 & $7.365 \mathrm{e}-05$ & -3.122 & $3.244 \mathrm{e}-03$ \\
CS(LAT, df = 4) & 0.09781 & $2.374 \mathrm{e}-02$ & 4.121 & $1.736 \mathrm{e}-04$ \\
ESTACAOoutono & -0.40138 & $1.639 \mathrm{e}-01$ & -2.449 & $1.857 \mathrm{e}-02$ \\
ESTACAOprimavera & -0.43819 & $1.874 \mathrm{e}-01$ & -2.338 & $2.422 \mathrm{e}-02$ \\
ESTACAOverao & -0.38085 & $2.171 \mathrm{e}-01$ & -1.754 & $8.667 \mathrm{e}-02$ \\
\hline
\end{tabular}

Apenas variáveis operacionais latitude e profundidade de operação das embarcações apresentaram significância dentro do modelo para esta espécie.

A variável resposta CPUE apresentou aumento conforme a diminuição da latitude (Figura 35). Isto demonstra que as maiores CPUEs para esta espécie ocorreram na região mais ao norte da área de estudo.

Com relação a variável MP a CPUE apresentou diminuição com o aumento desta variável (Figura 36). Sendo assim, este resultado corrobora com o comportamento da CPUE em relação a latitude, reafirmando que as maiores CPUEs para esta espécie ocorreram na plataforma continental e ao norte da área de estudo. 


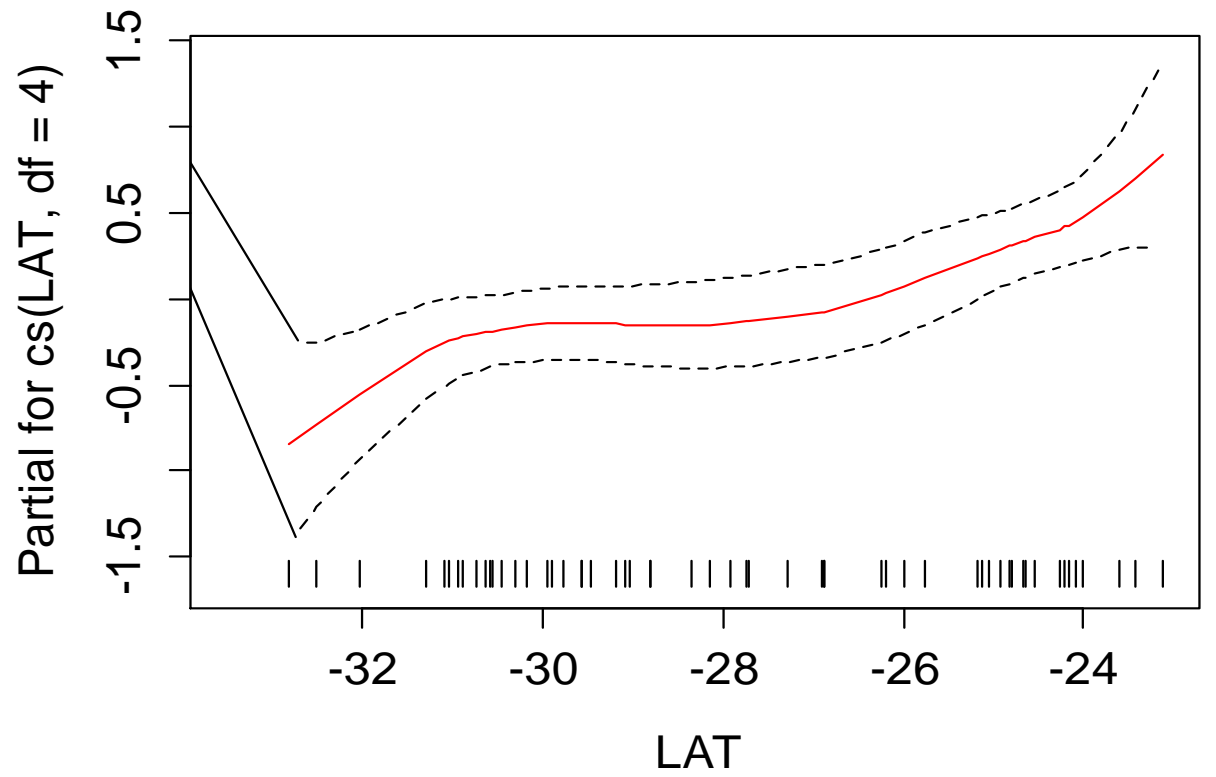

Figura 35. Relação entre a variável resposta CPUE e a variável latitude (LAT) para a espécie Dermochelys coriacea.

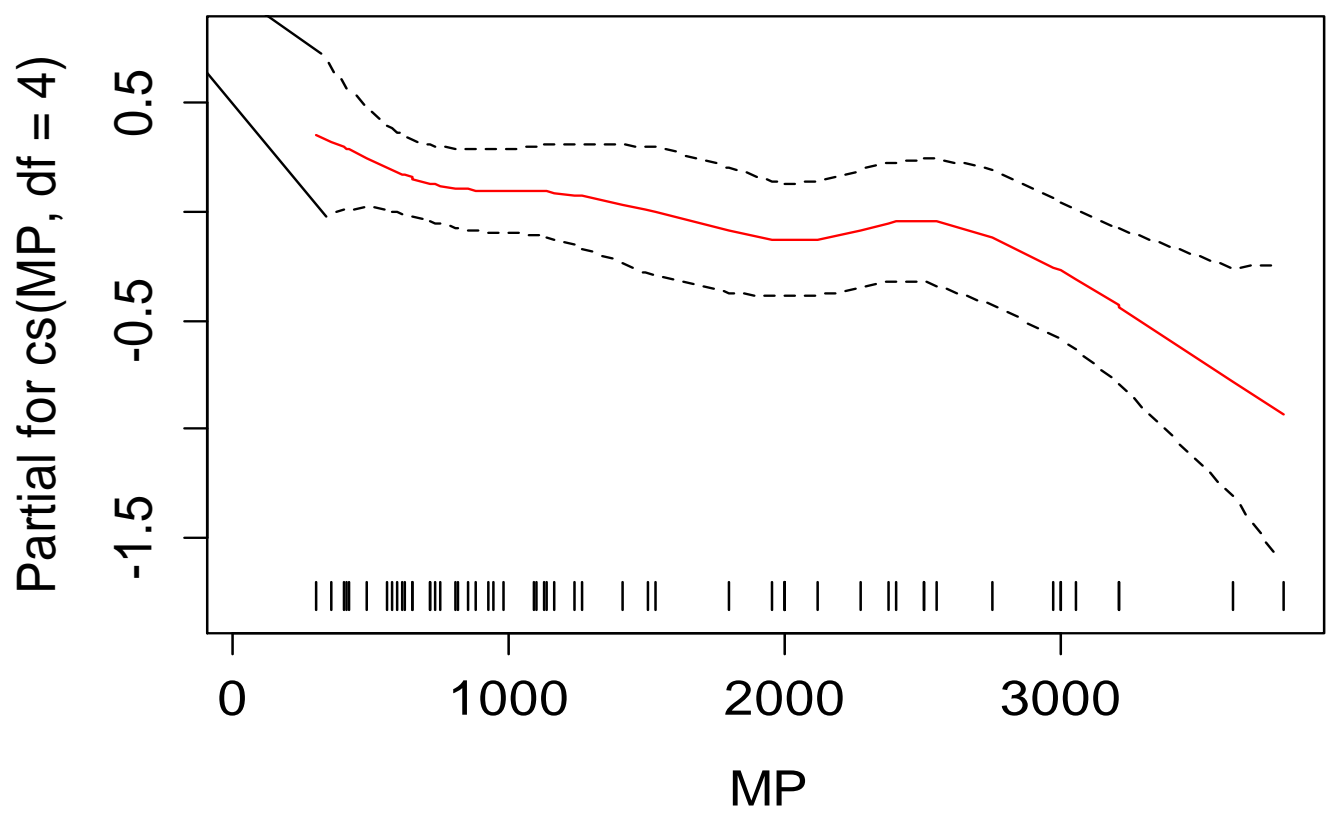

Figura 36. Relação entre a variável resposta CPUE e a variável média da profundidade (MP) para a espécie Dermochelys coriacea. 


\section{DISCUSSÃO}

O monitoramento das capturas acidentais, juntamente com o registro dos respectivos dados abióticos e operacionais da pesca, muitas vezes obtidos por observadores de bordo em frotas comerciais, deve ser considerado como uma rica fonte de informação, permitindo melhorar a compreensão do comportamento de populações de tartarugas marinhas, bem como apreciar a importância das variações ambientais sobre a dinâmica das populações. Apesar das eventuais limitações dos dados dependentes da pesca, foi esse 0 caso no presente estudo, os dados coletados forneceram diversas informações relevantes para uma melhor compreensão de certos padrões das populações de tartarugas marinhas na região Sudeste e Sul do Brasil, e principalmente, de sua interação com a pesca de espinhel, modelo americano. Embora existam vários estudos que analisam e avaliam as interações do espinhel pelágico com tartarugas marinhas em diferentes regiões do mundo (p.ex. NISEMURA \& NAKAHIGASHI, 1990; BOLTEN et al., 1996; LUTCAVAGE et al..1997; ROBINS et al., 2002; LEWISON et al., 2004), de fato, pouco ainda é referido a este tema no Oceano Atlântico Sul Ocidental (ACHAVAL et al., 2000; DOMINGO et al., 2003; SOTO et al., 2003; DOMINGO et al., 2004; KOTAS et al., 2004; LEWISSIN et al., 2004; PINEDO \& POLACHECK 2004; DOMINGO et al. 2005; COLUCHI,2006), sendo que o presente estudo representa uma contribuição mais recente, no que diz respeito à região Sudeste/Sul do Brasil. 
Deve-se considerar que a distribuição dos animais pelágicos está diretamente relacionada às propriedades físicas dos oceanos, tais como temperatura das massas d'agua e suas movimentações (BACKUS, 1986). Devido a este fato, a distribuição espacial de cada frota, ao longo do ano, pode estar intimamente ligada ao deslocamento da espécie-alvo da pesca (COLUCHI, 2006).

No presente estudo foi possível identificar, nitidamente, diferenças nos padrões de distribuição da frota analisada, tanto entre os anos, quanto sazonalmente. Durante alguns anos, foi verificado maior afastamento da plataforma continental do que em outros, e, em relação às estações do ano, foi possível verificar que durante o outono e inverno, os lances de pesca se concentraram próximo à plataforma continental. Isto pode estar associado à própria dinâmica das correntes oceânicas, que levaram a um deslocamento da espécie-alvo (COLUCHI, 2006), ou também a outros fatores operacionais intrínsecos da frota pesqueira.

No "Grande Ecossistema Marinho do Sul do Brasil" (sensu Heileman \& Gasalla, 2008), a tartaruga cabeçuda foi capturada com mais freqüência, e em maior número, do que a tartaruga de couro. Este padrão também foi observado entre a frota uruguaia que atua na região sul do Atlântico Ocidental (ACHAVAL et al., 2000, DOMINGO et al., 2003; DOMINGO et al., 2006). No Atlântico Sul, Barata et al. (1998) e Kotas et al. (2004) indicam a predôminancia da espécie C. caretta pelas frotas da região Sudeste e Sul do Brasil, com elevadas CPUE (4,31 tartarugas por 1000 anzóis) (COLUCHI, 2006). De fato, a tartaruga cabeçuda parece ser a espécie mais capturada pela frota espinheleira de todo o mundo (LEWISON et al., 2004). Cabe destacar que no Oceano Atlântico 
Norte, é também a espécie mais abundante (CARR, 1952; ERNEST \& BARBOUR, 1972; REBEL, 1974).

No Brasil, o espinhel pelágico para atuns, espadartes, e tubarões, capturam acidentalmente tartarugas marinhas da espécie $C$. caretta em regiões oceânicas, com destaque para a região Sudeste/Sul, e adjacente a águas internacionais (Sales et al., 2008). Para essa espécie, os resultados do modelo estatístico aplicado no presente estudo (GAMLSS) mostrou que a sua captura aumentou com o aumento da longitude, ou seja, foram as áreas mais oceânicas as que se destacaram com maior número de capturas, especialmente, próximo à Elevação do Rio Grande. Esta região, é referida por suas altas taxas de captura acidental de tartarugas marinhas, especialmente de cabeçudas e em desenvolvimento (SALES et al., 2008; MONTEIRO, 2008; GIFFONI et al., 2008), e parece ser importante habitat oceânico também para o desenvolvimento de tartarugas marinhas imaturas no Atlântico Sul (MARCOVALDI et al., 2006; BARCELÓ et al., 2013). O resultado encontrado neste estudo, a partir da distribuição do CCC das amostras de tartarugas cabeçudas, sugere que animais mais jovens e, consequentemente mais vulneráveis, sejam encontrados nessas áreas específicas (com altas taxas de captura), reforçando ainda mais a necessidade do estabelecimento ou delimitação de áreas espaciais prioritárias para a conservação dessa espécie.

Por outro lado, as capturas de $D$. coriacea se concentraram na região próxima à quebra da plataforma continental, com o aumento da CPUE, particularmente mais ao norte da área de estudo (Figura 6). Há de se considerar que, a variabilidade nas taxas de crescimento da população tem sido atribuída a uma série de fatores, incluindo a medida em que a população 
nidificante tem sido explorada, à distância entre alimentação e a mortalidade causada pela pesca (BRODERICK et al., 2006).

Nesse sentido, sabe-se que a maior população de nidificantes de tartarugas de couro é encontrada no Gabão, no continente africano (WITT et al., 2010). Estudos de telemetria mostraram que a tartaruga de couro do Gabão atravessa o oceano Atlântico em direção ao seu lado oeste (WITT et al., 2010), e algumas dessas tartarugas já foram capturadas por espinheleiros brasileiros (BILLES et al., 2005). Witt et al. (2010) sugerem que, pelo menos, 11 países devem participar na conservação da tartaruga de couro no Oceano Atlântico., Luschi et al. (2006) ressaltam que a proteção usada em zonas de nidificação não é suficiente para manter as populações em tamanhos saudáveis, A regulação da interação entre populações de tartarugas e a pesca, e a aplicação de regras de manejo em grandes áreas oceânicas, seria da maior importância, e esforços em tornar a gestão da pesca baseada no contexto de uma abordagem ecossistêmica iriam de fato, colaborar para levar isso a cabo.

Pode-se considerar que a identificação das áreas marinhas mais freqüentadas por tartarugas pode constituir o primeiro passo, fundamental para esse desenvolvimento de programas de gestão da pesca e conservação mais eficazes. Nesse sentido, o manejo da pesca baseado no ecossistema ("ecosystem-based fishery management "ou "EBFM") parece ser uma direção necessária também para a gestão das pescarias pelágicas.

Wallace et al. (2011), com base em áreas de alta prioridade de conservação de tartarugas, definiram Unidades de Gestão Regionais (RMU). Levando isso em conta, seria importante que as organizações regionais de 
gestão das pescas ("regional management organizations" ou RMFOs) considerassem essas RMU propostas. No entanto, o presente estudo demonstra que subáreas pertinentes dentro dos RMUs propostos por Wallace et al (2011), como é o caso desta área de estudo, possam ser mais apropriadas para a implementação prática do EBFM, especialmente para as pescarias pelágicas. De fato, esta área de estudo corresponde a definição de um Grande Ecossistema Marinho ( "Large Marine Ecosystem" ou LME), o que deveria ser considerado como a delimitação de uma área de manejo.

Com relação às variações temporais encontradas no presente estudo, algumas considerações devem ser feitas. Em termos da variação interanual, os picos de CPUE encontrados para a tartaruga cabeçuda e a de couro podem estar relacionados com a maior operação das embarcaçoes nas áreas de alta taxa de captura, nos anos em que ocorreram os picos. O modelo estatístico gerado para a tartaruga cabeçuda demostrou também haver influência da variável "ano" nos valores da variável resposta (CPUE). Para o presente estudo, pode ser considerado que a variação interanual encontrada seja explicada pela dinâmica da frota, concentração nas áreas com altas CPUEs. Foi observado, para ambas as espécies que, nos anos em que ocorreram os picos de CPUE, tambem houve migração da frota para as áreas de alto valor de CPUE, sendo mais altos os valores para a tartaruga cabeçuda na Região da Elevação do Rio Grande e para a tartaruga de couro, na plataforma Sudeste.

Com relação à variação sazonal encontrada, parece intrigante o fato dos picos de CPUE, para ambas espécies de tartaruga marinha, ocorrerem no outono. É possível que nessa estação ocorra algum fenômeno oceanográfico 
que favoreça a maior abundância relativa de tartarugas. No entanto, foi verificado que durante o outono existe uma aproximação da frota e das capturas acidentais junto à costa e que o número de anzóis utilizados foi inferior ao do verão e primavera. Desse modo, o pico de CPUE encontrado duranto o outono, pode estar relacionado à migração das mesmas para essa região mais costeira, possivelmente para alimentação, onde, consequentemente, uma maior vulnerabilidade ao espinhel possa ocorrer durante essa estação.

\subsection{Influência das variáveis abióticas e operacionais na captura acidental des tartarugas marinhas}

Conforme foi possível também constatar, a captura de $C$. caretta foi significativamente maior quando lulas foram usadas como isca em operações de pesca. Cabe destacar que observações feitas anteriormente por Watson et al. (2005), havendo encontrado reduções na captura de C. caretta usando, inclusive, a cavalinha (Scomber scombrus), parecem corroborar com esse resultado aqui obtido. A alimentação oportunista da tartaruga cabeçuda em sua fase juvenil oceânica torna a espécie muito suscetível à captura incidental em espinhel pelágico. A lula parece ser um item alimentar importante, embora oportunisticamente, considerando o grande volume e os altos valores energéticos relativos (BARROS et al., 2010).

Com relação à espécie $D$. coriacea, o tipo de isca não correlacionou com as capturas, o que também parece estar em consonância com o descrito em Miller (2008), de que a espécie é mais frequentemente capturada por 
emaranhamento na linha do espinhel, com o anzol encontrado externamente ao corpo.

O fato de a maior parte dos indivíduos da espécie $C$. caretta haver sido fisgado pela boca, é congruente com o fato da espécie se alimentar de peixes. Este resultado corrobora também os achados de Witzell (1984), Polovina et al. (2003), e Coluchi (2006). O fato do anzol ser encontrado na boca da tartaruga, e não internamente com a possibilidade de ferir um orgão, é o principal fator que permite que $88 \%$ dos animais possam ser resgatados e liberados com vida (COLUCHI, 2006). Contudo, animais com ferimentos mais internos, causados pelo anzol, podem vir a óbito pouco tempo após a soltura. Segundo Bjorndal et al. (2000), a tartaruga cabeçuda é mais vulnerável ao espinhel durante os seus primeiros oito anos de vida, duração média da sua permanência no estágio pelágico. Nessa fase, as tartarugas cabeçudas habitam zonas oceânicas e se alimentam nos primeiros cinco metros da coluda d' água (GOLDBERG et al., 2001; BOLTEN, 2003). Gilman et al, (2006) apontam que o desenvolvimento de técnicas adequadas para a retirada do anzol diminuem o risco de injúrias e de mortalidade das tartarugas após serem liberadas ao mar. Sendo assim, o monitoramento da atividade espinheleira é fundamental para a conservação desta espécie, com o intuito de se estabelecerem medidas para reduzir as capturas acidentais nestas áreas. É importante acrescentar que só o monitoramento não irá resolver o problema, as medidas propostas devem ser implementadas.

Já o fato da espécie $D$. coriacea haver sido, em sua maioria, encontrada com o anzol externamente ao corpo, pode estar relacionado com sua alimentação, já que a espécie se alimenta de plâncton gelatinoso e 
invertebrados pelágicos (BLEAKNEY, 1965). Colucchi (2006) também observou esse padrão, o que reforça que essa espécie seja possivelmente atraída pelos atratores luminosos do espinhel modelo americano, e termina se emaranhando na linha. Wang et al. (2005) descrevem que a utilização de atratores luminosos que piscam intermitentemente diminuem a atração da tartaruga de couro, sendo está uma alternativa para a redução da captura acidental desta espécie pelo espinhel.

Com relação às variáveis ambientais, os resultados do presente estudo mostraram uma tendência da tartaruga cabeçuda em relação à variação da TSM. A correlação negativa encontrada, indica que espécie poderia se agregar mais, ou ter alguma preferência, por temperaturas mais frias. De fato, outros autores como Coluchi (2006), registraram maior quantidade de C. caretta em maiores latitudes (entre $15^{\circ}$ a $20^{\circ} \mathrm{S}$ ), o que contribuiria também para sustentar sobre uma maior ocorrência da espécie em águas mais frias e profundas (OLSON et al. ,1994; BAKUN, 1996). Nesse sentido, a correlação negativa encontrada, também pode indicar que uma exposição da espécie a um aquecimento do oceano, poderia desempenhar um efeito negativo na sua abundância relativa, ao menos, na área de estudo. Se mudanças climáticas estão ainda previstas para ocorrer em taxas sem precedentes, a resistência com que as populações de tartarugas marinhas podem ser capazes de lidar com o aquecimento dos oceanos pode ainda permanecer incerta. Mas pode se especular que se essas tartarugas fracassarem em se adaptar a esses efeitos, através da combinação de mecanismos fisiológicos e comportamentais, estas populações poderiam de fato enfrentar uma drástica diminuição. Evidentemente, $\mathrm{o}$ fato das tartarugas migrarem e se alimentarem sobre 
grandes escalas espaciais, pode também conferir alguma flexibilidade e capacidade de adaptação aos efeitos negativos das alterações climáticas (WILLIAMS et al., 2008). Pode se considerar que as tartarugas marinhas ocuparam diferentes tipos de habitats ao longo de sua história de vida, incluindo praias temperadas e tropicais de areia, sistemas frontais oceânicos e giros, recifes neríticos, sargaços, e outras áreas de forrageio rasas (MUSICK \& LIMPUS 1997). Sabe-se que as tartarugas marinhas podem cruzar bacias oceânicas inteiras, e adultos e juvenis podem interagir com as principais correntes oceânicas superficiais (HAWKES et al., 2006, SEMINOFF et al., 2007, SHILLINGER et al., 2008). No entanto, a temperatura do mar, de fato, parece ter grande importância para as tartarugas marinhas, como um fator ambiental preponderante, que afeta as características da história de vida do filhote e determinação do sexo (YNTEMA \& MROSOVSKY, 1980) até a distribuição de adultos (SPOTILA \& STANDORA, 1985; HAWKES et al., 2009). Por essa razão, a robusta tendência observada no modelo da CPUE diminuindo com o aumento da TSM (GAMLSS) parece indicar um cenário, ao menos, de alarme ou advertência, se considerarmos as mudanças climáticas esperadas na região (WILLIAMS et al., 2008), o que alerta para o fato de que temperaturas mais elevadas poderiam afetar consideravemente essa população. 


\subsection{Distribuição espacial das tartarugas marinhas $C$. caretta e $D$. coriacea no grande ecossistema marinho do Sul do Brasil.}

Primeiramente, com relação à distribuição espacial do CCC, os resultados deste estudo sugerem que a tartaruga cabeçuda frequentaria habitats diferentes dependendo de sua fase de vida. na região da Elevação do Rio Grande, a espécie Caretta caretta foi capturada com CCC médio de 57,36 cm e máximo de $73 \mathrm{~cm}$. Coluchi (2006), no nordeste do Brasil, amostrou animais acidentalmente capturados, que eram inferiores a $80 \mathrm{~cm}$, assim como também Kotas et al. (2004), entre $23^{\circ}$ e $33^{\circ} \mathrm{S}$.

O tamanho médio da maioria dos indivíduos acidentalmente capturados no Brasil, parecem estar abaixo dos valores das fêmeas desovantes observados no Atlântico Norte (DODD, 1988), no Caribe (BJORNDAL et al., 2003) e no litoral do Brasil (BAPTISTOTTE et al., 2003). como sendo de aproximadamente $75 \mathrm{~cm}$. Logo, pode-se concluir que a partir dos resultados observados, parte das tartarugas cabeçudas capturadas acidentalmente na área de estudo, e, principalmente, na região oceânica próximo à Elevação do Rio Grande seriam de estágio juvenil.

A dieta dos indivíduos de $C$. caretta na fase oceânica (CCC médio de 57 cm) é composta principalmente por salpas (SANTOS et al., 2011), pirossomos e heteropodas (PARKER et al., 2005; BARROS et al., 2010). A alimentação oportunista da tartaruga cabeçuda em sua fase juvenil oceânica torna a espécie muito suscetível à captura pelo espinhel pelágico. A lula, utilizada 
como isca, parece ser um item alimentar importante, principalmente pelo grande volume e os altos valores energéticos relativos (BARROS et al., 2010).

Por outro lado, parte dos indivíduos aqui estudados, podem se tratar de animais em fase subadulta, ou adultos retornando à sua área de reprodução. Bolten (2003) ressalta que a tartaruga cabeçuda em estágio juvenil avançado e adulto, se torna nerítica e se alimenta principalmente no fundo. Já Barros et al. 2011 afirma que a tartaruga cabeçuda em estágio juvenil avançado passa a utilizar a plataforma continental, entre 11 e $75 \mathrm{~m}$ de profundidade, para sua alimentação. Os juvenis podem compartilhar algumas áreas utilizadas pelos adultos (KOPITSKY et al., 2000), até a maturidade sexual ser atingida (MUSICK \& LIMPUS 1997). Áreas de alimentação para C. caretta imaturas e adultas na fase nerítica são essencialmente a plataforma continental (HOPKINS-MURPHY et al. 2003),com dieta bentônica composta principalmente por crustáceos, que representaram $55 \%$ do volume da dieta. Moluscos e peixes também ocorrem na dieta, sendo os peixes provavelmente provenientes do descarte de pesca (BARROS et al., 2009; SANTOS et al., 2011).

A plataforma continental na região Sul do Brasil apresenta alta produtividade primária, devido principalmente à proximidade da Convergência Subtropical, formada pela corrente do Brasil e pelo ramo costeiro da corrente das Malvinas (SANTOS et al., 2011). A alta produtividade faz da região um local de reprodução, desenvolvimento e alimentação de inúmeras espécies (ODEBRECHT; GARCIA 1998).

Em um estudo sobre a dieta das tartarugas cabeçudas no Sul do Brasil, Barros et al. (2011) verificou que, tanto na fase oceânica como nerítica estas interagem com a atividade pesqueira para alimentação. Na fase oceânica, 
alimentando-se de lulas (24,9\% da dieta) que são utilizadas como isca na pesca de espinhel pelágico, e na fase nerítica alimentando-se do descarte de pescarias que atuam sobre a plataforma continental, como cabeças de peixeespada (Trichiurus lepturus), corvinas (Micropogonias furnieri) com tamanho médio de $19 \mathrm{~cm}$, e maria-luizas (Paralonchurus brasiliensis).

Como síntese do conhecimento sobre as principais áreas e possíveis deslocamentos ou rotas migratórias realizadas pela tartaruga cabeçuda na área de estudo, a Figura 30, apresenta um mapa esquemático.

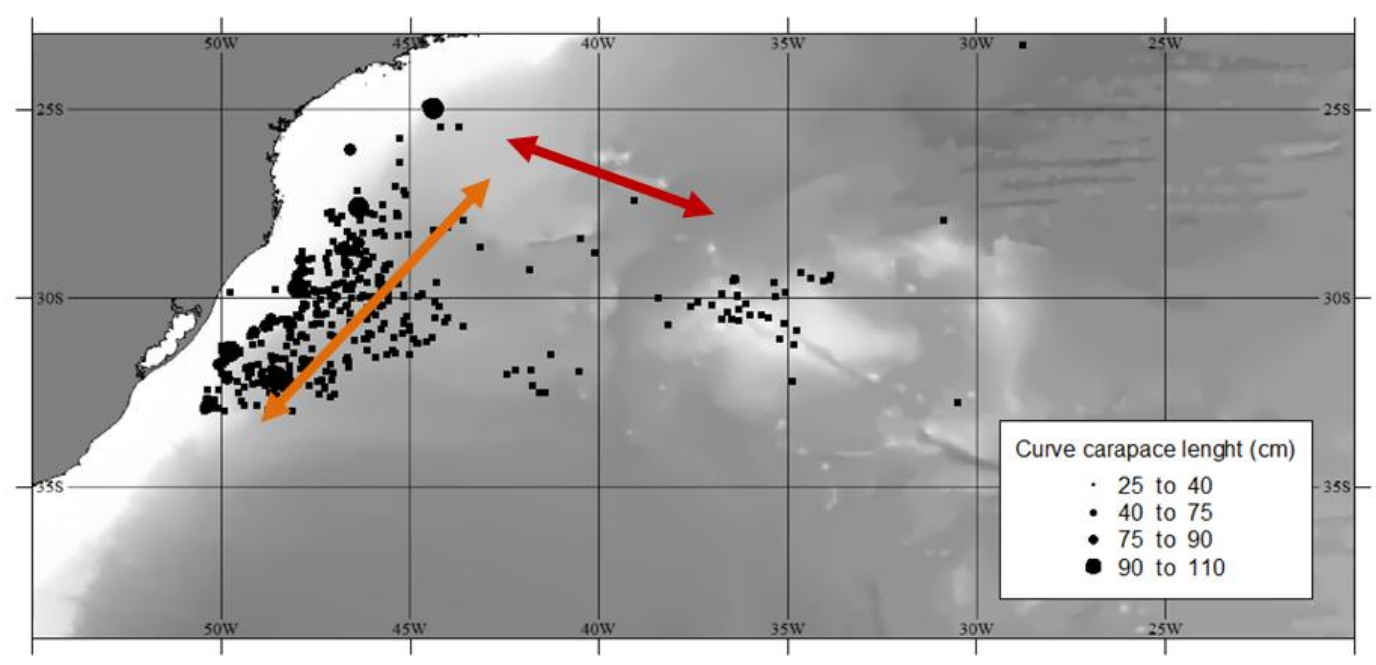

Figura 30. Movimento migratório da tartaruga cabeçuda na área de estudo durante seu desenvolvimento. Seta vermelha representa movimento dos animais em desenvolvimento e junenis e seta laranja dos animais afultos e subadultos.

\subsection{Considerações finais}

É importante salientar que os dados dependentes da pesca se mostraram muito úteis, podendo ser, às vezes, a única fonte de informação que 
possibilita a análise dos padrões de comportamento migratório, localização e habitat preferido das tartarugas marinhas em diversas partes do mundo. Pode parecer paradoxal que a própria atividade impactante seja a que nos permite conhecer, com mais detalhes, as populações impactadas, mas, de fato, o uso de dados de capturas acessórias ou acidentais, cada mais completos, pode permitir uma melhor identificação dos potenciais impactos que essas populações sofrem. Estas informações aliadas a dados de telemetria (HAYS et al., 2006) podem, no futuro, esclarecer sobre o comportamento destas populações e mitigar seus impactos.

O presente estudo cobriu apenas $5 \%$ dos cruzeiros realizados pela frota comercial espinheleira no período de 2003 a 2010, na área de estudo. Contudo, ao se comparar com a atuação total reportada para a frota, se o padrão encontrado se repetir, os resultados parecem alarmantes. Seria estimado que, durante o período, 26.221 indivíduos de tartaruga foram passíveis de serem capturados pela frota atuante na região. A mortalidade, consequente às injúrias causadas pelo espinhel, pode chegar a 2924 tartarugas marinhas por ano.

Tendo em vista a alta mortalidade, o conhecimento sobre 0 comportamento, no que se refere ao deslocamento e uso do habitat nas áreas de alimentação e reprodução, podem auxiliar na definição de áreas prioritárias onde os esforços de conservação precisam ser mais efetivamente implementados (LUSHI et al.,2006; DOYLE et al., 2008).

Neste estudo foi abordada a importância da Região da Elevação do Rio Grande para a tartaruga cabeçuda, assim como a plataforma continental Sudeste para a tartaruga de couro, sendo áreas que deveriam ser utilizadas 
pela pesca com certa cautela. O padrão sazonal encontrado também reforça a utilização da quebra da plataforma continental Sudeste e Sul como uma área importante durante o outono para as duas espécies, o que indica que durante essa estação, os esforços de manejo devam ser concentrados. Os padrões encontrados em relação à TSM alertam para uma preferência da tartaruga cabeçuda a certas temperaturas, e esse conhecimento aliado ao da biologia das espécie-alvo podem gerar medidas de conservação irrelevantes. A utilização de petrechos de pesca que diminuam a captura acidental de tartarugas marinhas, como por exemplo, a utilização de peixes como isca, bem como anzóis circulares e maiores, também são medidas de conservação para as tartarugas marinhas que deveriam ser implementadas.

Nesse sentido, com base nos resultados obtidos pelo presente estudo, podem ser propostas diversas iniciativas e medidas visando contribuir com a conservação das espécies de tartaruga marinha estudadas, e com o manejo da atividade pesqueira com maior enfoque ecossistêmico. 


\section{CONCLUSÕES}

- Na área de estudo, a tartaruga cabeçuda apresentou maior taxa de captura do que a tartaruga de couro, no período. A maioria dos lances com captura tiveram apenas uma tartaruga por lance capturada acidentalmente.

- A distribuição espacial do esforço pesqueiro da frota e das capturas acidentais apresentou variação interanual e sazonal para ambas as espécies de tartarugas marinhas.

- A variação temporal da CPUE demonstrou haver diferença interanual e sazonal para as tartarugas cabeçudas e de couro.

- A Região da Elevação do Rio Grande e áreas adjacentes demonstrou ser de extrema importância para o desenvolvimento da tartaruga cabeçuda, bem como uma região frequentada por tartarugas em fase de desenvolvimento susceptíveis à pesca do espinhel pelágico.

- A plataforma continental Sudeste demonstrou ser uma área de elevada CPUE para a tartaruga de couro, e possivelmente animais capturados acidentalmente nesta região fazem parte da população adulta, em idade reprodutiva.

- Este estudo evidenciou uma preferência da tartaruga cabeçuda por águas mais frias e profundas se comparado com a tartaruga de couro.

- A preferência dietética das duas espécies de tartarugas marinhas foi evidenciada pela sua forma de captura e pode determinar a sobrevivência póscaptura de cada espécie de tartaruga.

- O modelo (GAMLSS) gerado para a espécie Caretta caretta demonstrou o aumento da CPUE quando utilizado lula como isca. O fato de 
que o uso de lula pela frota espinheleira aumenta consideravelmente a CPUE da espécie Caretta caretta, também traz implicações para a gestão da pesca, onde o uso de iscas alternativas (peixe) poderia ser incentivado.

- A forte correlação entre a TSM e a abundância relativa de Caretta caretta, evidenciada também pelo modelo estatístico, levanta considerações sobre o efeito potencial das mudanças climáticas (aquecimento do oceano) para essa população.

- Com relação às áreas consideradas como prioritárias para a conservação das tartarugas marinhas, os modelos estatísticos indicaram a Elevação do Rio Grande para a espécie $C$. caretta, e, a região mais ao norte da área de estudo e próximo à plataforma continental, para a espécie Dermochelys coriacea.

- No geral, o manejo da pesca baseado no ecossistema (EBFM) parece ser uma nova direção necessária para a gestão da pesca pelágica. Nesse sentido, recomenda-se que organizações regionais de manejo da pesca, como o ICCAT, levem em consideração sub-areas de manejo mais apropriadas, ou a criação de uma organização regional de manejo para o Atlântico Sul Ocidental. 


\section{REFERENCIAS}

ACHAVAL, F.; MARIN, Y.; BAREA, L. C. 2000. Captura incidental de tortugas con palangre pelágico oceánico en el Atlántico Sudoccidental. En: Arena, G. \& M. Rey (eds.): Captura de grandes peces pelágicos (pez espada y atunes) en el Atlantico Sudoccidental, y su interacción con o traspoblaciones. INAPE-Uruguay, 83 - 88: $83-88$.

BACKUS, R. H. 1986. Biogeography boundaries in the open ocean. In: A. C. Pierrot-Bults, ;S. van der Spoel; R. K. Johnson, B. J. Zahuranec (eds.), Pelagic Biogeography. UNESCO Technical Papers in Marine Science, 49: $9-13$.

BAKUN, A. 1996. Patterns in the ocean. La Paz, BCS. México: Califórnia Sea Grant College / CIB.

BARROS, J. A.; MONTEIRO, D. S.; COPERTINO, M. S.; ESTIMA, S. C.; DUARTE, D. L. V. 2010. Feeding of juvenile Green Turtles (Chelonia mydas) in Southern Brazil. Proceedings of the twenty-eighth Annual Symposium on Sea Turtle Biology and Conservation. NOAA Technical Memorandum NOAA NMFS - SEFSC - 602: 128 p.

BAPTISTOTTE, C.; THOMÉ, J. C. A.; BJORDNAL, K. A. 2003. Reproductive biology and conservation status of the loggerhead sea turtle (Caretta caretta) in Espírito Santo State, Brazil. Chelonian Conservation and Biology 4(3): 523-529 
BARATA, P. C. R.; GALLO, B. M. G.; DOS SANTOS, S.; AZEVEDO, V.G.; KOTAS, J. E. 1998. Captura acidental da tartaruga marinha Caretta caretta na pesca de espinhel de superfície na zee Brasilleira e em águas internacionales. Resumos expandidos, XI Semana Nacional de Oceanografia, Rio Grande, RS, Brazil

BARTRAM, P. K.; KANEKO, J. J.; KUCEY-NAKAMURA; K. 2010. Sea turtle bycatch to fish catch ratios for differentiating Hawaii longline caught sea food products. Marine Policy 34:145 - 14 .

BJORNDAL, K.A. 1999. Priorities for research in foraging habitats. In: Eckert, K. A. BjorndaL; F. A. Abreu-Grobois \& M. Donnely (ed.). Research and Management Techniques for the conservation of Sea Turtles. IUCN/SSC Marine Turtle Specialist Group Publication. № $4: 12-18$.

BLEAKNEY, J. S. 1965. Reports of marine turtles from New England and Eastern Canada. Can Field Nat 79(2) : 120 - 128.

BRAGA, E. S.; NIENCHESKI, L. F. H. 2006. Composição das massas de água e seus potenciais produtivos na área entre o Cabo de São Tomé (RJ) e o Chuí (RS). In: ROSSI-WONGTSCHOWSKI, C. L. D. B.; MADUREIRA, L. S. P. (Ed.). O ambiente oceanográfico da plataforma continental e do talude na região sudeste - sul do Brasil, São Paulo, EDUSP - Editora da Universidade de São Paulo, p. 161-218.

BOLTEN, A. B.; BJORNDAL, K. A.; MARTINS, H. R.; BALAZS, G. H. 1996. Satellite telemetry of pelagic-stage juvenile loggerheads in the eastern 
Atlantic. Pages 39 - 41. In: KEINATH, J. A.; BARNARD, D. E.; MUSICK, J. A.; and BELL, B. A. (compilers). Proceedings of the Fifteenth Annual Symposium on Sea Turtle Biology and Conservation. U.S. Dep. Commer., NOAA Tech. Memo. NOAA - TM - NMFSSEFSC - 387.

BOLTEN, A.; BJORNDAL, K. 2003. Experiment to evaluate gear modification on rates of sea turtle bycatch in the swordfish longline fishery in the Azores - phase Final project report submitted to the US National Marine Fisheries service. Archie Carr Center for Sea Turtle Research, University of Florida, Gainesville, Florida, USA.

BORZONE, C. A.; PEZZUTO, P. R., MARONE, E. 1999. Oceanographic characteristics of a multispecific fishing ground of the Central South Brazil Bight. P.S.Z.N. Marine Ecology, 20 (2) : 131 - 146.

BUGONI, L.; KRAUSE, L.; PETRY, M. V. 2001. Marine debris and human impacts on sea turtles in southern Brazil. Marine Pollution Bulletin 41 : $1338-1342$.

BURNHAM, K. P.; ANDERSON, D. R. 2002. Model Selection and Multimodel Inference: A Practical Information-theoretic Approach, 2nd ed. SpringerVerlag, New York.

CARR, A. 1952. Handbook of turtles. Cornell University Press, Ithaca, New York.

CASTELLO, J. P.; HAIMOVICI, M.; ODEBRECHT, C.; VOOREN, C. M. 1998. A plataforma e o talude continental. Páginas 189 - 197. In: SEELIGER, U.; 
ODEBRECHT, C.; CASTELLO, J. P. (Eds.). Os ecossistemas costeiro e marinho do extremo sul do Brasil. Ecoscientia, Rio Grande.

CASTRO, F. O.; LORENZZETTI, J. A.; SILVEIRA, I. C. A.; MIRANDA, L. B. 2006. Estrutura Termohalina e Circulação na Região entre o Cabo de São Tomé (RJ) e o Chuí (RS). In: C.L.D.B. ROSSI-WONGTSCHOWSKI \& L.SP. MADUREIRA. (eds.). O ambiente oceanográfico da plataforma continental e do talude na região sudeste - sul do Brasil, São Paulo, EDUSP - Editora da Universidade de São Paulo, p 11-120.

COLUCHI, R. 2006. Caracterização da captura incidental de tartarugas marinhas pela pesca de espinhel pelágico no Nordeste do Brasil. 2006. 66f. Dissertação de Mestrado (Programa de Pós Graduação em Biologia Aquática - Centro de Biociências.) - Universidade Federal do Rio Grande do Norte, Natal - RN.

GIFFONI, B.; DOMINGO, A.; SALES, G.; FIEDLER, F. N.; MILLER, P. 2008. Interacción de tortugas marinas (Caretta caretta y Dermochelys coriacea) con la pesca de palangre pelágico en el Atlantico Sudoccidental: una perspectiva regional para conservacion. Collective Volumes of Scientific Papers, ICCAT, 62 (6): 1861 - 1870.

GOLDBERG, M. D.; CROSBY, D. S.; ZHOU, L. 2001. The limb adjustment of AMSU- A observations: Methodology and Validation. J. Appl. Meteor., 40, $70-83$. 
DOMINGO, A.; FALLABRINO, A.; FORSELLEDO, R.; QUIRICI, V. 2003. Incidental capture of loggerhead (Caretta caretta) and leatherback (Dermochelys coriacea) sea turtles in the Uruguayan long-line fishery in the southwest Atlantic Ocean. In: SEMINOFF, J.A. (comp.) Proceedings of the twenty-second Annual Symposium on sea turtle biology and conservation. NOAA Technical Memorandum NMFSSEFSC - 5039.

DOMINGO, A.; BUGONI, L.; PROSDOCIMI, L. 2005. Diagnóstico de Situación: Las Pesquerías y su Interacción con las Tortugas Marinas en el Océano Atlántico Sur Occidental (ASO), Grupo de Especialistas de Tortugas Marinas del ASO. Montevidéu. Uruguay. 22 pp.

DOMINGO, A.; SALES, G.; GIFFONI, B.; MILLER, P. H.; LAPORTA, M.; MAURUTTO, G. 2006. Captura Incidental de Tortugas Marinas con Palangre Pelágico em El Atlántico Sur por las Flotas Atuneras de Brasil y Uruguay. Col. Vol. Sci. Pap. ICCAT 59 (3): 992 - 1002.

DODD, C.K. 1988. Synopsis of the biological data on the loggerhead sea turtle Caretta caretta (Linnaeus, 1758). U. S. Fish Wildlife Service, Biological Report 88 (14), 110p.

ERNEST, C.; BARBOUR, R. 1972. Turtles of the United States. Lexington, Kentucky: The University Press of Kentucky.

GARDNER, B.; SULLIVAN, J. P.; MORREALE, S. J.; EPPERLY, S. P. 2008. Spatial and temporal statistical analysis of bycatch data: patterns of sea 
turtle bycatch in the North Atlantic Canadian Journal of Fisheries and Aquatic Sciences 65: $2461-2470$.

GIFFONI, B.; DOMINGO, A.; SALES, G.; FIEDLER, N.F.; MILLER, P. 2008. Interacción de tortugas marinas (Caretta caretta y Dermochelys coriacea) con la pesca de palangre pelágico en el Atlántico Sudoccidental: una perspectiva regional para la conservación. Collective Volumes of Scientific Papers, ICCAT, 62 (6): 1861-1870.

GONÇALVES, J. E. 2000. Características e circulação das massas de água no limite do Atlântico Sul entre 20 graus e 30 graus S. Tese de Doutorado. Universidade de São Paulo, Instituto Oceanográfico, 133p.

HAWKES, L. A.; BRODERICK; A. C.; COYNE, M. S.; GODFREY, M. H. 2006 Phenotypically linked dichotomy in sea turtle foraging requires multiple conservation approaches. Curr. Biol. 16: 990 - 995.

HAWKES, L. A.; BRODERICK, A. C.; GODFREY, M. H.; GODLEY, B. J. 2009. Climate change and marine turtles. Endang. Spec. Res. 7, 137-154.

HAYS, G. C.; BRODERICK, A. C.; GODLEY, B. J.; LUSCHI, P.; NICHOLS, W. J. 2010. Satellite telemetry suggests high levels of fishing-induced mortality in marine turtles. Marine Ecology Progress Series 262: 305 - 309. 2003.

HEILEMAN, S.; GASALLA, M. A. 2008. South Brazil Large Marine Ecosystem. In: SHERMAN, K. \& HEMPEL. G. (eds). The UNEP World's Large Marine Ecosystem Report: a perspective on changing conditions in LMEs of the 
World's Regional Seas. United Nations Environmental Program, Nairobi, p. $723-734$.

HOPKINS-MURPHY, S. R.; OWENS, D. W.; MURPHY, T. M. 2003. Ecology of immature loggerheads on foraging grounds and adults in interesting habitat in the eastern United States. In: Loggerhead Sea Turtles (ed. A. Bolten and B. Witherington), pp. 79-92. Washington, DC: Smithsonian Institution Press.

IUCN 2013. IUCN Red List of Threatened Species. Version 2013.1. <www.iucnredlist.org>. Downloaded on 11 August 2013.

KOCH, V.; NICHOLS, W. J.; PECKHAM, S. H.; DE LA TOBA, V. 2006. Estimates of sea tutle mortality from poaching and bycatch in Bahia Magdalena, Baja California Sur, Mexico. BiolConserv. 128: 327 - 33.

KOPITSKY, K.; PITMAN, R. L.; PLOTKIN, P. 2000. Investigations on at-sea mating and reproductive status of olive ridleys, Lepidochelys olivacea, captured in the eastern tropical Pacific. In: Proceedings of the 19th Annual Symposium on Sea Turtle Biology and Conservation. NOAA. 291p.

KOTAS, J. E.; SANTOS, S.; AZEVEDO, V. G.; GALLO, B. M. G.; BARATA, P. C. R. 2004. Incidental capture of loggerhead (Caretta caretta) and leatherback (Dermochelys coriacea) sea turtles by the pelagic longline fishery off southem Brazil. Fishery Bulletin.102: 393 - 399. 
LEWISON, R. L.; CROWDER, L. B.; FREEMAN, S. 2004. Quantifying the effects of fisheries on threatened species: the impact of pelagic longlines on loggerhead and leatherback sea turtles. Ecology Letters 7: $221-231$.

LUSCHI, P.; LUTJEHARMS J. R. E.; LAMBARDI, P. ; MENCACCI, HUGHES, G. R.; HAYS, G. C. 2006. A review of migratory behavior of sea turtles off southeastern Africa. South African Journal of Science 102: 51-58.

LUtCAVAGe, M. E.; PlOtKIN, P.; WITHERINGTON, B.; LUTZ, P. L. 1997. Human impacts on sea turtle survival. In: The biology of sea turtles (P. L. Lutz and J. A. Musick, eds.), p. 387- 409. CRC Press, Boca Raton, FL.

MARCOVALDI, M. A.; THOMÉ, J. C.; SALES, G.; COELHO, A. C.; GALLO, B.; BELLINI, C. 2002. Brazilian plan for reduction of incidental sea turtle capture in fisheries. Mar. Turtle Newsl. 96: 24-25.

MARCOVALDI, M. A.; MARCOVALDI; G. G. 1999. Marine turtles of Brazil: the history and structure of Projeto TAMAR-IBAMA. Biological Conservation $91: 35-41$.

MARCOVAlDI, M. A.; SAleS, G.; THOMÉ, J. C. A.; SILVA, A. C. C. D.; GALLO, B. M. G.; LIMA, E. H. S. M.; LIMA, E. P.; BELLINI, C. 2006. Sea turtles and fishery interactions in Brazil: identifying and mitigating potential conflicts. Marine Turtle Newsletter, 112: 4 - 8.

MARQUEZ, R. 1990. Sea Turtles of the World. An annotated and illustrated catalogue of the sea turtle species known to date. FAO Fisheries Synopsis 
No. 125, Vol. 11. Food and Agricultural Organization of the United Nations, Rome. $81 \mathrm{pp}$.

MILLER, J. D.; LIMPUS, C. J.; GODFREY, M. H. 2008. Nest site selection, oviposition, eggs, development, hatching, and emergence of loggerhead turtles. In: BOLTEN A. B.; WITHERINGTON, B.E. (eds) Loggerhead sea turtles. Smithsonian Books, Washington, DC, p 125 -143.

MONTEIRO, D. S. 2004. Encalhes e Interação de Tartarugas Marinhas com a Pesca no Litoral do Rio Grande do Sul. Monografia (Graduação em Biologia). Fundação Universidade Federal do Rio Grande. $63 f$.

MONTEIRO, D. S. 2008. Fatores Determinantes da Captura Incidental de Aves e Tartarugas Marinhas e da Interação com Orcas/Falsas-Orcas, na Pescaria com Espinhel Pelágico no Sudeste-sul do Brasil. Dissertação (Mestrado em Oceanografia). Universidade Federal do Rio Grande.

MUSICK, J. A.; LIMPUS, C. J. 1997. Habitat utilization and migration in juvenile sea turtles, p 137-164. In: Lutz, P.L. \& Musick, J.A. (Eds.). The Biology of Sea Turtles. CRC Press.

ODEBRECHT, C.; GARCIA, V. M. T. 1998. Fitoplâncton. Páginas 117-121. In: SEELIGER, U.; ODEBRECHT, C.; CASTELLO, J. P. (Eds.). Os ecossistemas costeiro e marinho do extremo sul do Brasil. Ecoscientia, Rio Grande. 
OLSON, D. B.; HITCHCOCK, G. L.; MARIANO, A. J.; ASHJIAN, C.; PENG, G.; NERO, R. W.; PODESTÀ, G. 1994. Life on the edge: marine life and fronts. Oceanography, 7,52 e 60.

PARKER, D. M.; COOKE, W. J.; BALAZS, G. H. 2005. Diet of oceanic loggerhead sea turtles (Caretta caretta) in the central North Pacific. Fishery Bulletin 103: 142-152.

PEREIRA, M. D.; SCHETTINI, C. A. F.; OMACHI, C. Y. 2009. Caracterização de Feições Oceanográficas na Plataforma de Santa Catarina através de imagens orbitais. Ver. Bra. Geof., n. 27, v.1.

PINEDO, M. C.; POLACHECK, T. 2004. Sea turtle by-catch in pelagic longline sets off southern Brazil. Biological Conservation 119: 335 - 339.

POLOVINA, J. J.; HOWELL, E.; PARKER, D. M.; BALAZS, G. H. 2003. Dive depth distribution of loggerhead (Caretta caretta) and olive Ridley (Lepidochelys olivacea) sea turtles in the central North Pacific: might deep longline sets catch fewer turtles? Fish Bull 101:189 -193. 2003.

REBEL, T. P. 1974. Sea turtles and the turtle industry of the West Indies, Florida and the Gulf of Mexico. Coral Gables, Fla. : University of Miami Press.

R DEVELOPMENT CORE TEAM. 2010. R: A language and environment for statistical computing. R Foundation for Statistical Computing, Vienna, Austria. ISBN 3-900051-07-0, URL http://www.R-project.org. 
ROBINS, C. M.; BACHE, S. J.; KALISH, S. R. 2002. Bycatch of sea turtles in pelagic longline fisheries-Australia. Bureau of Rural Sciences and Fisheries Resources Research Fund, 132 pp.

SALES, G.; GIFFONI, B.; BARATA, P. C. R. 2008. Incidental catch of sea turtles by the Brazilian pelagic longline fishery. Journal of the Marine Biological Association, 88 (4): 853 - 864.

SANTOS, A. S.; SOARES, L. S.; MARCOVALDI, M. A.; MONTEIRO, D. S.; GIFFONI, B.; ALMEIDA, A. P. 2011. Avaliação do estado de conservação da tartaruga marinha Caretta caretta (Linnaeus, 1758) no Brasil. Biodiversidade Brasileira (1): 3-11.

SEMINOFF, J. A.; ZARATE, P.; COYNE, M.; FOLEY, D.G.; PARKER, D.; LYON, B.; DUTTON, P. 2007. Post-nesting migrations of Galápagos green turtles Chelonia mydas in relation to oceanographic conditions: integrating satellite telemetry with remotely sensed ocean data. Endang Species Res 4: $57-72$.

SILVEIRA, I. C. A.; SCHMIDT, A. C. K.; CAMPOS, E. J. D.; GODOI, S. S.; IKEDA, Y. 2000. A Corrente do Brasil ao lago da costa leste brasileira. Revista Brasileira de Oceanografia, v. 48, n. 2, 2000. p.171-183

SHILLINGER, G.; PALACIOS, D. L.; BAILEY, H.; BOGRAD, S.; 2008. Persistent leatherback turtle migrations present opportunities for conservation. PLoSBiol 6(7): e171 
SPOTILA, J.; REINA, R.; STEYERMARK, A.; PLOTKIN, P.; PALADINO, F. 2000. Pacific leatherback turtles face extinction. Nature 405, $529-530$.

STANDORA, E. A.; SPOTILA, J. R. 1985. Temperature dependent sex determination in sea turtles. Copeia 1985: 779 - 782.

THOMAS, J.; AZNAR, F. J; RAGA, J. A. 2001. Feeding ecology of the loggerhead turtle Caretta caretta in the western Mediterranean. Journal of the Zoological Society of London 255: 525 - 532.

VANDELLI, D. 1761. Epistola de Holothurio et Testudine coriacea ad celeberrimun Carolum Linnaeum Equitem Naturae Curiosum Dioscoridem II. Consatti, Patavii (Padova). Italy.

WALLACE, B. P.; DIMATTEO, A. D.; BOLTEN, A. B.; CHALOUPKA, M. Y.; HUTCHINSON, B. J. 2011. Global Conservation Priorities for Marine Turtles PLoS ONE 6 (9): e24510.doi: 10.1371/journal.pone.0024510

WATSON, J.; HATAWAY, B.; BERGMANN, C. 2003. Eff ect of hook size on ingestion of hooks by loggerhead sea turtles. US National Marine Fisheries Service, Southest Fisheries Science Center, Pascagoula, MS, USA.

WATSON, J. W.; EPPERLY, S. P.; SHAH, A. K.; FOSTER, D. G. 2005. Fishing methods to reduce sea turtle mortality associated with pelagic longlines. Can J Fish Aqua Sci. 62: 965 - 981. 
POLOCZANSKA, E. S.; LIMPUS, C. J.; HAYS, G. C. 2009. Vulnerability of marine turtles to climate change. Advances in Marine Biology, 56: 151211.

WILLIAMS, S. E.; SHOO, L. P.; ISAAC, J. L.; HOFFMANN, A. A.; LANGHAM, G. 2008. Towards an integrated framework for assessing the vulnerability of species to climate change. PLoSBiol 6: 2621-2626.

WITT, M. J.; HAWKES, L. A.; GODFREY, M. H.; GODLEY, B. J.; BRODERICK, A. C. 2010. Predicting the impacts of climate change on a globally distributed species: the case of the loggerhead turtle. Journal of Experimental Biology 213: 901- 911.

WITZELL, W. N. 1984. The incidental capture of sea turtles in the Atlantic U.S. Fishery Conservation Zone by the Japanese tuna longline fleet, 19781981. Marine Fisheries Review 46: 56-58.

YNTEMA, C. L.; MROSOVSKY, N. 1980. Sexual differentiation in hatchling loggerheads (Caretta caretta) incubated at different controlled temperatures. Herpetologica 36: $33-36$.

ZAR, J. H. 1999. Biostatistical analysis. 4를. New Jersey, Prentice-Hall, Inc., $663 p+212 A p p$. 